\title{
Sex- and Gender-Based Pharmacological Response to Drugs ${ }^{\mathrm{\Phi}}$
}

\author{
Franck Mauvais-Jarvis, Heiner K. Berthold, Ilaria Campesi, Juan-Jesus Carrero, (D) Santosh Dhakal, Flavia Franconi, \\ Ioanna Gouni-Berthold, Mark L. Heiman, (D)Alexandra Kautzky-Willer, Sabra L. Klein, Anne Murphy, Vera Regitz-Zagrosek, \\ Karen Reue, and Joshua B. Rubin
}

Section of Endocrinology, John W. Deming Department of Medicine, Diabetes Discovery and Sex-Based Medicine Laboratory, Tulane University School of Medicine and Southeast Louisiana Veterans Health Care System Medical Center, New Orleans, Louisiana (F.M.--J.); Department of Internal Medicine and Geriatrics, Bethel Clinic (EvKB), Bielefeld, Germany (H.K.B.); Department of Biomedical Sciences, University of Sassari, Sassari, Italy (I.C.); Department of Medical Epidemiology and Biostatistics, Karolinska Institutet, Stockholm, Sweden (J.-J.C.); W. Harry Feinstone Department of Molecular Microbiology and Immunology, the Johns Hopkins Bloomberg School of Public Health, Baltimore, Maryland (S.D., S.L.K.); Laboratory of Sex-Gender Medicine, National Institute of Biostructures and Biosystems, Sassari, Italy (F.F.); Polyclinic for Endocrinology, Diabetes and Preventive Medicine (PEDP), University of Cologne, Cologne, Germany (I.G.-B.); Scioto Biosciences, Indianapolis, Indiana (M.L.H.); Department of Internal Medicine III, Clinical Division of Endocrinology, Metabolism and Gender Medicine, Medical University of Vienna, Vienna and Gender Institute Gars am Kamp, Vienna, Austria (A.K.-W.); Neuroscience Institute, Georgia State University, Atlanta, Georgia (A.M.); Berlin Institute of Gender Medicine, Charité, Universitätsmedizin Berlin, Berlin, Germany and University of Zürich, Switzerland (V.R.-Z.); Department of Human Genetics, David Geffen School of Medicine, and the Molecular Biology Institute, University of California, Los Angeles, California (K.R.); and Departments of Medicine, Pediatrics, and Neuroscience, Washington University School of Medicine, St. Louis, Missouri (J.B.R.)

Abstract. . .

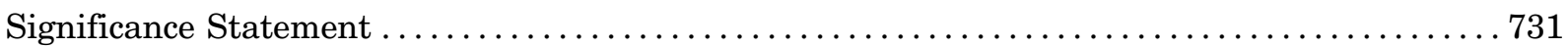

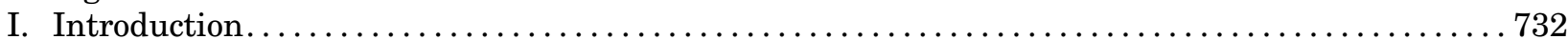

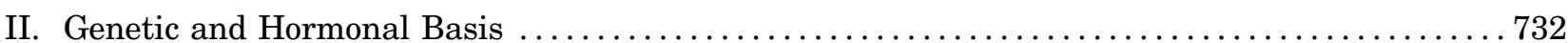

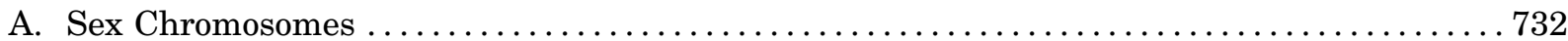

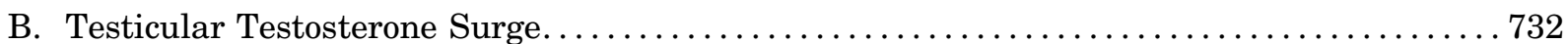

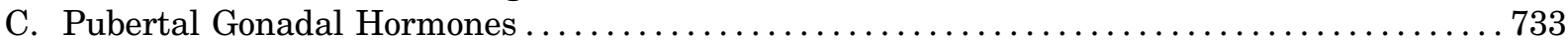

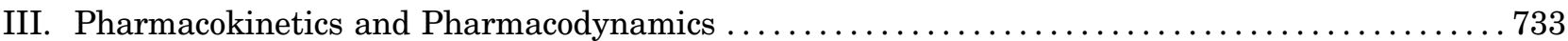

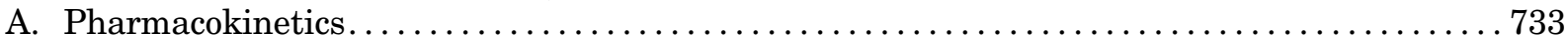

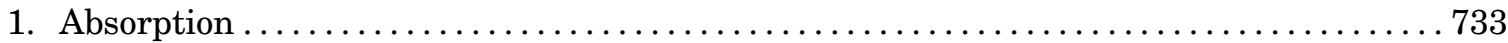

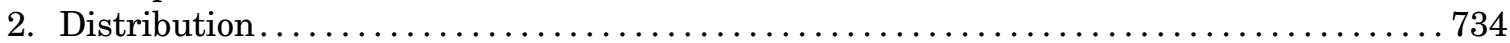

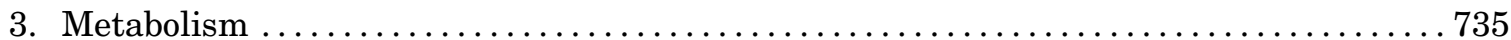

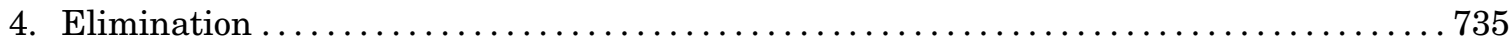

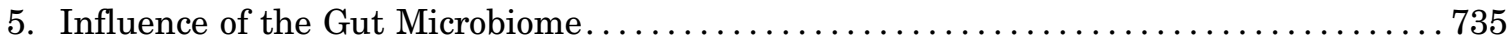

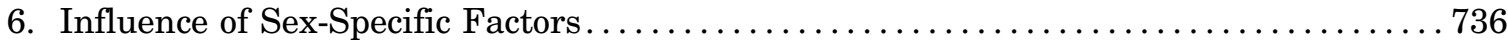

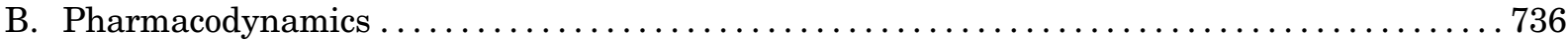

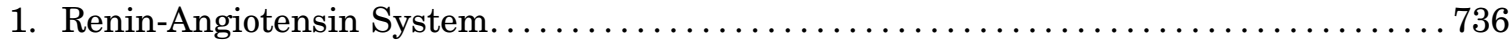

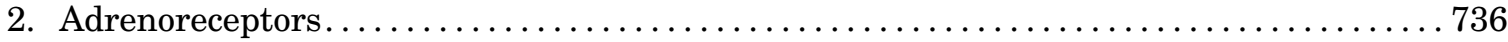

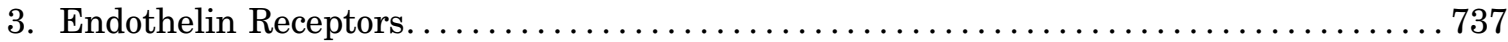

4. Arachidonic Acid Cascade and Aspirin ............................... 737

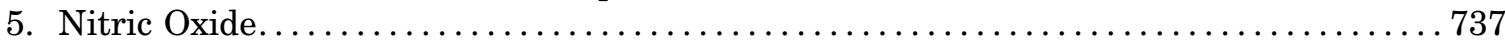

Address correspondence to: Dr. Franck Mauvais-Jarvis, Section of Endocrinology and Metabolism, John W. Deming Department of Medicine, Diabetes Discovery and Sex-Based Medicine Laboratory, Tulane University Health Sciences Center, 1430 Tulane Ave., New Orleans, LA 70112. E-mail: fmauvais@tulane.edu

This work was supported by National Institutes of Health (NIH) awards from National Institute of Diabetes and Digestive and Kidney Diseases [Grants DK074970 and DK107444] (to F.M.-J.), [Grant DK121594-01] (to M.L.H.), and [Grant DK120342] (to K.R.); National Institute of General Medical Sciences [Grant GM122130] (to M.I.H.); and National Institute on Drug Abuse [Grant DA041529] (to A.M.). US Department of Veterans Affairs Merit Review Award was given to F.M.-J. [Grant BX003725]. J.-J.C. was supported by Swedish Research Council [Grant 2019-01059]. V.R.-Z. was supported by the Anna Fischer Dueckelman guest professorship at the University of Zurich.

Financial disclosure statement

No authors have an actual or perceived conflict of interest with the contents of this article.

\$This article has supplemental material available at pharmrev.aspetjournals.org.

https://doi.org/10.1124/pharmrev.120.000206. 


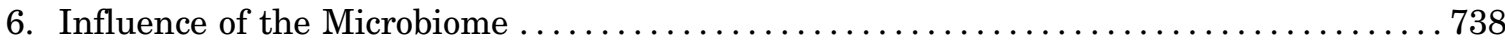

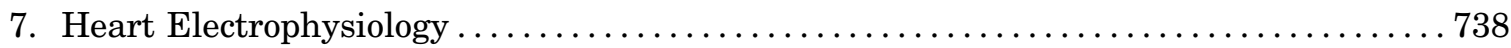

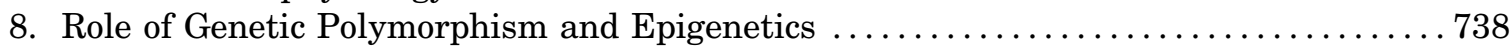

IV. Sex-Specific Pharmacology of Drugs Acting in Different Physiologic Systems............ 738

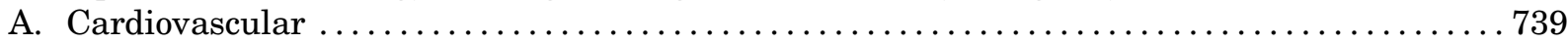

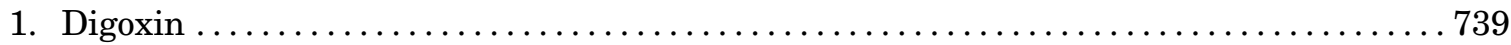

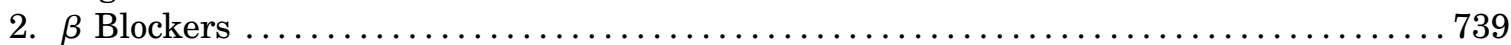

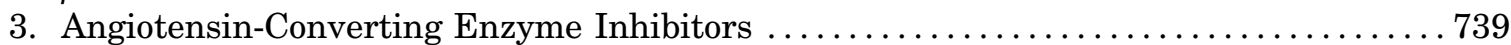

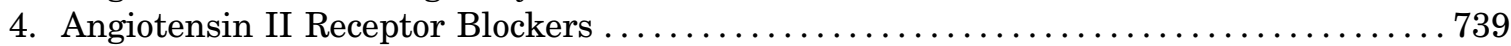

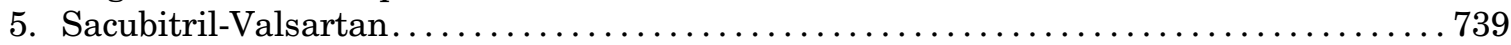

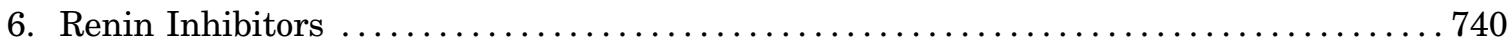

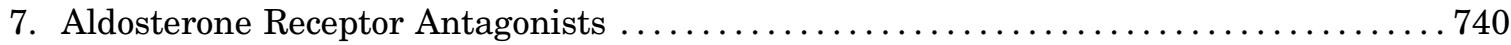

8. Antiarrhythmic Drugs............................................ 740

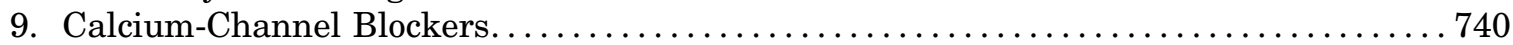

10. Sex-Specific Reporting of Effects and Adverse Effects $\ldots \ldots \ldots \ldots \ldots \ldots \ldots \ldots \ldots \ldots \ldots$

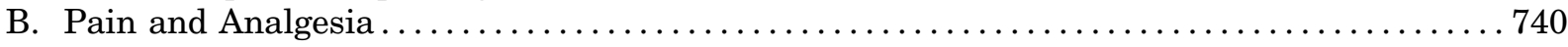

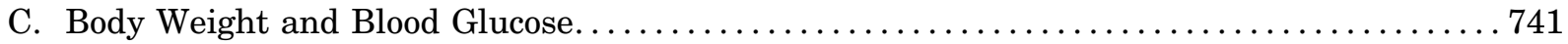

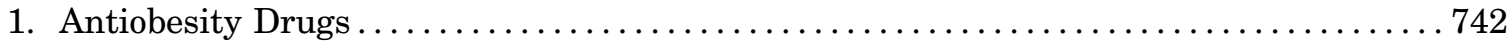

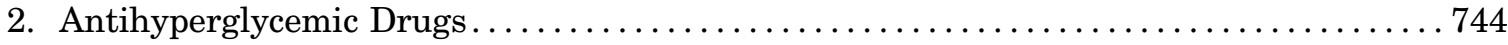

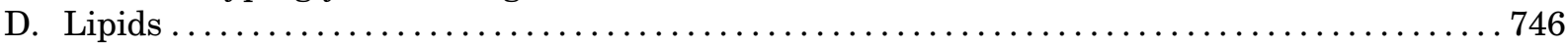

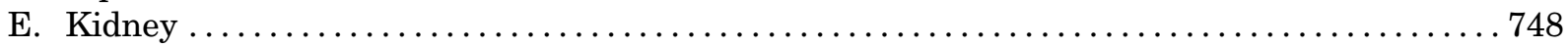

1. Kidney Function and Gender Bias of Glomerular Filtration Rate Equations ........ 748

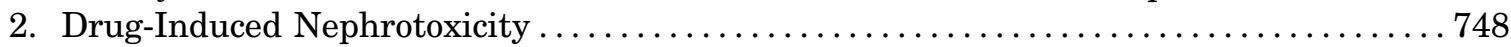

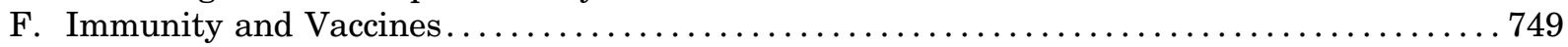

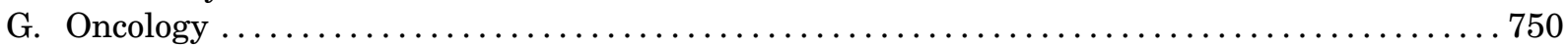

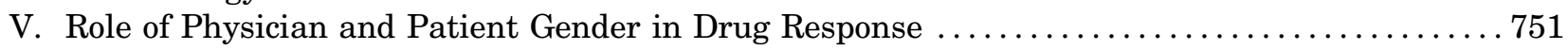

A. Epidemiologic Evidence for Differences in Physician Gender and Response to

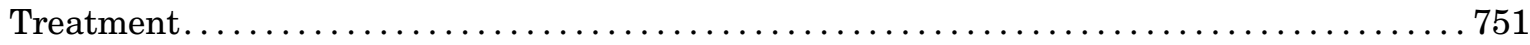

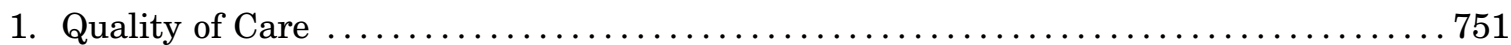

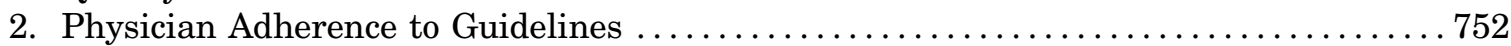

3. Patient Adherence to Treatment................................... 752

B. Potential Explanations for Differences in Physician Gender and Response to Treatment . . 753

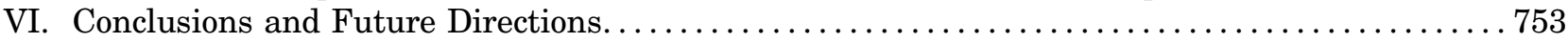

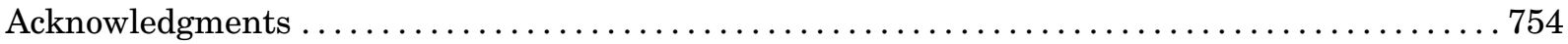

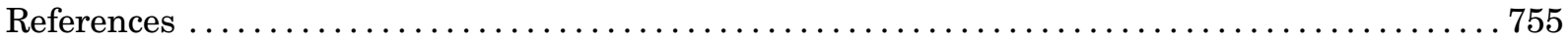

\begin{abstract}
In humans, the combination of all sexspecific genetic, epigenetic, and hormonal influences of biologic sex produces different in vivo environments for male and female cells. We dissect how these influences of sex modify the pharmacokinetics and pharmacodynamics of multiple drugs and provide examples for common drugs acting on specific organ systems. We also discuss how gender of physicians and patients may influence the therapeutic response to drugs. We aim to highlight sex as a genetic modifier
\end{abstract}

of the pharmacological response to drugs, which should be considered as a necessary step toward precision medicine that will benefit men and women.

Significance Statement_- This study discusses the influences of biologic sex on the pharmacokinetics and pharmacodynamics of drugs and provides examples for common drugs acting on specific organ systems. This study also discusses how gender of physicians and patients influence the therapeutic response to drugs.

\footnotetext{
ABBREVIATIONS: ACE, angiotensin-converting enzyme; ACEI, ACE inhibitor; ADR, adverse drug reaction; AhR, aryl hydrocarbon receptor; ARB, angiotensin receptor blocker; CAD, coronary artery disease; CIBIS II, Cardiac Insufficiency Bisoprolol Study II; CVOT, cardiovascular outcome trial; DPD, dihydropyrimidine dehydrogenase; DPP-4, dipeptidyl peptidase 4; ET, endothelin; 5FU, 5-fluorouracil; GFR, glomerular filtration rate; GI, gastrointestinal; GLP-1, glucagon-like peptide-1; GLP-1A, GLP-1 analog; GLP-1R, GLP-1 receptor; HF, heart failure; HFpEF, heart failure with preserved ejection fraction; $\mathrm{HFrEF}$, heart failure with reduced ejection fraction; ICI, immune checkpoint inhibition; $\mathrm{I}_{\mathrm{Kr}}$, rapidly activating delayed rectifier potassium channels; $\mathrm{I}_{\mathrm{Ks}}$, slowly activating delayed rectifier potassium channels; MERIT-HF, Metoprolol CRXXL Randomized Intervention Trial in Congestive Heart Failure; LDL, low-density lipoprotein; LQTS, long QT-interval syndrome; MACE, major adverse cardiac event; MI, myocardial infarction; NIH, National Institutes of Health; NO, nitric oxide; OC, oral contraceptive; PCSK9, proprotein convertase subtilisin/kexin type 9; PD, pharmacodynamics; PK, pharmacokinetics; POMC, pro-opiomelanocortin; RCT, randomized controlled trial; SGLT2, sodium/glucose cotransporter 2; TIV, trivalent inactivated influenza vaccine; TOPCAT, Treatment of Preserved Cardiac Function Heart Failure With an Aldosterone Antagonist; Vd, volume of distribution of a drug.
} 


\section{Introduction}

Historically, women's health was nicknamed "bikini medicine" because medical practitioners considered the only thing making women biologically different from men to be those body parts that could be covered with a bikini (Talesnik, 2018). For the safety of women and their offspring, women of fertile age were excluded from clinical trials, turning male physiology into the reference of the species in medical research and drug discovery (Clayton, 2016). In 1993, National Institutes of Health (NIH) Revitalization Act in the United States mandated the inclusion of women in NIH-funded clinical trials, but many investigators did not follow this policy or failed to analyze the results by sex (Schiebinger et al., 2016; Geller et al., 2018), minimizing the effectiveness of this mandate. Preclinical drug discovery has also predominantly used male cells and animal models (Danska, 2014; Klein et al., 2015; Mauvais-Jarvis et al., 2017). Perhaps as a result of these failures to consider sex in basic and clinical research, in 2001, a US Government Accountability Office report found that $80 \%$ of prescription drugs withdrawn from the market between 1997 and 2000 exhibited greater adverse effects and toxicity in women than in men (http://www.gao.gov/). To correct this error, in 2014, the NIH took the next step to mandate researchers to consider sex as a biologic variable in basic research by including both sexes in research designs (Clayton and Collins, 2014). Still, the field of sex-based biology and medicine is wrongly considered as peripheral and superficial.

In this review, we outline the fundamental genetic and hormonal differences between males and females and the resulting differences in pharmacokinetics $(\mathrm{PK})$ and pharmacodynamics (PD) between male and female biologic systems. We also provide examples of sex-specific responses to drugs acting on different organ systems. Finally, we discuss the effect of physician and patient gender in drug response.

\section{Genetic and Hormonal Basis}

Sex differences in physiology and pharmacological response to drugs begin during development from the interaction between genetic and hormonal events and they continue after puberty. They stem from the combination of three major events that have been recently reviewed (Mauvais-Jarvis, 2015, 2017, 2020) and are briefly described below.

\section{A. Sex Chromosomes}

The effect of sex chromosomes begins after fecundation in embryos carrying either $\mathrm{XX}$ or $\mathrm{XY}$ sex chromosomes (Arnold, 2017). The $\mathrm{X}$ and $\mathrm{Y}$ chromosomes are derived from an autosomal chromosome pair but have evolved separately such that the only region that still undergoes recombination between $\mathrm{X}$ and $\mathrm{Y}$ chromosomes is the pseudoautosomal region. As a result, the malespecific region of the $\mathrm{Y}$ chromosome carries genes that are not present in XX cells. The Y chromosome also carries some genes that are homologous to genes present on the X chromosome (e.g., ZFY vs. ZFX and UTY vs. UTX), but because of independent evolution on the $\mathrm{X}$ and $\mathrm{Y}$, these gene pairs may exhibit differential expression or function. Male-female differences also arise because of the presence of two $\mathrm{X}$ chromosomes in females versus a single $\mathrm{X}$ chromosome in males. The random inactivation of one of the $\mathrm{X}$ chromosomes in female cells prevents differences in $\mathrm{X}$ chromosome gene dosage between male and female cells for most genes. However, some X-linked genes escape inactivation in females $(12 \%-20 \%$ in humans), and therefore those genes are expressed at higher levels in females than in males (Arnold, 2017). Differences also exist in the epigenetic marks that are inherited on the $\mathrm{X}$ chromosome in males and females. In males, the $X$ chromosome carries maternal imprints, which are epigenetic marks that are established ("imprinted") in the parental germ cells (sperm or egg cells) and maintained in the somatic cells of the offspring, where they influence the expression levels of specific genes. Females inherit $\mathrm{X}$ chromosomes from both parents and therefore carry both maternal and paternal imprints, which alter the expression of a different group of genes than males. Thus, there are fundamental differences in gene expression in human male and female cells resulting from genetic heterogeneity between the $\mathrm{X}$ and $\mathrm{Y}$ chromosome gene dosage as well as parent-oforigin inheritance of epigenetic marks. These sex differences persist throughout life and likely contribute to sex differences in the pharmacological response to drugs.

\section{B. Testicular Testosterone Surge}

The testis-determining sex-determining region $\mathrm{Y}$ gene on the $\mathrm{Y}$ chromosome drives the development of testes in males (Arnold, 2017). The differentiated testis produces a testosterone surge in the second trimester of pregnancy in humans (Forest et al., 1976; Corbier et al., 1992). This surge is critical to masculinize the reproductive tract and to masculinize and defeminize the brain structure and function through the organization of neural circuits responsible for the activation of male behavior at puberty (Arnold and Gorski, 1984; Morris et al., 2004; McCarthy et al., 2009). This organizational effect of testosterone on neural circuits is likely to promote sex differences in the response to neurotropic drugs. Notably, in animal models, developmental testosterone produces epigenetic modifications of histone marks (Sinha et al., 2020) and programs body composition and the mass 
and function of adipose tissue, liver, and kidney in adults (Nilsson et al., 1998; Abbott et al., 2005; Nohara et al., 2011, 2013), which likely influence sex differences in the PK and PD of drugs.

\section{Pubertal Gonadal Hormones}

Most sex differences in biology and pharmacology are believed to be the consequence of the gonadal hormones after the onset of puberty. Although these effects are reversible, they are the most potent factors that make male and female tissues different in response to drugs. Testosterone is the main male gonadal hormone, whereas $17 \beta$-estradiol and progesterone (P4) are the main female gonadal hormones. The actions of these sex hormones on pharmacokinetics and pharmacodynamics will be described in the next section.

In summary, the combination of all sex-specific influences on cells results in different in vivo environments for male and female cells. Notably, genome-wide transcriptome analysis has demonstrated that there are sex biases in expression of genes across the genome; this includes genes that are conserved across mammalian species, and the differential expression levels in males and females contribute to sex differences in human traits (Naqvi et al., 2019). In addition, profiling of sex differences in serum metabolites revealed major sex differences in concentrations for over three-quarters of the metabolites studied (Mittelstrass et al., 2011). The sum of all genetic and hormonal sex-specific influences that affect cellular systems and alter the transcriptome, proteome, and metabolome-known as the "sexome" (Arnold and Lusis, 2012) - is likely to confer sex differences in the pharmacokinetics and pharmacodynamics of drugs, as we discuss below.

\section{Pharmacokinetics and Pharmacodynamics}

\section{A. Pharmacokinetics}

Sex differences in PK are well described and reported in numerous reviews (Anderson, 2005; Soldin and Mattison, 2009; Soldin et al., 2011; Franconi and Campesi, 2014a). Here, we provide an update of the most well characterized sex differences in absorption, distribution, metabolism, and elimination of drugs. They are summarized in Supplemental Table 1.

1. Absorption. Drugs can be administered through numerous routes. The oral route is the most common, although this route poses complications regarding reaching the intended pharmacological target. In general, drugs are absorbed in the gut and reach the liver through the portal circulation. Thus, the oral bioavailability of a drug depends on first-pass liver metabolism or presystemic metabolism and drug degradation. During this process, a portion of the drug is lost. For example, propranolol, spironolactone, and lidocaine undergo a significant first-pass liver metabolism. In men, propranolol metabolism is stimulated by testosterone, whereas in women androgen and estrogen do not modify the metabolism of this $\beta$ blocker (Walle et al., 1994). Gastric secretion and emptying are important for drug absorption. Gastric secretion is higher in men than in women, whereas gastric and intestinal emptying time is shorter in men than in women (Soldin and Mattison, 2009; Soldin et al., 2011; Franconi and Campesi, 2014a). At baseline, the higher gastric $\mathrm{pH}$ of women can elevate the ionization of weak acids (e.g., aspirin), attenuating their absorption. It can also decrease the ionization of weak bases (e.g., caffeine), increasing their absorption (Soldin and Mattison, 2009; Soldin et al., 2011; Franconi and Campesi, 2014a). The longer time of gastric and intestinal emptying in women suggests that they should wait longer than men after eating before taking drugs that should be administered on an empty stomach. This is observed with captopril and felodipine (Whitley and Lindsey, 2009).

Little information is available on the influence of sex on drug absorption for routes other than oral administration. Still, intramuscular absorption seems to be slower in women than in men. For example, intramuscular aspirin is absorbed more slowly in women than in men (Aarons et al., 1989). Interestingly, there is a sex difference regarding the site of intramuscular injection: After intramuscular injection of cephradine in gluteus maximus, vastus lateralis, or deltoid muscles, the area under the curve of drug concentration in plasma as a function of time and absorption rate is smaller in women than in men, the difference being the strongest when intramuscular injection is performed in the gluteus maximus (Vukovich et al., 1975). Notably, the depth of gluteal fat varies between men and women (Cockshott et al., 1982; Dayananda et al., 2014), but the length of the injection needle does not vary. In women, the rate of success of intramuscular injections is lower than in men (Soliman et al., 2018). In addition, sex differences are described in the composition of skeletal muscle fiber type. In particular, women have a higher capillarity for type II fibers in the vastus lateralis than men (Croley et al., 2005). In women, type II fibers have higher fiber type-specific capillary length than in men (Lyon et al., 2007). This is associated with over 3000 genes differentially expressed in male and female muscle (Welle et al., 2008; Haizlip et al., 2015). Together these studies highlight the complex differences that exist in skeletal muscle from both sexes and which may be associated with differences in blood flow and intramuscular drug absorption.

Some drugs (clonidine, nitroglycerin, steroid hormones) can be administered transdermally. Sex differences exist in the integrity and barrier qualities of the skin (Singh and Morris, 2011). For example, women have more subcutaneous adipose tissue than men and male keratinocytes, and skin pores are larger in male than in female skin (Soldin et al., 2011). However, the 
paucity of data does not permit any clear conclusions about sex-based variations in transdermal absorption. The transdermal absorption of nitroglycerin is influenced by body weight, which is higher in obese subjects of both sexes. However, nitroglycerin-induced temperature elevation has been reported especially in women who are obese (Haebisch, 1995). Given that skin parameters involved in drug absorption, such as hydration, transepidermal water loss, sebum, microcirculation, pigmentation, $\mathrm{pH}$, and thickness, differ between men and women (Rahrovan et al., 2018), the transdermal absorption drug is likely to be sexually biased. Finally, there is a paucity of data on the effect of sex in pulmonary absorption (Soldin and Mattison, 2009; Soldin et al., 2011), although the architecture of the airways exhibits numerous sex differences (LoMauro and Aliverti, 2018), and therefore sex differences in pulmonary absorption are likely to occur.

2. Distribution. The distribution of a drug is essential to reach its target site and depends on several factors that differ between women and men (Table 1). Compared with men, women are smaller and have a lower total body water volume, extracellular and intracellular water volumes, total blood volume, red blood cell content, cardiac output, and organ bloodflow rate, all of which influence the volume of distribution of a drug (Vd) (Fadiran and Zhang, 2015). In premenstrual and in late luteal phases, water retention and hyponatremia are observed, and this alters $\mathrm{Vd}$ (Ciccone and Holdcroft, 1999). Interestingly, isosorbide dinitrate-a drug used to prevent chest pain in patients with coronary artery disease-penetrates red blood cells where it is metabolized, and the metabolic rate is higher in men than in women. Thus, penetration in red blood cells not only modifies drug distribution but may alter drug metabolism, and this seems to be influenced by sex (Bennett et al., 1983).

The $\mathrm{Vd}$ is also influenced by plasma protein binding (Soldin and Mattison, 2009). Endogenous and exogenous estrogens decrease the levels of $\alpha-1$ acid glycoprotein (Kishino et al., 2002), which binds neutral drugs and is the primary carrier of basic drugs, such as lidocaine. As a result, the amount of free lidocaine in the plasma of women treated with oral contraceptives (OCs) is significantly higher than in men of similar age (Routledge et al., 1981). Albumin does not vary between sexes, and there is no significant sex difference in albumin drug binding (Routledge et al., 1981; Soldin and Mattison, 2009; Soldin et al., 2011).

Body composition diverges between the two sexes: Women have a greater amount of fat mass, whereas men have a greater amount of lean mass, and this difference decreases with age (Soldin and Mattison, 2009; Soldin et al., 2011). Therefore, if men and women receive the same dose of a water-soluble drug, the $\mathrm{Vd}$ will be higher in men who have greater lean mass and total body water volume. Conversely, the $\mathrm{Vd}$ of

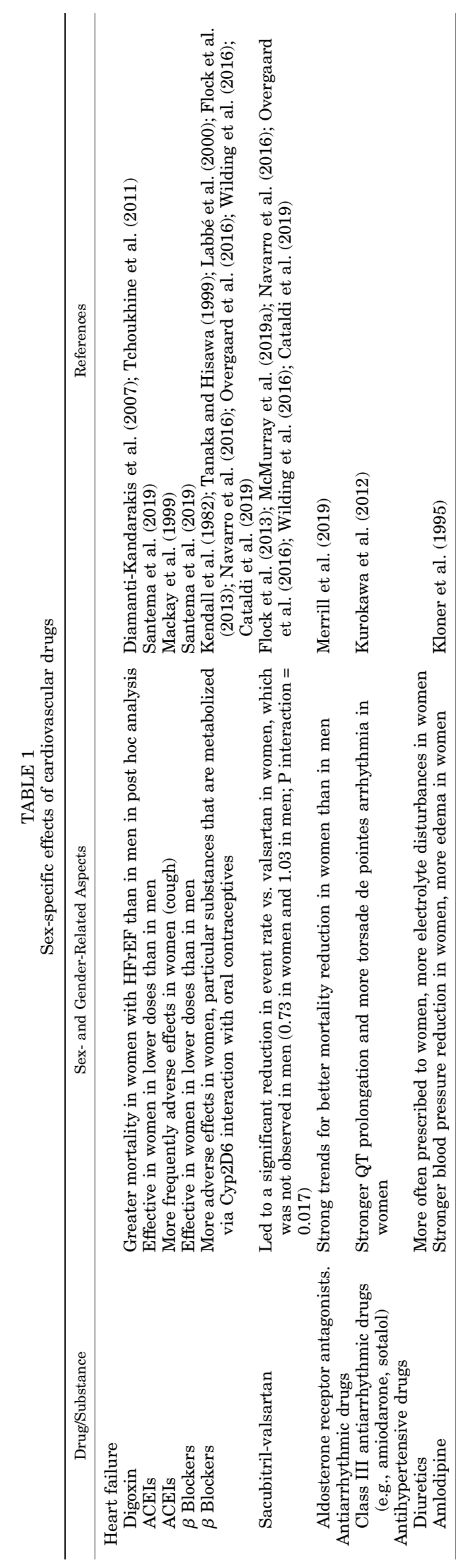


lipid-soluble drugs will be higher in women who have a greater percentage of fat mass. Thus lipid-soluble drugs, such as amiodarone, lidocaine, procainamide, and digoxin, can reach higher $C_{\max }$ (peak concentration) in women, elevating the risk of adverse drug reaction (ADR) (Stolarz and Rusch, 2015), especially with long-term therapy.

3. Metabolism. The first pharmacological sex difference was described in 1932, when Nicholas and Barron described that the hypnotic effect of hexobarbital lasted longer in female rats than in male rats (Nicholas and Barron, 1932). Years later, Quinn et al. (1958) showed that it depended on the metabolism of hexobarbital. In particular, the presystemic metabolism may diverge between sexes. This is the case for the calcium-channel blocker verapamil (Dadashzadeh et al., 2006), as norverapamil production is higher in women than in men because of higher activity of CYP3A4 or lower activity of $\mathrm{P}$-glycoprotein in women. P-glycoprotein is located in the gut, liver, and kidney and mediates drug efflux out of the cells. At the level of the intestinal epithelium, it reduces the absorption of numerous drugs, including digoxin (Shi et al., 2011).

The liver is the main site of drug metabolism, which depends on cardiac output and liver blood flow, both of which are lower in women than in men. It also depends on phase 1 and 2 drug-metabolizing enzymes and transporters that exhibit sex differences in expression and activity (Soldin and Mattison, 2009; Soldin et al., 2011; Yang et al., 2012; Franconi and Campesi, 2014a,b) (summarized in Supplemental Table 1). The expression and activity of these enzymes and multidrug resistance protein are regulated by endogenous factors, such as genetics, age, sex, sex hormones, and microbiota, as well as by exogenous factors, such as drugs, diet, and environmental pollutants, which in part act through the nuclear receptors constitutive androstane receptor, pregnane $\mathrm{X}$ receptor, and aryl hydrocarbon receptor (AhR) (Smirnova, 2012; Bright et al., 2016). Notably, $\mathrm{AhR}$, constitutive androstane receptor, and pregnane $\mathrm{X}$ receptor exhibit sexually biased expression and mode of action (Hernandez et al., 2009; Lu et al., 2013). Botanicals may also induce CYP enzymes through these nuclear receptors, which is of special interest in women because they are the most prevalent users of botanicals (Campesi et al., 2019). In particular, focusing on 374 drug-metabolizing enzymes and transporters in a published gene expression data set of human male $(n=234)$ and female $(n=193)$ liver samples, Yang et al. (2012) identified 77 genes showing differential expression due to sex. Finally, the gut microbiota have recently emerged as an important player in drug metabolism and drug interactions in a sexually dimorphic manner (Carmody and Turnbaugh, 2014). This will be discussed further in a later section.

4. Elimination. Renal elimination depends on tubular secretion, reabsorption, and glomerular filtration rate, which are lower in women than in men (Soldin and Mattison, 2009). It also depends on body weight (Soldin and Mattison, 2009). Drugs that are mainly or exclusively excreted unchanged by the renal route are cleared more slowly in women than in men (Schwartz, 2003). This is the case of commonly used drugs, such as gabapentin, pregabalin, aminoglycosides, cephalosporins, fluoroquinolones, or vancomycin, all of which have shown decreased renal clearance in women (Anderson, 2005; 2008). Other remarkable examples are methotrexate (Schwartz, 2003) and digoxin (Yukawa et al., 1997), which have a $17 \%$ and $13 \%$ slower clearance in women, respectively. Similarly, the anticoagulant lepirudin, exhibits a longer half-life in women (up 48 hours) than in men ( 2 hours), which increases the risk of bleeding in women (Abdel-Rahman, 2017). Being aware of these differences may allow the prescription of lower dosages of these medications based on glomerular filtration rate (GFR) in women to avoid adverse effects.

Sex differences in expression of drug transporters in human kidney also contribute to changes in sex-specific pharmacokinetics. In a study of human kidney, 23 genes coding for drug transporters exhibited sex differences in their mRNA expression. Twenty-one of them were expressed at higher levels in men, whereas two were expressed at higher levels in women (Joseph et al., 2015).

5. Influence of the Gut Microbiome. The absolute bioavailability of a drug administered orally is often less than $100 \%$ and typically less than $60 \%$. Thus, the gastrointestinal (GI) microbiome is likely to be exposed to drugs during oral administration. In fact, the efficacy of some drugs may be enhanced or worsened because they modulate the GI microbiome. Recent data demonstrate sex differences in the GI microbiota populations of rodents (Bernbom et al., 2006; Markle et al., 2013) and humans (Li et al., 2008; Dominianni et al., 2015). The sexually dimorphic GI microbiome may alter exposure to a drug in females differently than males by differentially modulating digestion, absorption, distribution, and elimination. Men have faster mean GI transit rates, greater stool weights, greater bile acid excretion, and less fiber fermentation than women (Lampe et al., 1993). The opposite appears to be true in mice. Male mice consuming a control chow have slower gastric emptying and GI transit rate than female mice (France et al., 2016). Conjugation of xenobiotic drugs, such as steroids and nonsteroidal anti-inflammatory drugs, with sugars is an important mechanism for detoxification and clearance. If the conjugates are secreted from the hepatobiliary system into the small intestine, they can be deconjugated by $\beta$-glucuronidase of several commensal bacteria species in the gut and reabsorbed (Leung et al., 2001; LoGuidice et al., 2012). Sex differences in abundance of such taxa are reported (Haro et al., 2016). Thus, the GI microbiome may modulate pharmacokinetic 
properties of drugs, particularly those administered orally.

6. Influence of Sex-Specific Factors. In women, PK is influenced by endogenous or exogenous sex hormones, menopausal hormone therapy, and xenobiotics, including phytoestrogens, which influence hormonal status. In particular, exogenous sex hormones may modify drug clearance through inhibition or induction of CYP enzymes (Brunton, 2018; Campesi et al., 2019). For example, $17 \beta$-estradiol attenuates CYP1A1/2 gene expression via inhibition of AhR transcription (Lai et al., 2004), and treatment with OC may require a modification of the dosage to avoid overdosing or underdosing.

In women, oral absorption, distribution, metabolism, and elimination can be influenced by the phase of the menstrual cycle, pregnancy, and lactation. We focus on pregnancy because 1\%-2\% of pregnancies are complicated by cardiovascular diseases and because more women with congenital heart diseases survive reaching reproductive age (Regitz-Zagrosek et al., 2018). In addition, at least in Western countries, pregnancy at an advanced age is increasing, and age may increase cardiovascular diseases, such as hypertension (RegitzZagrosek et al., 2018; Cooke and Davidge, 2019).

During pregnancy, the physiology of women changes in a time-dependent manner, and these changes alter PK and PD (Supplemental Table 1). In pregnancy, there are additional compartments-the fetus and the amniotic fluid-that may lead to increased drug accumulation and to an apparent increase in Vd of certain drugs (Feghali et al., 2015). Furthermore, cardiac output is enhanced beginning in the first trimester, whereas glomerular filtration rate is increased by $50 \%$ starting in the second trimester and until 3 months postpartum. Therefore, during pregnancy, the clearance of drugs that are excreted unchanged in the urine, such as heparin, is increased (Ansari et al., 2016). Furthermore, liver enzymes involved in drug metabolism are increased in expression and activity, resulting in enhanced in drug metabolism (Supplemental Table 1) (Ansari et al., 2016). For example, pregnancy induces CYP2D6, resulting in increased metabolism of metoprolol, a $\beta$ blocker, and thus plasma levels of metoprolol are reduced in women who are pregnant compared with women who are nonpregnant (Ansari et al., 2016). A few liver drug metabolism enzymes exhibit decreased activity (Supplemental Table 1), such as CYP1A2, which is the primary enzyme for caffeine metabolism (Ansari et al., 2016). Finally, the placenta and fetus can also metabolize drugs, thus participating in the changes in drug PK associated with pregnancy (Ansari et al., 2016). The effect of pregnancy on drug transporters is not well understood (Moyer et al., 2019). Significant hormonal changes that can modify PK profile also occur in women who are menopausal and in women taking menopausal hormone therapy. For example, intestinal CYP3A4 activity is reduced by about $20 \%$ during menopause, reducing the first-pass effect for substrates of intestinal CYP3A4 (Paine et al., 2005). Conversely, in adult men, testosterone remains quite stable and has minimal effects on PK parameters.

Additionally, the excipients [small or large molecules present in the final drug, defined by the US Food and Drug Administration as "inactive" substances] can have a role in inducing sex differences in PK. For example, the bioavailability of ranitidine, a selective histamine $\mathrm{H} 2-$ receptor antagonist, is enhanced by polyethylene glycol in healthy men but not in women (Ashiru et al., 2008). These results suggest the complexity of sex influences in the context of drug delivery.

Finally, and most importantly, PK is largely influenced by stress, which exhibits a strong sexual dimorphism (Kokras et al., 2019). Stress can modify gastrointestinal function, metabolism, lipid distribution, blood flow, albumin binding capacity, and renal excretion (Kokras et al., 2019). This is of particular relevance in women who are more frequently exposed to some types of stress conditions than men (American Psychologic Association, 2017).

\section{B. Pharmacodynamics}

Sex differences in PD are less studied than sex differences in PK. In part, this is a consequence of a lower number of women being included in clinical trials than men and the predominance of male animals used in preclinical studies (Franconi et al., 2015, 2017, 2019; Regitz-Zagrosek et al., 2016; Mauvais-Jarvis et al., 2017; Ventura-Clapier et al., 2017). Here, we discuss sex differences in PD with focus on cardiovascular signaling and the influence of the gut microbiome.

1. Renin-Angiotensin System. Regarding the reninangiotensin-aldosterone system, sex differences are not limited to the receptors but also involve the synthesis of the components of this system (Ahmed et al., 2019). Preclinical evidence indicates that the renin-angiotensin-aldosterone system is under the control of sex hormones: Estrogens increase angiotensinogen levels and the number of angiotensin II receptor type 2 receptors and decrease renin levels, increased ACE, and aldosterone production as well as the number of angiotensin II receptor type 1 receptors (Hilliard et al., 2013). Although the role of androgens is poorly studied, testosterone appears to improve renin levels and ACE activity (Fischer et al., 2002; Komukai et al., 2010). In addition, women who are premenopausal have lower renin levels than their male counterparts and women who are postmenopausal (Schunkert et al., 1997). These sex differences may lead to differences in drug treatment efficacy and adverse reaction between the sexes (see section A. Pharmacokinetics).

2. Adrenoreceptors. In the case of adrenoceptors, sex differences are due to estrogens. Vessels of female rats constrict less and relax more in response to adrenergic 
stimulation compared with males; this sex differences is eliminated by ovariectomy in female rodents (Riedel et al., 2019). Ovariectomy elevates norepinephrineinduced vasoconstriction and reduces isoprenaline and $\beta_{3}$-agonist vasorelaxation, and this is associated with reduction of mRNA of $\beta_{1}$ and $\beta_{3}$ receptors. Estrogens restore sex-specific differences in $\beta_{1^{-}}$and $\beta_{3}$-adrenoreceptor expression (Riedel et al., 2019). Moreover, the $\alpha$-adrenergic constriction is lower in human mammary artery from women than it is from men, and this sex difference disappears with aging (Al-Gburi et al., 2017). Some authors reported that norepinephrine reduces forearm blood flow more in men than in women, whereas flow increases more in women after selective $\beta$-adrenergic stimulation (Kneale et al., 2000; Dart et al., 2002).

3. Endothelin Receptors. The expression of endothelin (ET) receptor subtypes exhibits sexual dimorphism, even after menopause. Saphenous veins isolated from men have higher ET receptor density than those isolated from women (Mouat et al., 2018). Thus, the maximum binding capacity for ETA and ETB receptors is lower in women than in men (Ergul et al., 1998). The ratio of ETA to ETB is also higher in men (3:1) than in women (1:1), which explains the stronger vasoconstriction induced by endothelin-1 in men than in women (Mouat et al., 2018). There are clinical implications, as women with pulmonary arterial hypertension treated with antagonists of ET receptors (ambrisentan, bosentan, sitaxsentan) seem to respond better than men (Gabler et al., 2012).

4. Arachidonic Acid Cascade and Aspirin. Arachidonic acid can be liberated by phospholipases A2, $\mathrm{C}$, and $\mathrm{D}$ and locally converted into prostaglandins, prostacyclin, thromboxane A2, leukotrienes, lipoxins, and hepoxylins and platelet-activating factor. Moreover, it is a substrate of CYP. The arachidonic acid cascade is regulated by estrogens that decrease the activity of cyclooxygenase 1 and cyclooxygenase 2 through the $G$ protein-coupled estrogen receptor (Mouat et al., 2018). In healthy men, acute testosterone treatment increases the density of thromboxane A2 receptors in platelets, thus increasing platelet aggregation (Ajayi et al., 1995). In contrast, estrogens desensitize thromboxane receptors (Mouat et al., 2018). In human endothelial cells, estradiol elevates the generation of prostacyclin in a dose-dependent manner, which is inhibited by tamoxifen and its metabolites that compete with estrogens to occupy estrogen receptors (Mikkola et al., 1995). Additionally, the genetic deletion of prostacyclin receptor 1 , which is coupled to $\mathrm{G} \alpha \mathrm{q} / 11$, reduces systolic blood pressure only in men (Audoly et al., 1999). Prostaglandin $\mathrm{E}$ production and activities, the cytochrome P450 metabolic pathway (epoxyeicosatrienoic acids and 20-hydroxyeicosatetraenoic acid), lypo-oxygenases, and lipoxins are influenced by sex (Pace et al., 2017; Mouat et al., 2018). The administration of low doses of aspirin induces a direct relationship between age and aspirintriggered 15-epi-lipoxin A 4 in women but not in men (Pace et al., 2017). Furthermore, women absorb aspirin more rapidly, distribute it in larger apparent $\mathrm{Vd}$, and hydrolyze it more rapidly than men (Müller and Fromm, 2011; Soldin et al., 2011). In addition, in women, glycine and glucuronic conjugation of aspirin is lower than in men (Ho et al., 1985). However, the use of OC in women elevates glycine and glucuronic acid conjugation and makes aspirin bioavailability similar to that of men (Spranger et al., 1989). Aspirin is effective in the secondary prevention of cardiovascular diseases in both sexes (Pace et al., 2017). However, the situation is less clear in primary prevention: The American College of Cardiology and the American Heart Association downgraded the recommendation for aspirin. Some studies indicate that the antithrombotic effects of aspirin are present only in men (Harris et al., 1977; Canadian Cooperative Study Group, 1978). However, the Women's Health Study revealed that aspirin reduces the risk of total and ischemic strokes in women, whereas the risk of MI or death from cardiovascular events were not reduced (Ridker et al., 2005). A meta-analysis including six randomized studies concluded that in primary prevention, aspirin provides men and women with a similar reduction of cardiovascular events (Berger et al., 2006). However, these are not unequivocal results, and a second meta-analysis including the same six studies concluded that aspirin lowers major coronary events only in men (Baigent et al., 2009). Finally, resistance to aspirin is higher in old women (Awidi et al., 2011). Mechanistically, emerging evidence suggest the existence of agonist-dependent sex differences in platelet responses to aspirin. Despite higher cyclooxygenase 1 inhibition in women, daily aspirin exposure for 4 weeks resulted in a paradoxical attenuation of platelet inhibition in response to epinephrine and ADP over time in women but not in men (Friede et al., 2020). These data could explain at least in part the sexually dimorphic outcome observed with antiplatelet drugs for the prevention of cardiovascular diseases. The main adverse effect of aspirin is bleeding, and a Swedish study reported that aspirin-induced bleeding is lower in men than in women (Rydberg et al., 2014). In contrast, aspirin use is associated with a risk of hearing loss only in men (Curhan et al., 2010). Beyond aspirin, other antiplatelet therapies are more efficient in males than in females (Becker et al., 2006; Mehta et al., 2006; Qayyum et al., 2008; Capodanno and Angiolillo, 2010; Patti et al., 2014).

5. Nitric Oxide. Another important sex-divergent target is nitric oxide (NO) (Ahmed et al., 2019), which is generated in part through different NO synthases, some of which are regulated by sex hormones (Duckles and Miller, 2010); by chemical reduction of the inorganic 
anions nitrate and nitrite; and by microbiota (Kapil et al., 2018). In basal conditions and after nitrate supplementation, females reduce oral nitrate to a greater extent, which leads to higher levels of nitrite, a precursor of NO (Kapil et al., 2018).

6. Influence of the Microbiome. As discussed above for PK, the efficacy of some drugs may be mediated via modulation of the GI microbiome. For example, oral antibiotics (Iizumi et al., 2016) are a class of drugs that inadvertently disrupt the GI microbiome. Metformin was shown to not only modulate the GI microbiome but likely has efficacy in improving glucose regulation by GI microbiome modulation (Forslund et al., 2015; Wu et al., 2017; Vallianou et al., 2019). Additionally, PD of an oral drug, which is at least partially dependent on drugmicrobiome interactions, may be confounded by modulations of the gut microbiome because of diet (David et al., 2014), sex hormones (Markle et al., 2013; Org et al., 2016), and sex-by-diet interactions (Org et al., 2016). Although early studies suggest that the human GI microbiome is relatively stable and adult-like after the first 3 years of life (Yatsunenko et al., 2012), recent data indicate that the GI microbiota community of preadolescent children is different than that of adults when compared taxonomically (Hollister et al., 2015), suggesting that changes may occur during puberty. GI microbiota taxonomical shifts occur also during pregnancy with vast expansion of diversity from the first trimester to the third trimester (Koren et al., 2012). Moreover, stress during early pregnancy not only induces a shift in maternal fecal bacteria community structure but also differentially alters the GI microbiome of the offspring in a male-specific manner (Jašarević et al., 2017). Furthermore, castration of either adult male or female mice shifts their GI microbiome profiles (Harada et al., 2016). These data suggest that sex hormones influence the community of GI microbiota. The reverse is also documented. Transfer of fecal microbiota from mature male mice to female mice increases serum testosterone levels in the recipient females (Markle et al., 2013), suggesting that microbiota may function to regulate sex hormones, at least in rodents. Thus, gut microbiota influence sex differences in both PK and PD, and this needs more specific research in humans.

7. Heart Electrophysiology. There are important electrophysiological sex differences in the heart, including faster resting heart rates and longer QT intervals in women than in men (Regitz-Zagrosek and Kararigas, 2017). These differences seem to be influenced at least in part by sex hormones. For example, endogenous testosterone upregulates both rapidly $\left(\mathrm{I}_{\mathrm{Kr}}\right)$ and slowly $\left(\mathrm{I}_{\mathrm{Ks}}\right)$ activating delayed rectifier potassium channels leading to a short action potential. In contrast, endogenous estrogens downregulate $\mathrm{I}_{\mathrm{Kr}}$ and $\mathrm{I}_{\mathrm{Ks}}$, lengthening the action potential (Pham et al., 2001). Expression levels of Cav1.2 $\alpha$ (primary subunit of the L-type calcium-channel protein 1) and sodium-calcium exchange protein 1 are higher at the base than at the apex of the epicardium only in women who are fertile (Papp et al., 2017). Such differences in ion channel expression may explain why male sex is a risk factor for either Brugada syndrome or Brugada druginduced syndrome and sudden death (Konigstein et al., 2016; Yuan et al., 2018), whereas being a female is a risk factor for long QT-interval syndrome (LQTS) (Regitz-Zagrosek et al., 2016). The Brugada syndrome is induced by sodium-channel blocking drugs prescribed both for cardiac arrhythmias as well as for non-cardiovascular drugs such as psychotropic and analgesic-anesthetic medications (www.brugadadrugs. org). LQTS is induced by QT-prolonging antiarrhythmic drugs, antibiotics, and antihistaminic and psychotropic drugs. For example, moxifloxacin and levofloxacin, which are two antibiotics, exert sex-specific effects on the QT subintervals probably related to the $\mathrm{I}_{\mathrm{Ks}}$ and $\mathrm{I}_{\mathrm{Kr}}$ inhibitory properties of moxifloxacin versus inhibition of $\mathrm{I}_{\mathrm{Kr}}$ only of levofloxacin (Taubel et al., 2019). Together, the above data indicate that the heart is a sex-specific toxicological target. This is also confirmed by tramadol adverse reaction, which induces tachycardia and S-wave abnormalities, especially in men, whereas LQTS and right bundle branch blocks prevail in women (Alizadeh Ghamsari et al., 2016).

8. Role of Genetic Polymorphism and Epigenetics. Sex differences in PD may be influenced by genetic polymorphisms. For example, a variant of the ACE1 (I and D alleles) modifies the ACEI activity, with these drugs being more renoprotective in women with $\mathrm{D} / \mathrm{D}$ genotype versus men with $\mathrm{D} / \mathrm{D}$ genotype (Ruggenenti et al., 2008). This polymorphism also affects pharmacological response of hydrochlorothiazide, with mean decline in blood pressure being greater in II than in DD homozygotes among women. In contrast, in men, the mean decline in blood pressure is greater in DD than in II homozygotes (Schwartz et al., 2002).

Epigenetics modifications could play a role in the sexually dimorphic PD of drugs. First, DNA methylation and histone acetylation differ between the two sexes (Ghahramani et al., 2014; Shen et al., 2015), and epigenetic changes can alter the regulation of drugmetabolizing enzymes and drug transporters (Tracy et al., 2016); for example, hydralazine, a vasodilator, and procainamide, an antiarrhythmic sodium-channel blocker, inhibit DNA methylation and can trigger a lupus-like autoimmune disease (Cornacchia et al., 1988). Taken together, the above data suggest that the sexually dimorphic epigenome may participate in sex differences in the PD and PK of drugs.

\section{Sex-Specific Pharmacology of Drugs Acting in Different Physiologic Systems}

Sex differences in the therapeutic and adverse effects of drugs are described. Here we focus on acting on cardiovascular and metabolic diseases as well as pain. 


\section{A. Cardiovascular}

Unfortunately, most cardiovascular studies do not report effects and adverse effects specified according to sex, which hampers meta-analysis that might lead to new insights. In this section, we report on sex and gender differences in the most prominent cardiovascular drugs (summarized in Table 1).

1. Digoxin. In 1997, the Digitalis Investigation Group confirmed the efficiency of digoxin therapy for patients with heart failure (Digitalis Investigation Group, 1997). Thereafter, guidelines strongly endorsed the use of digoxin in heart failure with reduced ejection fraction (HFrEF) without considering sex. However, in a post hoc subgroup analysis, digoxin was associated with significantly higher mortality among women taking digoxin compared with those taking placebo, an effect that was not observed in men (Rathore et al., 2002). Subsequently, unfavorable survival effects reported in women were attributed to higher drug serum levels in the upper normal range. In the absence of definitive evidence, digoxin plasma concentration should be below $0.8 \mathrm{ng} / \mathrm{ml}$ in women and men (Rathore et al., 2003).

2. $\beta$ Blockers. $\beta$ Blockers are cornerstones in the treatment of heart failure. Two major trials, the MERIT-HF (metoprolol CR/XL) study (MERIT-HF, 1999) and the Carvedilol Prospective Randomized Cumulative Survival (COPERNICUS) trial (Packer et al., 1996), failed to find a beneficial effect on mortality in the small subgroups of women. In the CIBIS II study, women profited significantly from treatment with bisoprolol (CIBIS-II, 1999; Simon et al., 2001). Pooling of mortality results from MERIT-HF, CIBIS II, and COPERNICUS showed survival benefits in both women and men (Ghali et al., 2002). The lack of evidence in some large $\beta$ blocker studies is therefore probably due to the underrepresentation of women in these trials.

Metoprolol and propranolol are primarily metabolized by liver cytochrome CYP2D6, which has a lower activity in women than in men (Tanaka and Hisawa, 1999; Labbé et al., 2000). Propranolol reaches plasma levels that are up to $80 \%$ higher in women compared with men. The optimal effect of the $\beta$ blocker metoprolol may also be achieved with lower doses in women than in men: A 50-mg metoprolol dose in adult women provided an approximately similar drug exposure to a $100-\mathrm{mg}$ dose in adult men (Eugene, 2016). Oral contraceptives can also interact with metoprolol metabolism and further increase its plasma levels in women (Kendall et al., 1982). A recent post hoc analysis in the BIOSTAT-CHF (Biology Study to Tailored Treatment in Chronic Heart Failure) study performed in 11 European countries suggested that women with $\mathrm{HFrEF}$ might require lower doses of $\beta$ blockers and ACEI than men for optimal effects (Santema et al., 2019). The results from the European study were confirmed in an Asian cohort (Santema et al., 2019).

3. Angiotensin-Converting Enzyme Inhibitors. In early multicenter studies [e.g., CONSENSUS I, Survival and Ventricular Enlargement (SAVE), and Studies of Left Ventricular Dysfunction (SOLVD)], ACEIs led to smaller mortality reductions in women compared with men (Regitz-Zagrosek, 2006). Later trials, including Acute Infarction Ramipril Efficacy (AIRE) and Heart Outcomes Prevention Evaluation (HOPE) as well as a number of smaller studies, showed significant benefits of ACE inhibition in women (RegitzZagrosek, 2006). However, the "Second Australian National Blood Pressure Study" (ACE inhibitors vs. diuretics) reported a significant reduction in cardiovascular events in men but not in women despite similar reductions in blood pressure in both sexes (Wing et al., 2003). Most recently, the Biostat HF trial suggested that women with $\mathrm{HFrEF}$ reach the same treatment effects (i.e., mortality and reduction of cardiovascular events) with lower doses than men and do not benefit from uptitrating to guideline-recommended doses (Santema et al., 2019). Thus, the underlying pathophysiology of cardiovascular disease may interfere with treatment results in a sex-specific manner. Adverse effects of ACEI, especially a typical dry cough, that occur early with treatment and seem to be dose-independent are more frequent in women than in men (Mackay et al., 1999).

4. Angiotensin II Receptor Blockers. Major ARB studies in patients with hypertension after myocardial infarction and heart failure found no sex-specific differences and showed the same safety profile in both sexes. This was true for Losartan Intervention for Endpoint Reduction in Hypertension, Evaluation of Losartan In The Elderly II, Optimal Trial in Myocardial infarction with Angiotensin II Antagonist Losartan, Valsartan Antihypertensive Longterm Use Evaluation, Valsartan Heart Failure Trial, I-PRESERVE (Irbesartan in Heart Failure), and Candesartan in Heart Failure: Assessment of Reduction in Mortality and Morbidity (Seeland and RegitzZagrosek, 2012).

5. Sacubitril-Valsartan. Recently, completely unsuspected sex differences were found in a large RCT comparing the combined Neprilysin inhibitor/ARB (sacubitril-valsartan) and valsartan in patients with heart failure with preserved ejection fraction (HFpEF) (McMurray et al., 2019a; Solomon et al., 2019). Neprilysin inhibition augments endogenous biologically active natriuretic peptides and other vasoactive compounds with increased generation of cGMP, a signaling molecule that is reduced in $\mathrm{HFpEF}$ and is beneficial in HFrEF (McMurray et al., 2014a,b). Sacubitril-valsartan did not result in a significantly lower rate of total hospitalizations for heart failure and death from cardiovascular causes in a mixed-sex cohort of patients 
with HFpEF/HFrEF (Solomon et al., 2019). However, it led to a significant reduction in event rate versus valsartan in women, which was not observed in men $(0.73$ in women and 1.03 in men; $\mathrm{P}$ interaction $=0.017)$ (McMurray et al., 2019a). Unfortunately, the study could not provide a definite mechanistic basis for this finding.

6. Renin Inhibitors. Aliskiren, the first nonpeptide active renin inhibitor, provided equally effective, dosedependent blood pressure lowering in women and men with mild-to-moderate hypertension and also in the elderly, obese, or those with metabolic syndrome (Gradman et al., 2010).

7. Aldosterone Receptor Antagonists. The Randomized Aldactone Evaluation Study found no difference in the effect of spironolactone on symptomatic heart failure between men and women (Pitt et al., 1999). However, women represented only $30 \%$ of the enrolled patients, and the trial was not powered to detect sex differences. The major clinical trial of eplerenone in patients with acute MI and left ventricular dysfunction, Eplerenone Post-AMI Heart Failure Efficacy and Survival Study (EPHESUS) showed a trend toward greater benefit for women treated with eplerenone at 30 days, which was not confirmed at 16 months (Pitt et al., 2003). Furthermore, in an exploratory, post hoc, nonprespecified analysis of the TOPCAT (Aldosterone Antagonist Therapy for Adults With Heart Failure and Preserved Systolic Function) trial, evidence for sex differences was found. In TOPCAT, subjects with symptomatic $\mathrm{HF}$ and a left ventricular ejection fraction $\geq 45 \%$ were randomized to spironolactone or placebo. In a post hoc subgroup analysis in which only subjects enrolled from the Americas were analyzed, spironolactone therapy was associated with reduced allcause mortality in women (hazard ratio: $0.66 ; P=$ 0.01 ) but not in men ( $\mathrm{p}$ interaction $=0.02$ ) (Merrill et al., 2019). Thus, even though the interaction between spironolactone and sex in TOPCAT overall and in the present analysis was not significant for the primary cardiovascular outcome, there was a reduction in all-cause mortality associated with spironolactone therapy in women, with a significant interaction between sex and treatment arm. More prospective studies are needed for confirmation and mechanistic understanding.

8. Antiarrhythmic Drugs. A number of antiarrhythmic drugs prolong cardiac repolarization. As discussed in the PD section, women have longer rate-corrected QT intervals than men and are more prone to adverse effects with such drugs. Women consistently exhibited a higher incidence of QT prolongation and torsades de pointes than men for QT-prolonging drugs, including amiodarone, bepridil, disopyramide, quinidine, erythromycin, halofantrine, ibutilide, probucol, sotalol, and terfenadine (Kurokawa et al., 2012).

9. Calcium-Channel Blockers. The major hypertension trials with calcium antagonists revealed no evidence for sex differences in outcomes (Seeland and RegitzZagrosek, 2012). Only the Amlodipine Cardiovascular Community Trail trial therapy with amlodipine resulted in more pronounced blood pressure reduction in women than in men. Women also had a higher incidence of edema. The sex differences were small, and further evidence is needed to support clinical relevance. No sex differences of verapamil treatment were confirmed.

10. Sex-Specific Reporting of Effects and Adverse Effects. Knowledge on sex differences in effects and adverse effects in RCTs is crucial to understand the mechanisms of drug action in women and men and to optimize therapy. However, most RCTs do not present their results in a sex-disaggregated manner. A recent RCT reporting positive effects of colchicine for MI included only $20 \%$ women and did not segregate the results by sex (Tardif et al., 2019). In a recent systematic search of PubMed and EMBASE to collect all available information on ADRs to ACE inhibitors, $\beta$-blockers, angiotensin II receptor blockers, mineralocorticoid receptor antagonists, ivabradine, and digoxin in both women and men with HF identifying 155 eligible records, only $11(7 \%)$ reported ADR data for women and men separately (Bots et al., 2019). Three of the 11 studies reported a higher risk of ACE inhibitor-related ADRs in women, and one study showed higher digoxinrelated mortality risk for women. These results underline the scarcity of ADR data stratified by sex. The study investigators called for a more comprehensive reporting of ADR data for women and men separately (Bots et al., 2019).

\section{B. Pain and Analgesia}

Chronic pain, defined as pain lasting over 3 months in duration, is one of the most commonly reported health problems in the United States (Elzahaf et al., 2012; Kennedy et al., 2014). The Centers for Disease Control and Prevention estimates that over $20 \%$ of US adults experienced chronic pain in 2016, with $8 \%$ experiencing high-impact chronic pain (Nahin, 2015). These statistics are much worse for the elderly population, in which an estimated $45 \%-80 \%$ of persons aged 65 or older suffer from chronic pain on a daily basis. Despite being introduced over 5 millennia ago, opioids remain the most common therapeutic treatment of the management of chronic pain (Brookoff, 2000a,b), and it is estimated that as many as $3 \%-5 \%$ of adults in the United States are prescribed long-term opioid therapy (Boudreau et al., 2009). Among pain sufferers, women are more likely than men to be prescribed opioids at higher doses and for longer periods of time (Campbell et al., 2010; Frenk et al., 2015; Manubay et al., 2015). This may have potentially important implications for the development of tolerance and addiction to opioids. Indeed, although men are more likely to die from drug overdose than women, between 1999 and 2010, overdose deaths due to opioid pain relievers increased by 
$415 \%$ in women compared with $265 \%$ in men [Centers for Disease Control and Prevention (CDC), 2013].

It is becoming increasingly clear that opioids may not offer the same degree of pain relief in women than in men, with research over the last 3 decades implicating sex as a biologic variable influencing opioid modulation of pain. The majority of this research comes from preclinical studies on rodents. Indeed, despite the significantly higher prevalence of pain reports and disorders in women, very few clinical studies include sex as an independent variable. Among studies that include sex as a factor, the majority demonstrate decreased analgesic efficacy of opioids in women (Berkley, 1997; Cepeda and Carr, 2003; Miller and Ernst, 2004; Aubrun et al., 2005; Fillingim et al., 2009; Mogil and Bailey, 2010). Notably, one clinical study reported that females required $30 \%$ more morphine to reach the same level of analgesia as males (Cepeda and Carr, 2003). In contrast, other studies report that the analgesic efficacy of opioids was comparable between the sexes (Bijur et al., 2008; Fillingim et al., 2005; Glasson et al., 2002; Sarton et al., 2000). Sex differences in morphine consumption (i.e., patientcontrolled analgesia) have also been reported. However, as women consistently experience a greater preponderance of the negative side effects associated with acute opioid consumption, including nausea, dysphoria, headache, and vomiting (Myles et al., 1997; Cepeda et al., 2003; Fillingim et al., 2005; Comer et al., 2010), opioid consumption is not a reliable indicator of morphine analgesia (Myles et al., 1997; Cepeda et al., 2003; Fillingim et al., 2005; Comer et al., 2010). A recent meta-analysis with moderate quality of evidence reported that in acute pain, the analgesic response to opioid does not diverge between men and women. However, when women self-administer the drug, they take a lower daily amount of opioids. When chronic pain is investigated, the quality of studies decreases, and in noncancer pain, women receive lower daily doses of opioid, whereas the daily dose of opioids for cancer pain does not diverge among women and men. The above results were strongly influenced by age, comorbid mental disorders, type of administration, type of opioids, type of patients, and body weight. However, these factors are not considered in the prescription of opioids, and this may explain the variability in clinical trial results (Pisanu et al., 2019).

Studies in rodents examining the impact of sex on opioid modulation of acute or persistent pain have consistently reported that morphine is more efficacious in males than in females (Kepler et al., 1989; Boyer et al., 1998; Craft et al., 1999; Cicero et al., 2002; Krzanowska et al., 2002; Holtman et al., 2003; Ji et al., 2006; Loyd and Murphy, 2006; Wang et al., 2006; Loyd et al., 2008; Posillico et al., 2015). Sex differences in morphine action are not trivial; in both persistent inflammatory pain (Krzanowska and
Bodnar, 1999; Craft, 2003; Stoffel et al., 2003; Craft et al., 2004; Ji et al., 2006; Wang et al., 2006; Bernal et al., 2007; Loyd et al., 2008; Doyle et al., 2017; Doyle and Murphy, 2018) and visceral pain (Ji et al., 2006, 2007, 2008; Murphy et al., 2009; Larauche et al., 2012), the $\mathrm{ED}_{50}$ is approximately 2-fold higher for females than for males. Sex differences in opioid analgesia are not limited to morphine. Greater pain relief is also observed in male rats for almost every opioid tested (Barrett et al., 2002; Terner et al., 2003; Stoffel et al., 2005; Peckham and Traynor, 2006; Bai et al., 2015). Several factors have been shown to contribute to the sex differences in the ability of morphine to attenuate persistent and/or severe pain, including sex differences in the neuroanatomical, neurophysiological, and neuroimmunological aspects of central nervous system circuits subserving pain and analgesia. Sex differences in $\mu$-opioid receptor expression and signaling (Bernal et al., 2007; Loyd et al., 2008) as well as spinal $\mu$-opioid receptor and $\kappa$-opioid receptor dimerization (Chakrabarti et al., 2010) have all been shown to contribute to the sexually dimorphic effects of morphine. In addition to neural mechanisms, sex-specific differences in glial signaling have also been implicated (Sorge et al., 2011; Doyle et al., 2017; Doyle and Murphy, 2017, 2018; Averitt et al., 2019). The fact that so many seemingly competitive theories exist to account for the dimorphic response to morphine implies a parallel and/or upstream mediator of these effects.

The necessity of sex-specific research on pain and pain management is clear. Unfortunately, despite growing literature reporting sex differences in pain and morphine analgesia, the overwhelming majority of preclinical studies of pain (approximately 79\%) are still conducted exclusively in males (Mogil, 2012). At this point, it is clear that sex differences in opioid modulation of pain exist and warrant additional, comprehensive investigation into the underlying mechanisms. Building on what is currently known regarding sex differences in pain and analgesia will likely identify additional targets for the development of novel pain therapeutics; only then will we be able to advance effective pain management in both women and men.

\section{Body Weight and Blood Glucose}

From a global view, there are more men living with diabetes but more women who are obese with expected further increase of the combination of obesity and diabetes (diabesity) in the near future (International Diabetes Federation, 2019; https://www.who.int/newsroom/fact-sheets/detail/obesity-and-overweight). Overall women who are diabetic bear a greater excess risk of cardiovascular disease and of excess mortality compared with men (Labib, 2003; Kautzky-Willer et al., 2016; Ostan et al., 2016; Kautzky-Willer and Harreiter, 2017). On the other hand, women more often show "metabolically healthy obesity," which may in part be 
ascribed to more favorable fat distribution and sex hormones (Mauvais-Jarvis et al., 2013; KautzkyWiller et al., 2016). The cause of increased vascular risk in women with diabesity is not entirely known, but both sex and gender differences in treatment modalities, clinical inertia, adherence to drug therapy, and metabolism of drugs (sex-specific cytochrome expression) as well as cultural and lifestyle factors must be considered (Rossi et al., 2013; Ostan et al., 2016). There is evidence that women reach therapeutic goals for cardiometabolic health less often than men (Krämer et al., 2012; Franzini et al., 2013). Women who are diabetic show worse risk control and are less likely to be on target for HbA1c despite comparable antihyperglycemic treatment (Penno et al., 2013). Therefore, potential sex differences in intensity of pharmacological management or quality of care may be ascribed to different pharmacokinetic or pharmacodynamic factors, drug efficacy, or side effects as well as differences in communication and patient or physician attitudes.

1. Antiobesity Drugs. Most studies show greater weight loss in men compared with women in response to diet, exercise, or combined lifestyle interventions as well as after bariatric surgery (Harreiter and KautzkyWiller, 2018; Cataldi et al., 2019). However, conflicting results exist in regard to pharmacological therapy, with many more women taking antiobesity drugs because of greater obesity-related psychosocial problems and stigmatization. Most antiobesity drugs act via central mechanisms by suppressing food intake or increasing energy expenditure. The serotonergic drugs fenfluramine and dexfenfluramine were withdrawn from the market because of palpitations, insomnia, heart valve disease, and incident pulmonal hypertension, which were mainly reported in women (Kautzky-Willer and Lemmens-Gruber, 2012). In parallel, the antiobesity drugs sibutramine (serotonergic and adrenergic drug) and rimonabant (selective cannabinoid-1 receptor blocker), which also targeted the central control of appetite and body weight, were withdrawn from the market based on serious adverse cardiovascular events or psychiatric side effects and safety concerns, including cases of death and suicide, especially in women (Kautzky-Willer and Lemmens-Gruber, 2012).

Data on sex differences in regard to orlistat, a pancreatic and gastric lipase inhibitor that is commonly used in Europe and United States as a prescribed or over-the-counter medication, are scarce and in part controversial (Kautzky-Willer and Lemmens-Gruber, 2012; Cataldi et al., 2019) (Table 2). Otherwise, this drug is well studied and appears to have low rates of long-term side effects. It can cause oily stools and gastrointestinal problems by reduction of fat absorption, thereby reducing energy intake, and may further lead to deficiency in fat-soluble vitamins (Bessesen and Van Gaal, 2018). The probability of losing more than $5 \%$ body weight is modest compared with the other weight-loss drugs (Bessesen and Van Gaal, 2018). Studies in patients who were orlistat-treated showed greater weight loss in men but better improvement of metabolic parameters in women (Tchoukhine et al., 2011) as well as a decrease in androgen levels and improved ovulation rates in women with polycystic ovary syndrome independent of changes in body mass index (Diamanti-Kandarakis et al., 2007; KautzkyWiller and Lemmens-Gruber, 2012). In addition, orlistat was shown to be more beneficial for women for weight maintenance (Robertson et al., 2016). Orlistat was the most commonly prescribed weight-management drug in the MOVE! Study, with female sex being related both to higher use of antiobesity drugs in general and higher use of orlistat in particular (Thomas et al., 2019). Postmarketing analysis revealed that use of weight-loss drugs and orlistat is higher in women and patients who are diabetic, but sex did not affect long-term adherence, which was in general poor and much lower than in clinical trials (Hemo et al., 2011). A large number of (in most cases serious) adverse events reported for antiobesity drugs, including orlistat, were assessed in the Eudra Vigilance Database from 2007 to 2014, which reported 159 deaths and a majority of adverse events occurring in women (Aagaard et al., 2016).

The GLP-1 receptor (GLP-1R) agonist liraglutide was originally approved for the therapy of type 2 diabetes. The effects of GLP-1 analogs (GLP-1As) are complex, acting at different central and peripheral levels affecting glucose and energy homeostasis and glucosedependent insulin secretion. Because liraglutide induced a marked weight loss in patients who were obese and diabetics, it was subsequently investigated in RCTs in patients who were nondiabetic with obesity and finally approved as an antiobesity drug at a higher dose (3 $\mathrm{mg}$ vs. $1.8 \mathrm{mg} /$ day). Preregistration trials indicated that women show greater weight loss in response to liraglutide independent of the dosage up to $3 \mathrm{mg}$ (Wilding et al., 2016). Exposure-response analysis from RCTs further revealed that weight loss increased in parallel with drug exposure; in women, effects of liraglutide appeared to level off at the highest dose of $3 \mathrm{mg}$, but men did not reach a plateau at this dose (Wilding et al., 2016). Sex differences in pharmacokinetics leading to greater disposition of liraglutide in females could be responsible for about $50 \%$ of the greater weight loss in women compared with men under the dose of $3 \mathrm{mg}$ liraglutide (Wilding et al., 2016). Weight-adjusted exposure was increased by about $30 \%$ in women in comparison with men in the preregistration trials, and the effect of sex was independent of the effect of body weight (Overgaard et al., 2016). The exact underlying causes for the decreased clearance of liraglutide in women compared with weight-matched men (other than different body composition) are not clear. However, sex steroids appear to impact liraglutide pharmacodynamics. The progesterone receptor 


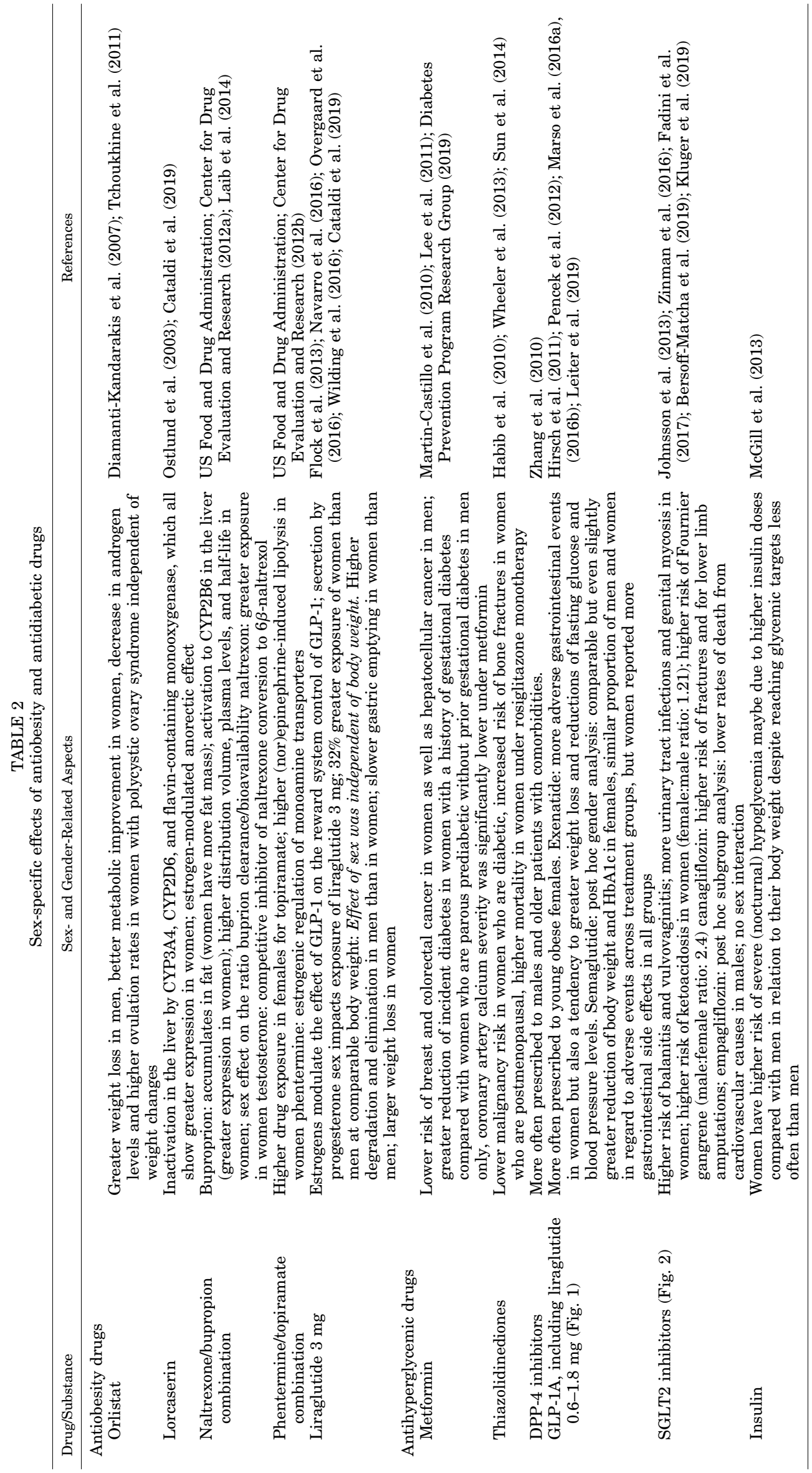


membrane component 1 and the GLP-1R belong to a multimolecular complex (Zhang et al., 2014), and progesterone has been shown to stimulate GLP-1 secretion in animal studies (Flock et al., 2013). In human islets, the androgen receptor agonist dihydrotestosterone exerts insulinotropic effects on $\beta$ cells via activation of GLP-1R, thereby amplifying the incretin effect of GLP-1 (Navarro et al., 2016). GLP-1 regulates feeding behavior at the level of the central nervous system by stimulating anorexigenic proopiomelanocortin neurons and attenuating orexigenic neuropeptide $\mathrm{Y}$ and Agouti-related peptide neurons (Secher et al., 2014). Estrogens modulate GLP-1 effects on feeding behavior and the reward system and its anorexigenic activity in key nodes of the central reward circuitry (Cataldi et al., 2019). In addition, GLP-1 analogs can stimulate gastric vagal afferents and consequently slow gastric emptying and promote satiety in brain regions. Women exhibit slower gastric emptying in general, but possible clinically relevant sex differences in gastric emptying by use of GLP-1A are unclear at present. Despite all of the sex differences described above, differential dosing based on sex or body weight has not been instituted, and the highest tested dose of $3 \mathrm{mg}$ is currently recommended for women and men based on the exposure-response analysis.

Lorcaserin, a 5HT2c receptor agonist, stimulates serotonin anorectic effects at multiple levels. There are conflicting data in regard to sex differences in response to lorcaserin (Cataldi et al., 2019). Estradiol is known to modulate serotoninergic neurotransmission, thereby enhancing the anorectic effects of serotoninergic drugs. It was also postulated that estradiol could enhance the expression of 5HT2c receptors in the caudal hindbrain or that estradiol and serotonin could interact at postreceptor levels. A converging signaling pathway in regulation of energy homeostasis between serotonin 5HT2c receptors and estrogens appears plausible.

Naltrexone/bupropion combination was shown to promote greater weight loss in women in preregistration trials (US Food and Drug Administration; Center for Drug Evaluation and Research, 2014). This combination exerts central anorectic effects by blocking transporters for dopamine and noradrenaline as well as $\mu$-opiod receptors and the $\beta$-endorphin autofeedback on POMC neurons (Cataldi et al., 2019). Thus, reuptake of dopamine and noradrenalin is inhibited. Naltrexone counteracts the opioid-dependent feedback mechanism potentiating the anorectic effects of bupropion. Sex steroids can enhance the antidepressive effects of this combination (Dhir and Kulkarni, 2008). There is evidence for sexually dimorphic effects of naltrexone on the activation of the hypothalamic-pituitary-adrenal axis, with higher increase of cortisol levels in women and estrogen interactions. Therefore, the hypothalamicpituitary-adrenal axis of women appears to be more sensitive to opioid antagonism (Roche et al., 2010). In addition, it was shown that hormonal and subjective effects to naltrexone differed across the menstrual cycle (Roche and King, 2015). Greater increase of cortisol and prolactin as well as more pronounced adverse effects were described after acute naltrexone administration in women during the luteal phase compared with the early follicular phase and in women compared with men. These findings could have clinical implications for naltrexone treatment in women. In a mouse model, the antiobesity combination of naltrexone and buproprion profoundly reduced alcohol drinking via hypothalamic POMC/melanocortin 4 receptor-dependent mechanisms in males but was ineffective in females (Zhou et al., 2019).

With phentermin/topiramate, these weight-loss drugs were combined to achieve a prolonged clinical effect. Larger effects on relative weight reduction were reported for women compared with men (Cataldi et al., 2019). The effects of topiramate, which is approved for epilepsy and migraine prophylaxis, are complex, multilevel, and not fully understood (Cataldi et al., 2019). Main mechanisms appear to be related to potentiation of insulin and leptin actions mainly in the hypothalamus as well as an increase in anorectic neuropeptides including POMC and thyrotropin-releasing hormone (Caricilli et al., 2012). Because estrogens further control the $\alpha$-amino-3-hydroxy-5-methyl-4-isoxazolepropionic acid receptor expression, which is inhibited by topiramate, sex hormones could be responsible for possible sex differences in topiramate efficacy (Cataldi et al., 2019). Phentermine, a substituted amphetamine, enhances adrenergic and dopaminergic neurotransmission, which also appears to be estrogen-dependent. Overall, sexspecific effects of weight-loss drugs are described. Sex and gender differences regarding $\mathrm{PK}$ and $\mathrm{PD}$ of these drugs are described in more detail in a recent review (Cataldi et al., 2019).

2. Antihyperglycemic Drugs. Gender-dimorphic effects of antidiabetic therapies have been described. In a German multicenter observational study, women experienced greater weight loss after treatment with lifestyle, metformin, or sulfonylurea, whereas men showed higher HbA1c reductions after therapy with lifestyle and metformin only (Schütt et al., 2015). Diabetic males also achieved better glycemic control under drug therapy than females in a systematic review (Mannucci et al., 2014). In addition, a retrospective cohort study showed that female sex predicted earlier secondary failure after metformin monotherapy (Mamza et al., 2016). Some studies reported associations between antihyperglycemic drug treatment and various cancers (Table 2). Overall, insulin-sparing drugs appear to relate to lower cancer risk than insulinproviding drugs, with some sexually dimorphic effects (Kautzky-Willer et al., 2017), although data are still conflicting. A 9-fold increased risk for colon, liver, and 
lung cancer together with a decreased risk for prostate cancer was found in men under insulin or sulfonylurea therapy (Kautzky-Willer et al., 2017). In women, glitazones treatment was associated with lower risk of skin and colon cancer, and metformin treatment was associated with lower risk of non-Hodgkin lymphoma in an Austrian diabetic population. In both men and women, insulin and sulfonylureas were associated with higher risk of pancreas and brain cancers.

In the analysis of 15 years of postrandomization follow-up of the diabetes prevention trial, the incidence of diabetes under initial metformin therapy was reduced by $36 \%$, with a trend of greater risk reduction in males than females in subgroup analysis; however, among women, metformin's effect was significantly greater for women with a history of prior gestational diabetes mellitus compared with women who were parous prediabetic without gestational diabetes mellitus (Diabetes Prevention Program Research Group, 2019). The diabetes prevention trial also reported no coronary artery calcium differences between lifestyle and placebo intervention groups in either sex, but it showed lower coronary artery calcium severity and presence among men in the metformin versus the placebo group, even after adjustment for age, statin use, and other confounders (Goldberg et al., 2017). On the contrary, no metformin effect was seen in women.

For incretin-based therapies, a gender-imbalanced prescription practice was reported with more frequent prescription of dipeptidyl peptidase 4 (DPP-4) inhibitors to males, particularly patients who were older with comorbidities, but more frequent prescription of GLP-1 analogs to young obese females (Zhang et al., 2010; Hirsch et al., 2011). This gender-specific channeling may be ascribed to weight-loss effects of GLP-1As in light of greater stigmatization of obesity in women and low risk of clinical side effects of DPP-4 inhibitors. Studying the effectiveness and tolerability of the GLP$1 \mathrm{~A}$ exenatide in subgroups showed that women experienced greater reduction of weight and fasting glucose and blood pressure levels but more severe gastrointestinal side effects (Pencek et al., 2012). However, in a real-world study, after 1 year of exenatide therapy, glycemic response prevailed in men, whereas weight loss was higher in women without significant gender differences observed in gastrointestinal side effects (Anichini et al., 2013). Based on recent cardiovascular outcome trials (CVOTs) of new antihyperglycemic drugs, beneficial cardiorenal effects were shown for the class of sodium/glucose cotransporter 2 (SGLT2) inhibitors as well as for GLP-1A (Figs. 1 and 2; Table 2). In all trials, there was a preponderance of males, with participation by women ranging from $23 \%$ to $38 \%$ in the SGLT2 CVOTs and from 30\% to $46 \%$ in the GLP-1A CVOTs (Pfeffer et al., 2015; Zinman et al., 2015; Marso et al., 2016a,b; Holman et al., 2017; Neal et al., 2017; Hernandez et al., 2018; Gerstein et al., 2019; McMurray et al., 2019b; Wiviott et al., 2019). Subgroup analysis showed a significant reduction of cardiovascular risk and thus a greater benefit in men than in women, although a trend for lower risk was also shown for women, and no sex interaction was reported in some studies. This may be attributed to lower cardiovascular event rates in females in general, as evidenced in both the placebo and active compound groups of women compared with male counterparts. Therefore, longer study duration in female subgroups to allow reaching significant primary outcome events is warranted. To confirm beneficial effects in women, we performed a meta-analysis of MACE as a primary endpoint of CVOTs for both drug classes, and this could show significant risk reduction in both sexes (Figs. 1 and 2).

Analysis of fracture rates under antihyperglycemic medication is necessary because diabetes, per se, is related to alterations of bone quality and increased fracture risk in both sexes, with particular high risk in women who are postmenopausal. Regarding specific classes, data are controversial, but overall, metformin and GLP-1A related to lower fracture risk, whereas insulin and sulfonylurea therapy was associated with higher risk in some studies (Gilbert et al., 2016; Napoli et al., 2017; Smieszek et al., 2018). There is evidence that glitazones are associated with higher rates of fractures in women who are postmenopausal and that only canagliflozin among the SGLT2 inhibitors relates to decreased bone mineral density and increased fracture risk in some analysis (Habib et al., 2010; Mannucci and Monami, 2017).

For SGLT2 inhibitors, higher rates of urinary tract infections, vulvovaginitis, and balanitis with higher incidence of urogenital infections among women were documented (Johnsson et al., 2013). In addition, higher numbers of severe adverse events, such as ketoacidosis, were reported for women than for men (Fadini et al., 2017). Moreover, case series of Fournier gangrene were documented in patients receiving SGLT2 inhibitors with clear predominance of men (Bersoff-Matcha et al., 2019). The event rate was much higher than that documented for other antihyperglycemic classes in the past (55 events in 6 years vs. 19 events in a 35-year timeframe).

Women more often experience severe hypoglycemia when using insulin compared with men. Therapy initiation or titration with higher insulin doses in relation to body weight of women could be one reason for this finding. Nevertheless, women reach glycemic targets less often than men (Kautzky-Willer et al., 2012; McGill et al., 2013). Furthermore, higher levels of stress, anxiety or uncertainty, and greater impact of psychologic distress could contribute to the higher risk of hypoglycemia in women, which consequently also relates to increased risk of falls and fractures and possibly cardiovascular problems (Trento et al., 2015; Kautzky-Willer and Harreiter, 2017). 


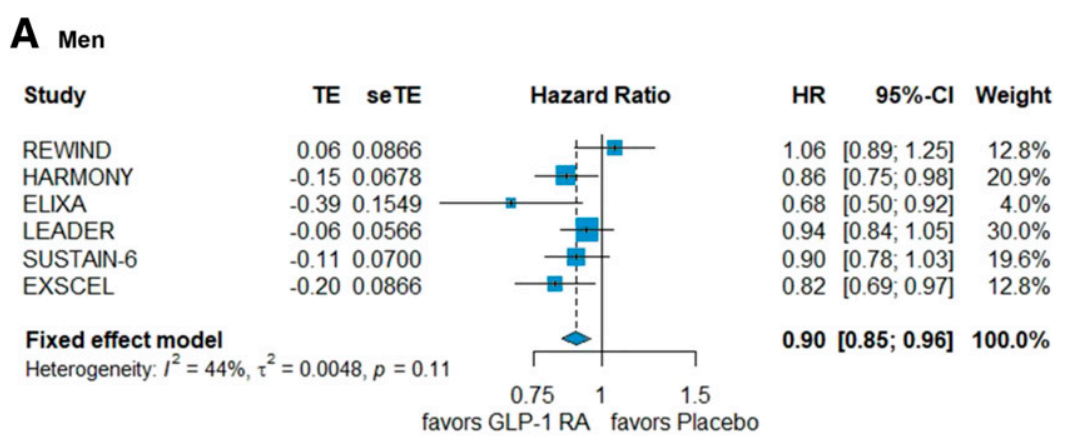

\section{B Women}
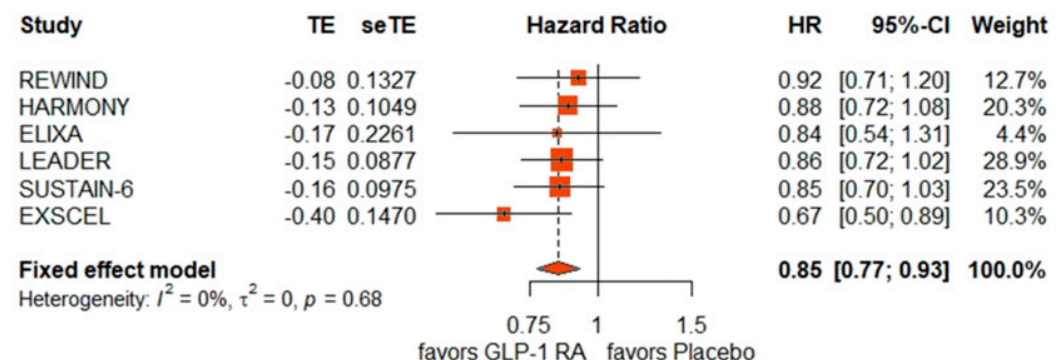

Fig. 1. Subgroup analyses (Borenstein et al., 2010) for the primary cardiovascular outcome* of GLP-1 receptor agonists (RAs). (A) Men. (B) Women. *Primary cardiovascular outcome: REWIND (Gerstein et al., 2019): first occurrence of any component of the composite outcome, which comprised nonfatal myocardial infarction, nonfatal stroke, and death from cardiovascular causes or unknown causes; HARMONY (Hernandez et al., 2018): first occurrence of any component of the composite outcome, which comprised death from cardiovascular causes, myocardial infarction, and stroke; ELIXA (Pfeffer et al., 2015): death from cardiovascular causes, nonfatal myocardial infarction, nonfatal stroke, or hospitalization for unstable angina; LEADER (Marso et al., 2016b): first occurrence of death from cardiovascular causes, nonfatal (including silent) myocardial infarction, or nonfatal stroke; SUSTAIN-6 (Marso et al., 2016a): first occurrence of death from cardiovascular causes, nonfatal myocardial infarction (including silent), or nonfatal stroke; and EXSCEL (Holman et al., 2017): first occurrence of any component of the composite outcome of death from cardiovascular causes, nonfatal myocardial infarction, or nonfatal stroke (three-component MACE outcome). CI, confidence interval; seTE, standard error of treatment estimate; TE, treatment estimate.

During pregnancy and in the preconception period of women with chronic hyperglycemia, insulin is still the gold-standard therapy, as both metformin and glyburide pass the placenta and are associated with worse outcome in the offspring. However, given the steady increase in the use of oral antidiabetic medications in women of reproductive age, better knowledge of their effects on neonatal and long-term outcomes of the offspring as well as addressing barriers and needs of women who are pregnant and diabetic for inclusion in clinical trials are needed for improvement of clinical management in the future (Kautzky-Willer and Harreiter, 2018; Rubin, 2018).

\section{Lipids}

Coronary artery disease (CAD) is the leading cause of death in both women and men in most developed countries and accounts for a larger proportion of deaths in women $(51 \%)$ than in men $(42 \%)$ in European populations (Maas and Appelman, 2010). There are sex differences in risk factors and pathology of CAD, and women typically develop disease 10 years later than men, which has been attributed to the protective effects of ovarian hormones that dissipate after menopause (Garcia et al., 2016). In both sexes, elevated circulating lipid levels, particularly cholesterol carried in lowdensity lipoproteins (LDLs)-C, is a well established risk factor for CAD (Stone and Grundy, 2019). Several factors interact with sex to contribute to the development of dyslipidemia, including lipid-rich diet, sedentary lifestyle, and genetic variation in genes that influence lipid metabolism (Link and Reue, 2017).

There is wide availability of drugs that effectively lower LDL-C levels and decrease the risk of coronary events, including statins, proprotein convertase subtilisin/kexin type 9 (PCSK9) inhibitors, and ezetimibe (Last et al., 2017). These drugs act on distinct targets to influence LDL-C. Statins, which are among the most widely prescribed drugs of all types in the Western world, inhibit the rate-limiting enzyme for cholesterol biosynthesis, 3-hydroxy-3-methylglutaryl CoA reductase. This both reduces endogenous cholesterol synthesis and increases LDL uptake from the circulation through feedback regulation of LDL receptor production. PCSK9 inhibitors are injectable monoclonal antibodies that block the degradation of LDL receptors by the PCSK9 proprotein convertase, thereby increasing LDL uptake from the circulation. Ezetimibe partially blocks dietary cholesterol absorption by targeting an intestinal receptor for cholesterol uptake: NiemannPick C1-like protein 1 . All of these drugs are generally most effective at lowering LDL-C levels in combination with lifestyle modifications, such as reducing dietary fat and increasing physical activity. Cotherapies of statins 


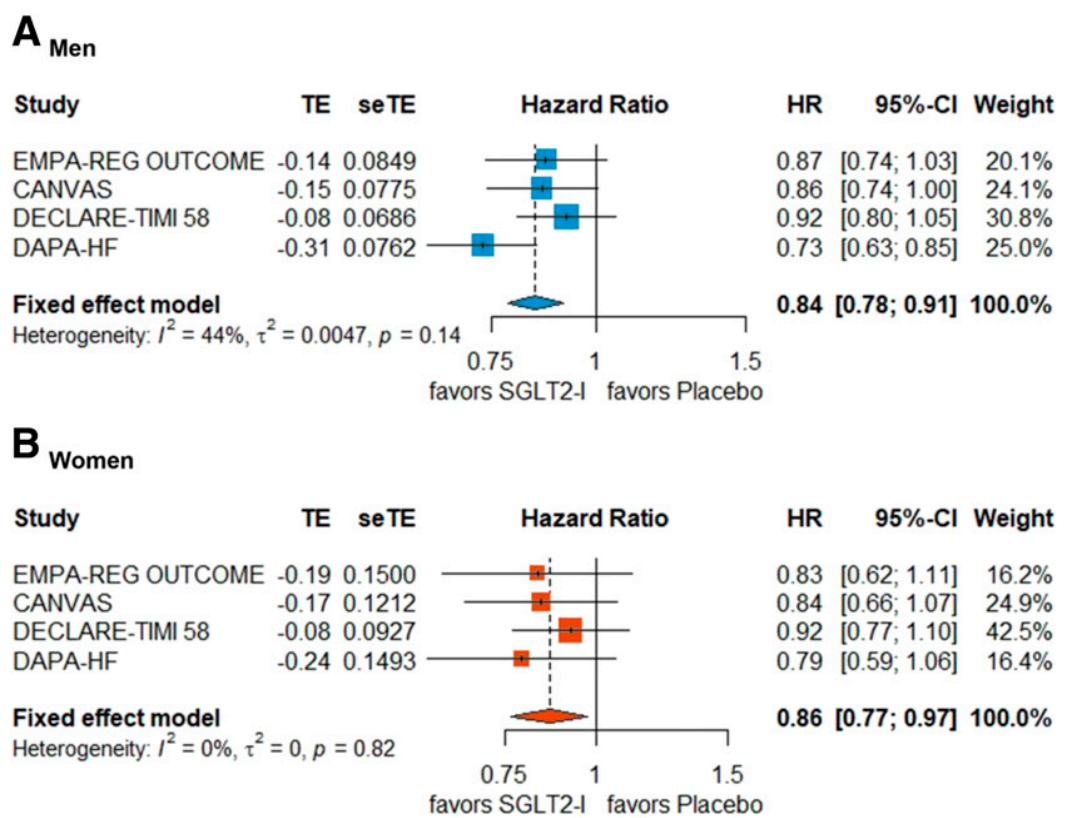

Fig. 2. Subgroup analyses (Borenstein et al., 2010) for the primary cardiovascular outcome* of SGLT2 inhibitors. (A) Men. (B) Women. *Primary cardiovascular outcome: EMPA-REG OUTCOME (Zinman et al., 2015): composite of death from cardiovascular causes, nonfatal myocardial infarction (excluding silent myocardial infarction), or nonfatal stroke; CANVAS (Neal et al., 2017): composite of death from cardiovascular causes, nonfatal myocardial infarction, or nonfatal stroke; DECLARE-TIMI 58 (Wiviott et al., 2019): MACE defined as cardiovascular death, myocardial infarction, or ischemic stroke; DAPA-HF (McMurray et al., 2019b): composite of worsening heart failure or death from cardiovascular causes. CI, confidence interval; HR, hazard ratio; seTE, TE.

with PSCK9 inhibitors or ezetimibe are sometimes used to maximize cholesterol-lowering effects.

Although cholesterol-lowering drugs are beneficial to both women and men, there are sexual inequities in the prevalence of use and adverse effects of these drugs. Numerous, large-scale studies indicate that statins and PCSK9 inhibitors also effectively prevent secondary coronary events in both sexes (Baigent et al., 2010; Kostis et al., 2012; Stein and Raal, 2014; Fulcher et al., 2015; Collins et al., 2016). However, the proportion of individuals that receive and persistently use these drugs to reduce disease risk is lower in women than in men (Chen et al., 2014; Victor et al., 2014). There appear to be several reasons for this. First, women are underrepresented in clinical trials for cholesterol-lowering drugs, which is due in part to later age of onset for dyslipidemia (Manteuffel et al., 2014). In addition, women are less likely to be evaluated by a cardiologist and more likely to experience adverse effects of statins, as discussed further below (Zhang et al., 2016).

Female sex is now recognized as a risk factor for the two most common statin adverse effects: myopathy and new-onset diabetes (Regitz-Zagrosek, 2006; Stroes et al., 2015; Thompson et al., 2016; Rosenson et al., 2017). Myopathy (muscle pain, weakness, and stiffness) occurs in an estimated $10 \%-15 \%$ of statin users (Thompson et al., 2003; Mohassel and Mammen, 2013), and female sex increases the odds of myopathy by 2 -fold (Nguyen et al., 2018). An additional statin adverse effect is the development of new-onset diabetes. An increased occurrence of new-onset diabetes (9\%) during 4 years after statin use has been reported in a meta-analysis of 13 placebo-controlled statin trials, but this varied by study (Sattar et al., 2010). A subsequent analysis of several of these same studies plus additional studies revealed a positive correlation between the proportion of women in the trial groups and the risk of statinrelated incident diabetes. This assessment of 14 statin trials demonstrated a positive correlation between female sex and statin-related incident diabetes $(r=$ $0.6, P=0.036$ ) (Goodarzi et al., 2013). In this metaanalysis, a study consisting exclusively of men [West of Scotland Coronary Prevention Study (WYSCOPS)] had the lowest incidence of new-onset diabetes, whereas a study consisting exclusively of women (Women's Health Initiative) had the highest incidence; studies that included both sexes had intermediate levels of incident diabetes that correlated with the proportion of women. Additionally, stratification of subjects within individual trials revealed important sex effects. For example, in the Justification for the Use of Statins in Prevention: An Intervention Trial Evaluating Rosuvastatin study, the incidence of new-onset diabetes was $25 \%$. However, stratification by sex showed that the risk of incident diabetes was increased by $49 \%$ in women, whereas it was increased by only $14 \%$ in men (Mora et al., 2010; Goodarzi et al., 2013). Furthermore, data from 150,000 participants in the Women's Health Initiative indicated that women who are postmenopausal might be particularly vulnerable to developing diabetes after statin use, with a reported $48 \%$ increase in risk of new-onset diabetes (Culver et al., 2012). 
The mechanisms underlying the increased susceptibility of females to statin adverse effects have not been delineated but likely include sex differences in physiology and PK. Statin adverse effects are thought to be associated with elevated blood concentrations of the drug, allowing increased exposure of tissues, such as muscle to drug, leading to potential alterations in mitochondrial function and calcium signaling pathways (Ward et al., 2019). Since statin drugs are prescribed at unisex doses, the blood and tissue levels of statins in smaller individuals may be higher than in larger individuals such that on average women may experience higher concentrations. Sex differences in drugmetabolizing enzymes and transporters likely also influence statin PK. Statins are catabolized by hepatic cytochrome P450 enzymes, particularly CYP3A4 (simvastatin, lovastatin) and CYP2C9 (rosuvastatin, fluvastatin) (Schachter, 2005). CYP3A4 mRNA and protein levels are typically higher in women compared with men and could lead to differential amounts of bioactive statin in the two sexes (Waxman and Holloway, 2009). The concomitant use of other drugs that are metabolized by CYP3A4 (approximately half of widely used drugs) can alter statin catabolism and lead to elevated plasma levels. Sex differences in the levels of additional enzymes that participate in the conversion of statin prodrugs to their active forms, their uptake into hepatocytes and other cell types, and their degradation and elimination may differ between males and females and should be carefully examined to better define sex differences in statin adverse effects (Thompson et al., 2003; Regitz-Zagrosek, 2006; Sirtori, 2014). Finally, statins are modulators of microRNAs (Allen and Mamotte, 2017), and their beneficial effects have recently been linked with epigenetic changes of the long noncoding RNA MANTIS (Leisegang et al., 2019). Therefore, epigenetic mechanisms, including alterations in microRNAs, could participate to the mechanisms responsible for statin-induced diabetes (Paseban et al., 2019).

Statin drug use for the prevention of CAD will likely increase under recent recommendations from The American College of Cardiology/American Heart Association (Stone et al., 2014). Statins may also be promising treatments for conditions such as osteoporosis, fragile X syndrome, Angelman syndrome, and Rett syndrome (Buchovecky et al., 2013; Çaku et al., 2014; An et al., 2017; Chung et al., 2018). However, whether statin therapy impacts the risk of osteoporosis is still debated, and more studies are required to clarify potential effects of statins on bone health. A dose-dependent relationship between statins and the diagnosis of osteoporosis was found in the general Austrian population; although low-dose statin treatment was related to an underrepresentation of diagnosed osteoporosis when compared with patients who were nonstatin-treated, an overrepresentation of diagnosed osteoporosis was found in those on higher statin dosages. Overall, the impact was greater in women, particularly in younger women (Leutner et al., 2019). Notably, cholesterol is a precursor of steroid hormones, and thus, statins could also lower gonadal hormone levels.

In summary, it is critical to optimize statin treatment of members of both sexes through greater inclusion of females in clinical trials and in basic research of the mechanisms that underlie adverse drug effects.

\section{E. Kidney}

1. Kidney Function and Gender Bias of Glomerular Filtration Rate Equations. Men, in general, have larger and wider kidneys compared with women (Miletic et al., 1998), and women have higher renovascular resistance, lower renal plasma flow, and lower absolute GFR compared with men (Munger and Baylis, 1988). Thus, GFRs are in the range of 15\%-25\% slower in women (Neugarten et al., 2002; Schwartz, 2007). Because measuring GFR is laborious and expensive, in the clinic we often estimate GFR through equations that use sex, serum creatinine levels, and sometimes body weight. These equations have been shown to underestimate kidney function in women to a larger extent than in men (Inker et al., 2017). In humans, body surface area is the main predictor of kidney size. Therefore, given that men tend to have larger kidneys than women, the standardization of estimated GFR by a constant body surface area of $1.73 \mathrm{~m}^{2}$, as we do currently with estimated GFR equations in clinical practice, may introduce gender bias (Carrero et al., 2018). Underestimation of kidney function in women possibly leads to infratherapeutic dosages and low efficacy for drugs that require strict dose adjustment, such as the direct oral anticoagulants (that is, dabigatran, rivaroxaban, apixaban, and edoxaban) (Andrade et al., 2018).

2. Drug-Induced Nephrotoxicity. Medications are a relatively common cause of acute kidney injury, a sudden decline in kidney function. Up to $25 \%$ of hospitalizations for acute kidney injury are attributed to drug-induced nephrotoxicity (Uchino et al., 2005). Drug-induced nephrotoxicity is more common in patients who were hospitalized, particularly patients in the intensive care unit (Hoste et al., 2015). There is evidence to suggest that drug-induced nephrotoxicity may be in some cases sex-related, but this is an area that is largely unexplored. For instance, women have been reported to be more susceptible to nephrotoxicity from gentamicin (Moore et al., 1984) or renin-angiotensin system inhibitors ACEi/ARB (Mansfield et al., 2016), but men may be more prone to develop cisplatin (Nematbakhsh et al., 2013) or tobramycin (Goodrich and Hottendorf, 1995) nephrotoxicity compared with women.

Finally, ACEi/ARB are common drugs for the treatment of hypertension, heart failure, myocardial 
infarction, and kidney disease. Because of antagonism of angiotensin II-mediated efferent arteriolar constriction (Lesogor et al., 2013), some patients may experience a sudden decline in kidney function after starting on these medications. Such sudden decline in kidney function has been associated with worse clinical outcomes and appears to be more common among women (Schmidt et al., 2017b; Sinnott et al., 2017; Fu et al., 2019). Why women are more prone to this is not well known but may be attributed to drug overdosing; although ACEi/ARB recommended dosages are sex-neutral, experimental studies show an interaction between estrogens and the renal expression and activity of components of the renin-angiotensin system (Sandberg and Ji, 2003; Liu et al., 2010). Recent studies indicate that women may need lower dosages than men to achieve the same therapeutic effect (Santema et al., 2019). Unfortunately, many of these complications probably remain undetected, given that less than $20 \%$ of new users of ACEi/ARB in routine care undergo the guideline-recommended monitoring for serum creatinine during the initial weeks of therapy (Schmidt et al., 2017a; Nilsson et al., 2018).

\section{F. Immunity and Vaccines}

Biologic sex has its most profound impact on the development of innate and adaptive immune responses after vaccination. Most inactivated viral vaccines induce predominantly humoral immunity, but viral vaccines that use adjuvants or live attenuated viruses can also induce innate and cellular immunity as well. Among adults (18+ years), females often develop antibody responses that are about two times greater than the those of males after receiving vaccines that protect against influenza, hepatitis B, herpes, yellow fever, and smallpox viruses (Flanagan et al., 2017). The live attenuated yellow fever (YF17D) vaccine also induces greater expression of toll-like receptor signaling and interferon-associated genes (i.e., innate immune signaling) in vaccinated females compared with males (Klein et al., 2010). Because of mutations in seasonal, circulating influenza viruses, vaccination is recommended annually; thus, there is considerably more data about sex differences in vaccine-induced immunity for vaccines against influenza than other pathogens. In young adult (18-49 years) females, immunization with halfdose of seasonal trivalent inactivated influenza vaccine (TIV) induced antibody responses against $\mathrm{H} 1 \mathrm{~N} 1, \mathrm{H} 3 \mathrm{~N} 2$, and influenza $\mathrm{B}$ antigens that are equivalent to the antibody responses in males who received full-dose TIV (Engler et al., 2008). Across diverse ages, females develop higher antibody responses against either influenza monovalent vaccines or TIV (Cook et al., 2006; Talaat et al., 2010; Fink and Klein, 2015). In contrast, pneumococcal vaccines, which are administered to adults 65 years and older, result in greater antibody responses in aged males than in females (Brandão et al., 2004; Goldblatt et al., 2009). The sex differences in vaccine-induced immunity also influence vaccine efficacy and effectiveness. For example, in Guinea-Bissau, the efficacy of the measles vaccine in children tested by measles-associated hospitalizations was better in girls than it was in boys (Aaby et al., 2010). Likewise, influenza vaccine studies have consistently shown that the risk of influenza-associated hospitalization and death is lower in vaccinated females than in vaccinated males (Dhakal and Klein, 2019). An analysis in Canada across seven influenza seasons reported that the overall vaccine effectiveness was greater in females than males, with the female bias being greatest against $\mathrm{A} / \mathrm{H} 3 \mathrm{~N} 2$ and influenza B viruses (Chambers et al., 2018). The mechanisms mediating sex differences in vaccine-induced immunity are only starting to be explored in humans, which have provided data on possible immunomodulatory effects of sex-steroid hormones (Furman et al., 2014; Potluri et al., 2019). Animal models are currently providing the most detailed mechanistic insights into how females develop greater immunity after vaccination. Immunization with sublethal doses of either H1N1 or H3N2 influenza A viruses in C57BL/6 mice results in greater neutralizing antibody titers in both serum and bronchoalveolar lavage fluid; cellular immune responses, including memory CD8+ $\mathrm{T}$ cells responses in the lungs (i.e., the site of infection); and crossprotection against heterologous virus challenge (Lorenzo et al., 2011; Fink et al., 2018). Vaccination of mice with an inactivated $\mathrm{H} 1 \mathrm{~N} 1$ vaccine, TIV, or the quadrivalent inactivated vaccine consistently results in significantly greater quality and quantity of antibody as well as protection against live virus challenge in female mice as compared with male mice (Živković et al., 2015, 2018; Fink et al., 2018). Greater immunity in females can be passively transferred to males through transfer of vaccine-induced antibodies (Fink et al., 2018). The greater antibody responses in influenza-vaccinated females compared with males involve sex chromosome complement. Both estradiol concentrations as well as greater expression of the $\mathrm{X}$-linked gene toll-like receptor 7 underlie induction of greater antibody responses and protection in adult females compared with males (Fink et al., 2018; Potluri et al., 2019). With aging, influenza vaccineinduced immunity is reduced but to a greater extent in females than in males among both humans and mice and is associated with declining concentrations of circulating estradiol with age in females (Potluri et al., 2019). Sex-steroid hormones impart sex differential effects on immunity and protection induced by vaccines, including influenza vaccines. A more detailed exploration of the direct contribution of X-linked genes as well as sex-steroid hormones and their interactions in mediating sex differences to other vaccines is lacking and needs further investigation. Understanding the 
mechanisms of sex differences in immunity to vaccines will help with precision in the development of more efficacious and safe vaccines, including for coronavirus disease 2019.

Males and females also differ in the uptake and acceptance of vaccines and reporting of vaccineassociated adverse events, which ultimately also impacts the protection provided (Flanagan et al., 2017). Because behavior and beliefs about vaccines as well as biologic responses to vaccines play roles in male-female differences, it can be difficult to tease apart the role of sex and gender effects in the context of vaccines in humans. Acceptance of vaccines, in general, is greater in males than in females (Flanagan et al., 2017). For example, the receipt of TIVs is apparently lower among females (Bean-Mayberry et al., 2009; Endrich et al., 2009). After receipt of inactivated vaccines (e.g., TIV), which are administered intramuscularly, local reactions (e.g., redness, itching, pain, swelling) and systemic adverse events (e.g., fever, nausea, myalgia, rash) are more commonly reported in females than males (Flanagan et al., 2017). Greater adverse events in females are reported after immunization with many different vaccines, including influenza, hepatitis B, pneumococcal, herpes zoster, tetanus, pertussis, and yellow fever vaccines (Flanagan et al., 2017). Even a recent randomized, double-blind, placebocontrolled, phase 2 clinical trial of an adenovirus type5 -vectored coronavirus disease 2019 vaccine in China reported that females are more likely than males to experience fever postvaccination (Zhu et al., 2020). Whether reporting of adverse events reflects social norms associated with reporting biases between males and females or biologic sex differences in responses to the vaccine associated with inflammation remains to be determined (Flanagan et al., 2017). The role of patient gender in response to drugs will be discussed in detail in section V. Role of Physician and Patient Gender in Drug Response.

\section{G. Oncology}

Overall, females with cancer have a survival advantage compared with patients who are male with cancer (Dong et al., 2020). Although the reasons for this disparity are incompletely understood and likely to be complex, a readily obtainable research goal with great clinical significance would be a thorough evaluation of sex differences in cancer chemotherapy PK and PD.

Based on the sex differences in drug absorption, distribution, metabolism, and elimination described above, it is expected that the most commonly prescribed chemotherapeutics including anthracyclines, platinum agents, 5-fluorouracil (5FU), methotrexate, taxanes, decitabine, vincristine, and cyclophosphamide/ifosfamide will exhibit sex differences in PK because they depend upon biotransformation for activation or detoxification as well as renal and biliary excretion for elimination. Variation in chemotherapy clearance would affect both tumor and normal tissue exposure and, thus, would be predicted to affect concordantly survival and toxicity in chemotherapy-responsive cancers. 5FU-containing regimens for colon and esophageal cancers provide a case in point. Across multiple clinical trials involving thousands of patients, females treated with $5 \mathrm{FU}$ experience greater numbers of adverse events compared with males (Watanabe et al., 2018; Abdel-Rahman, 2019; Lim et al., 2019; Yamada et al., 2019; Athauda et al., 2020; Wagner et al., 2020), with one study documenting that females completed fewer planned chemotherapy cycles than males (Athauda et al., 2020). Multiple studies have examined whether there are differences in survival between male and female patients. Although the literature contains reports with inconsistent findings, in colon cancer the largest study involving 26,908 patients treated at Mayo Clinic sites between 1972 and 2017 indicates that women exhibited a longer median survival time compared with men (89.1 vs. 76.4 months) (Wang et al., 2019). A similar survival advantage has been reported for esophageal cancer (Athauda et al., 2020).

Females exhibit slower clearance of $5 \mathrm{FU}$ than males (Milano et al., 1992), and even though 5FU is among the most commonly prescribed chemotherapeutics, this knowledge has never been integrated into study design for sex-specific dosing. 5FU is primarily metabolized by dihydropyrimidine dehydrogenase (DPD). Genetic variants in DPD have been associated with increased 5FU toxicity and in prospective clinical trial have been used to guide dose modifications, which had the expected effects on toxicity (Henricks et al., 2018). In addition to patient genotype, DPD expression levels measured in plasma and saliva were predictive of $5 \mathrm{FU}$ area under the curve values and severity of adverse events (Neto et al., 2018). Accordingly, lower levels of DPD expression were associated with better outcome in patients who were pancreatic and treated with $5 \mathrm{FU}$ (Elander et al., 2018). Notably, intratumoral DPD expression levels are lower in female colon cancer specimens compared with male specimens (Yamashita et al., 2002). Interestingly, in a meta-analysis of three clinical trials comparing conventional with chronomodulated chemotherapy administration for colon cancer, survival was affected by the timing of administration, resulting in improvements in male patients but decreased survival in female patients (Giacchetti et al., 2012). In a rat model, DPD expression was shown to be modulated in a circadian manner with peak expression during midsleep phase corresponding to the decreased toxicity observed with nighttime dosing in human clinical trials (Abolmaali et al., 2009). Together, these findings indicate how critically important it could be to evaluate PK as the basis for sex differences in chemotherapy-induced 
toxicity and therapeutic responses to treatment. The fact that DPD genotype has been evaluated for $5 \mathrm{FU}$ dose modifications in clinical trial raises the question of why sex differences in 5FU metabolism have not been similarly evaluated.

In addition to sex differences in PK affecting outcome and toxicity, sex differences in systems level and cellular biology have the potential to impact PD and therapeutic responses. Cancer responses to immune checkpoint inhibition (ICI) represent the clearest example. Immunotherapy has produced robust responses in subsets of patients with melanoma (Hodi et al., 2010; Robert et al., 2015), nonsmall cell lung cancer (Brahmer et al., 2015; Reck et al., 2016), and other cancers (Motzer et al., 2015; Ferris et al., 2016). Subsequent metaanalyses of data from randomized clinical trials have found that male patients benefit more from ICI alone than do female patients (Conforti et al., 2018; Conforti et al., 2019).

Although the mechanistic basis for these differences remains to be completely elucidated, two known mechanisms may be contributing. The first is the differences in female versus male immune function and response to vaccines described above in section $F$. Immunity and Vaccines. Overall, females exhibit more robust immunity, including antigen-driven immune responses. Thus, the therapeutic index (i.e., potential for pharmacodynamic effect) for increasing neo-antigen immune response in cancer may be lower in females than that in males, resulting in the greater therapeutic response in males.

Sex differences in immunity and immune surveillance for neo-antigens could also have more indirect effects on immunotherapy response. As an example, sex and age effects on immunity have been correlated with driver mutation profiles (Castro et al., 2020) suggesting that less antigenic neo-epitopes are present in male versus female cancers. Thus, it may be easier to enhance male immune response if male cancers contain more strong antigens than female cancers. Sex differences in response to ICI may also reflect the greater mutational burden in male cancers. A consequence of sex differences in antigen-driven immune surveillance would be a higher prevalence of strong antigens in male cancers. In addition, tumor mutational burden, which is reported to be a biomarker of ICI response, is greater in males versus females (Gupta et al., 2015; Xiao et al., 2016), also predicting that ICI response would be greater in males compared with females.

Optimal outcomes in cancer like longer survival and decreased toxicity will require greater personalization according to factors that drive variations in $\mathrm{PK}$ and PD. Sex is clearly among the important factors to be considered. As more information becomes available regarding the biology of sex differences in cancer, it will be essential to consider how they may alter PK and PD considerations.

\section{Role of Physician and Patient Gender in Drug Response}

\section{A. Epidemiologic Evidence for Differences in Physician Gender and Response to Treatment}

The last section of this review examines the role that gender of the treating physician and/or of the patient may play in the pharmacological response to drug treatment and indirectly in the quality of care provided. This potential association has been controversially discussed over the years. Some studies have suggested that female physicians provide more comprehensive care than male physicians do for both male and female patients, whereas other studies found no such difference (Gouni-Berthold and Berthold, 2011). A detailed analysis of the role that physician gender plays in drug therapy has been recently reviewed (Gouni-Berthold and Berthold, 2012).

1. Quality of Care. The first major study on this topic examined the association between the gender of primary care physicians (1213 female and 473 male) and the quality of diabetes care they provided to their patients in a US population participating in the Translating Research Into Action for Diabetes study (Kim et al., 2005). This study reported that patients treated by female physicians $(n=4585)$ were more likely to receive lipid and $\mathrm{HbA} 1 \mathrm{c}$ measurements and to have LDL-C levels under $130 \mathrm{mg} / \mathrm{dl}$ than patients treated by male physicians $(n=1783)$. Berthold et al. (2008) also showed that physician gender influences the quality of care in patients with type 2 diabetes and that female physicians provided an overall better quality of care, especially in major risk-factor management. They performed a cross-sectional study using data from the DUTY (Diabetes mellitus needs unrestricted evaluation of patient data to yield treatment progress) registry in 51,053 outpatients ( $48.6 \%$ male) with type 2 diabetes in Germany treated by 3096 office-based physicians (66.3\% male; $74.0 \%$ general practitioners, $21.8 \%$ internists, and $4.2 \%$ diabetologists) to examine processes of care, intermediate outcomes, and medical management. They found that patients treated by female physicians were more often women, more obese, and older, and they more often had atherosclerotic disease (34\% in the total cohort). Using hierarchical regression models, they showed that patients treated by female physicians reached glycemic, lipid, and blood pressure target values significantly more often (14\%, $16 \%$, and $11 \%$, respectively). Interestingly, although patients treated by female physicians did not receive more statins than patients treated by male physicians, they were more likely to achieve LDL-C goals, suggesting better compliance/adherence to treatment in patients treated by female physicians. They were also $35 \%$ more likely to receive antihypertensive drug therapy in general and $17 \%$ more likely to receive ACE inhibitors in particular. This study led to the 
interesting and humorous suggestion that being treated by male physicians should become a new risk factor for suboptimal diabetes care (Pedersen, 2009). A subsequent cross-sectional survey of 6537 consecutive patients from Sweden with hypertension (52\% women) (Journath et al., 2008) examined the association of physician gender with blood pressure, lipid control, and cardiovascular risk factors in men who are hypertensive and women treated by 187 male and 77 female primary care physicians. They found that women with hypertension more often reached target systolic/diastolic blood pressure levels ( $<140 / 90 \mathrm{~mm} \mathrm{Hg}$ ) when treated by female physicians than when treated by male physicians (32\% vs. $24 \%$ ). Furthermore, male and female patients achieved significantly better control of total and LDL-C levels when treated by female physicians than when treated by male physicians. Those results were achieved with a similar number of drugs prescribed by both groups, suggesting again a potential better adherence/ compliance by the patients treated by female physicians. Baumhäkel et al. (2009) performed an observational cross-sectional trial in 1857 consecutive patients from Eastern Germany with chronic heart failure and treated by 829 physicians (66\% general practitioners, $27 \%$ internists, and $7 \%$ cardiologists) with the purpose of determining the interactions of gender with medical treatment of this disease. They found that guidelinerecommended drug use and achieved target doses tended to be higher in patients treated by female physicians. There was no difference in the treatment between male and female patients when treated by female physicians, but male physicians used significantly fewer medications in female patients. In a multivariable analysis, an independent predictor of use of the guideline-recommended $\beta$ blockers was female physician gender. Notably, a large sample of Massachusetts physicians $(n=10,408)$ treating 13 million adult patients was studied to examine the relationship between physician characteristics and performance scores on 124 quality measures from RAND's Quality Assessment Tools (Reid et al., 2010). The authors found three physician characteristics to be independently associated with significantly higher overall performance: female gender ( $1.6 \%$ points higher than male, $P<0.001)$, board certification (3.3\% points higher than noncertified, $P<0.001)$, and graduation from a US medical school (1.0\% points higher than international, $P<0.001$ ). A Swiss retrospective cohort study of 1001 randomly selected patients ( $44 \%$ women) based on four university primary care settings and followed by 189 physicians $(48 \%$ men) reported that female physicians provided significantly more preventive care than male physicians to both male (73.4\% vs. $70.7 \%$ ) and female patients (66.7\% vs. $63.6 \%$ ) (Krähenmann-Müller et al., 2014). Even after multivariate adjustment, the differences according to physician gender remained significant. Recently, a study investigated whether patient outcomes differ between male and female physicians
(Tsugawa et al., 2017). Over a 3-year period, they examined whether 30-day mortality and readmission rates between patients 65 years or older hospitalized with a medical condition and treated by general internists differed depending on the gender of the treating physician. The authors reported that patients treated by female physicians had significantly lower 30-day mortality and lower 30-day readmissions than patients cared for by male physicians, even after accounting for potential confounders. However, the differences were numerically small (around a half \%) and the study was criticized for flaws, including the fact that the male and female physician populations were not comparable (Ladouceur, 2017). Another recent study from the United States examined patient gender disparities in survival rates after acute myocardial infarctions based on the gender of the treating physician (Greenwood et al., 2018). They found higher mortality among female patients treated by male physicians. When treated by female physicians, however, both male and female patients experienced similar outcomes. They also observed that male physicians were more effective at treating female patients with an acute myocardial infarction when they worked with female colleagues and had treated female patients in the past. Whether these differences were partially related to different drug treatment chosen by female and male physicians was not examined.

Taken together, these studies suggest that the differences in practice patterns between male and female physicians may have important clinical implications for patient outcomes.

2. Physician Adherence to Guidelines. A crosssectional study from Canada (Dahrouge et al., 2016) investigated the relationship between the gender of family physicians ( $n=4,195,31 \%$ female) and the quality of primary care they provided. They found that patients treated by female physicians were significantly more likely to have received recommended diabetes management drugs, such as ACE/ARB and lipidlowering agents. Similarly, a French study of 41,453 patients with diabetes ( $53 \%$ male) and treated by 2545 general practitioners $(76 \%$ men) showed that female physicians were more likely to order three or four HbA1c tests during the year, as required by a local performance indicator regarding the quality of care provided for patients with diabetes (Chauvel et al., 2013).

3. Patient Adherence to Treatment. Gender differences also exist in patient adherence to treatment. As discussed above (Journath et al., 2008), studies have suggested a potential better adherence and compliance by patients treated by female physicians compared with patients treated by male physicians (Berthold et al., 2008). Another study from Israel addressed this issue, focusing on 7041 patients with atherosclerosis $(61 \% \mathrm{men})$ and treated by 127 primary care physicians ( $42.5 \%$ men) 
for dyslipidemia. They reported that being treated by a male physician was associated with $13 \%$ lower adherence to the respective pharmacotherapy (Vashitz et al., 2011).

\section{B. Potential Explanations for Differences in Physician Gender and Response to Treatment}

Female physicians may be more careful and conservative in their approaches to prescribing drugs, as indicated by the more frequent use of the lower-thanrecommended dose of cholinesterase inhibitors in patients with dementia (Rochon et al., 2018).

Altogether, and as previously discussed (GouniBerthold and Berthold, 2012), the available evidence for a role of physician gender in the efficiency of drug therapy remains relatively small. It seems that female physicians may provide better overall drug therapy and specialized drug therapy in some medical areas. The reasons for these findings are largely unclear but may include different communication styles and the higher empathy of female doctors (Roter et al., 2002; Phillips and Austin, 2009; Hegazi and Wilson, 2013). Physician's empathy has been associated with a higher likelihood of achieving target values of risk factors (Hojat et al., 2011). However, the available literature is limited by inconsistent inclusion of common covariates and a lack of multivariable analyses. Physician/patient communication is also crucial to the quality of drug therapy, for example, for adherence and persistence. Differences in the communication patterns within the four possible physician/patient dyads (female or male physician, female or male patient) seem to play a major role (Brink-Muinen et al., 2002). Communication patterns of the dyad female/female were found to differ from the ones in the other three dyads, such as that biomedical patterns are observed more often than psychosocial ones. An association between gender concordant dyads and cardiovascular risk-factor control and diabetes treatment was found in a large study $(n=157,458$ patients, treated by 972 male and 778 female primary care physicians) of health insurance data (Schmittdiel et al., 2009). It was shown that female patients of female physicians had the highest adjusted rates of HbA1c control (HbA1c $<8 \%$ ) of the four patient-physician gender dyads (70\% vs. $66 \%-68 \%)$ and that male patients of male physicians were the most likely to be at or below LDL-C target in the four dyads. However, the influence of gender dyads on the quality of drug therapy has been investigated only in a limited numbers of studies with inconsistent results, and thus its effect on treatment remains to be established. Furthermore, it is methodologically difficult to separate the influence of the quality of drug therapy from non-drugrelated influences in the overall quality of care, especially in the treatment of complex chronic diseases, such as diabetes, coronary heart disease, or chronic heart failure (Gouni-Berthold and Berthold, 2012).
In conclusion, physician gender as an independent parameter influencing drug therapy is difficult to establish. As of today, there is no evidence in any area of medicine to suggest that a patient will consistently receive better quality of drug therapy by switching to a physician of a specific gender.

\section{Conclusions and Future Directions}

Biologic sex is a genetic modifier of the pharmacological response to drugs. The combination of all sexspecific genetic, epigenetic, and hormonal influences on cellular systems discussed in the first part of this review produces different in vivo male and female biologic systems, which results in sex differences in the PK and PD of multiple drugs, as discussed in the second and third parts. These biologic sex differences are further exacerbated by polymorphisms modifying drug response and the interference of menstrual cycle, pregnancy, menopause, age, sexually dimorphic microbiome, underlying pathophysiology, comorbidities, and comedications. Additionally, physician gender as an independent parameter may influence drug therapy. The sum of all of these sex and gender influences on the pharmacological response to drugs is summarized in Fig. 3. Since preclinical research has been historically predominantly performed in male experimental models and women are still underrepresented in clinical trials, women are at greater risk than men of experiencing adverse reactions to most drugs. Several steps can be taken at all levels of the biomedical enterprise as described below.

Consideration of sex and gender to evaluate disparities in drug safety and efficacy is largely absent from clinical trials, and this should be revisited and be incorporated in an international guideline. Sex and gender should be considered at each step of the research process, from the design of clinical trials to the interpretation of the results, with segregation of results by sex and/or gender. When justified on the basis of initial findings of sex/gender differences, clinical trials should be designed and powered to address sex-specific pharmacology. This approach would help develop personalized sex- and gender-specific guidelines for drug efficacy. The pharmaceutical industry should also consider sex early in the discovery phase of research, as the acquisition of sex-specific data will inform the design and interpretation of downstream clinical trials that will advance the development of therapeutics optimized by sex. Efforts to bring sex and gender into the mainstream of modern medical education should be undertaken. Medical schools use curricula are based on the physiology of an average man and need to incorporate sex-based physiology and pharmacology into the early stages of instruction. All clinicians should be aware of sex differences in body surface area, pharmacokinetics, and pharmacodynamics to avoid overdosing women. Potential interaction of drugs with endogenous 


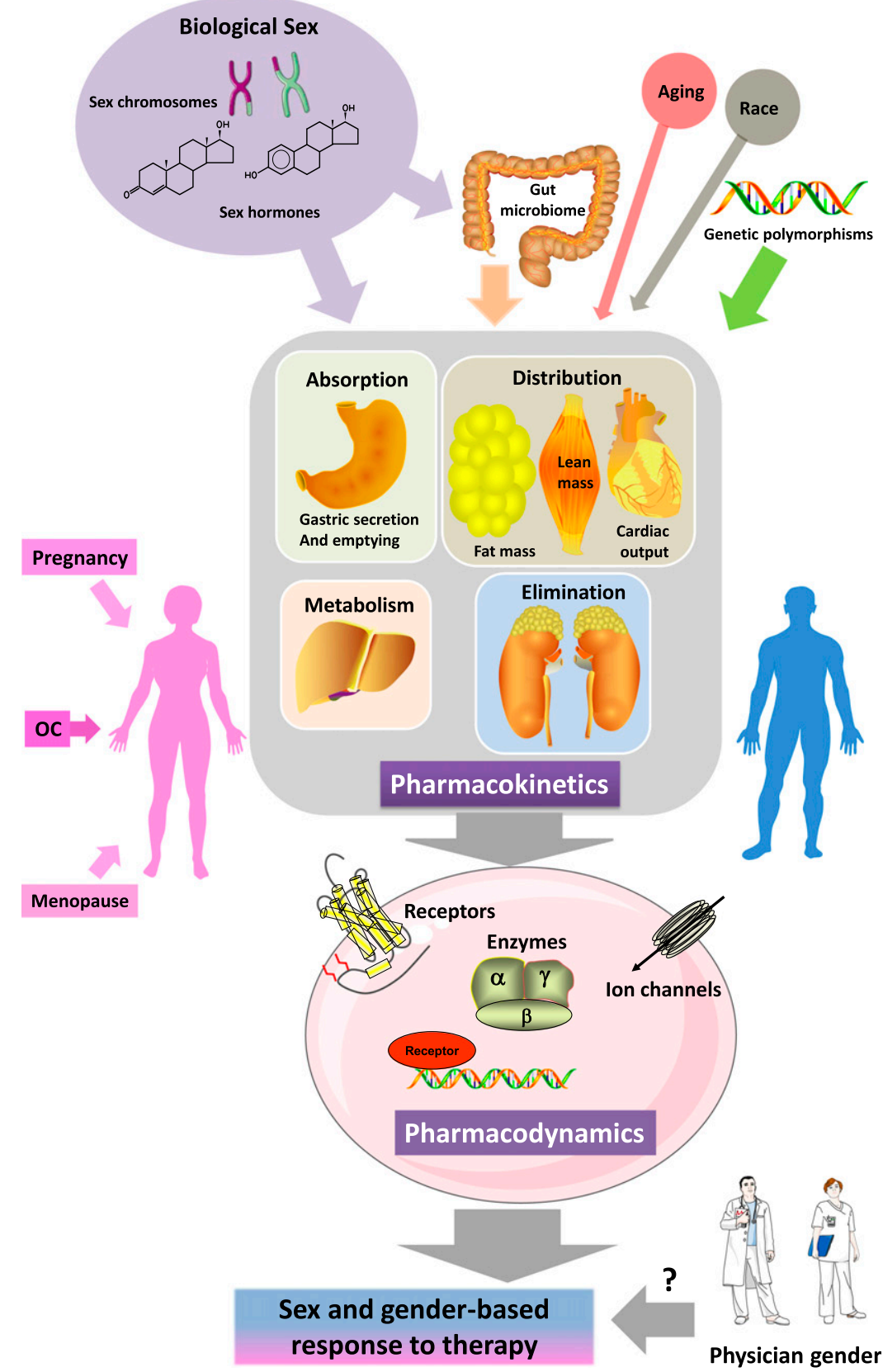

Fig. 3. Summary of sex and gender influences on the pharmacological response to drugs. Biologic sex via sex-specific genetic and hormonal influences on cellular systems alters the transcriptome, proteome, and metabolome of all cells and organs as well as the gut microbiome and influences pharmacokinetics (e.g., absorption, distribution, metabolism, and elimination of drugs) and pharmacodynamics (e.g., the effect of drugs on receptors, ion channels, enzymes, and signaling pathways). Aging, race, and genetic polymorphism also influence pharmacokinetics and pharmacodynamics parameters in a sex-specific manner. In women, the hormonal influences of pregnancy, menopause, and the use of OCs also produce sex differences in the pharmacokinetics and pharmacodynamics of drugs. Finally, physician gender could add an additional level of difference in response to treatment.

hormones or therapeutically supplied hormones should be considered as well as differences in the adequate dose of drugs between women who are premenopausal and postmenopausal, depending on hormonal status, intestinal uptake, hepatic metabolism, and kidney function.

Consideration of sex is one of the pillars of precision medicine. The inherent differences between male and female biology should inform drug prescription to promote gender equity in health.

\section{Acknowledgments}

A.K.-W. thanks Peter Klimek from the Center of Science of complex systems of the Medical University of Vienna for his assistance with data analysis and production of Figs. 1 and 2.

\section{Authorship Contributions}

Participated in research design: Mauvais-Jarvis, Berthold, Campesi, Carrero, Dhakal, Franconi, Gouni-Berthold, Heiman, KautzkyWiller, Klein, Murphy, Regitz-Zagrosek, Reue, Rubin.

Performed data analysis: Mauvais-Jarvis, Berthold, Campesi, Carrero, Dhakal, Franconi, Gouni-Berthold, Heiman, Kautzky-Willer, Klein, Murphy, Regitz-Zagrosek, Reue, Rubin. 
Wrote or contributed to the writing of the manuscript: MauvaisJarvis, Berthold, Campesi, Carrero, Dhakal, Franconi, Gouni-Berthold, Heiman, Kautzky-Willer, Klein, Murphy, Regitz-Zagrosek, Reue, Rubin.

\section{References}

Aaby P, Martins C, Bale C, Garly ML, Rodrigues A, Biai S, Lisse IM, Whittle H, and Benn CS (2010) Sex differences in the effect of vaccines on the risk of hospitalization due to measles in Guinea-bissau. Pediatr Infect Dis $J$ 29:324-328.

Aagaard L, Hallgreen CE, and Hansen EH (2016) Serious adverse events reported for antiobesity medicines: postmarketing experiences from the EU adverse event reporting system EudraVigilance. Int J Obes 40:1742-1747.

Aarons L, Hopkins K, Rowland M, Brossel S, and Thiercelin JF (1989) Route of administration and sex differences in the pharmacokinetics of aspirin, administered as its lysine salt. Pharm Res 6:660-666.

Abbott DH, Barnett DK, Bruns CM, and Dumesic DA (2005) Androgen excess fetal programming of female reproduction: a developmental aetiology for polycystic ovary syndrome? Hum Reprod Update 11:357-374.

Abdel-Rahman AA (2017) Influence of sex on cardiovascular drug responses: role of estrogen. Curr Opin Pharmacol 33:1-5.

Abdel-Rahman O (2019) Impact of sex on chemotherapy toxicity and efficacy among patients with metastatic colorectal cancer: pooled analysis of 5 randomized trials. Clin Colorectal Cancer 18:110-115 e2.

Abolmaali K, Balakrishnan A, Stearns AT, Rounds J, Rhoads DB, Ashley SW, and Tavakkolizadeh A (2009) Circadian variation in intestinal dihydropyrimidine dehydrogenase (DPD) expression: a potential mechanism for benefits of $5 \mathrm{FU}$ chrono-chemotherapy. Surgery 146:269-273.

Ahmed S, Hu R, Leete J, and Layton AT (2019) Understanding sex differences in long-term blood pressure regulation: insights from experimental studies and computational modeling. Am J Physiol Heart Circ Physiol 316:H1113-H1123.

Ajayi AA, Mathur R, and Halushka PV (1995) Testosterone increases human platelet thromboxane A2 receptor density and aggregation responses. Circulation 91 $2742-2747$

Al-Gburi S, Deussen A, Zatschler B, Weber S, Künzel S, El-Armouche A, Lorenz K, Cybularz M, Morawietz H, and Kopaliani I (2017) Sex-difference in expression and function of beta-adrenoceptors in macrovessels: role of the endothelium. Basic Res Cardiol 112:29.

Alizadeh Ghamsari A, Dadpour B, and Najari F (2016) Frequency of electrocardiographic abnormalities in Tramadol poisoned patients; a brief report. Emergency (Tehran) 4:151-154.

Allen SC and Mamotte CDS (2017) Pleiotropic and adverse effects of Statins-Do epigenetics play a role? J Pharmacol Exp Ther 362:319-326.

American Psychological Association (2017) Stress in America: The State of Our Nation, American Psychological Association, Washington, DC.

An T, Hao J, Sun S, Li R, Yang M, Cheng G, and Zou M (2017) Efficacy of statins for osteoporosis: a systematic review and meta-analysis. Osteoporos Int 28:47-57.

Anderson GD (2005) Sex and racial differences in pharmacological response: where is the evidence? Pharmacogenetics, pharmacokinetics, and pharmacodynamics. $J$ Womens Health (Larchmt) 14:19-29.

Anderson GD (2008) Gender differences in pharmacological response. Int Rev Neurobiol 83:1-10.

Andrade JG, Hawkins NM, Fordyce CB, Deyell MW, Er L, Djurdjev O, Macle L, Virani SA, and Levin A (2018) Variability in non-vitamin K antagonist oral anticoagulants dose adjustment in atrial fibrillation patients with renal dysfunction: the influence of renal function estimation formulae. Can J Cardiol 34:1010-1018.

Anichini R, Cosimi S, Di Carlo A, Orsini P, De Bellis A, Seghieri G, Franconi F, and Baccetti F (2013) Gender difference in response predictors after 1-year exenatide therapy twice daily in type 2 diabetic patients: a real world experience. Diabetes Metab Syndr Obes 6:123-129.

Ansari J, Carvalho B, Shafer SL, and Flood P (2016) Pharmacokinetics and pharmacodynamics of drugs commonly used in pregnancy and parturition. Anesth Analg 122:786-804.

Arnold AP (2017) A general theory of sexual differentiation. J Neurosci Res 95 $291-300$.

Arnold AP and Gorski RA (1984) Gonadal steroid induction of structural sex differences in the central nervous system. Annu Rev Neurosci 7:413-442.

Arnold AP and Lusis AJ (2012) Understanding the sexome: measuring and reporting sex differences in gene systems. Endocrinology 153:2551-2555.

Ashiru DA, Patel R, and Basit AW (2008) Polyethylene glycol 400 enhances the bioavailability of a BCS class III drug (ranitidine) in male subjects but not females. Pharm Res 25:2327-2333.

Athauda A, Nankivell M, Langley RE, Alderson D, Allum W, Grabsch HI, Starling N, Chau I, and Cunningham D (2020) Impact of sex and age on chemotherapy efficacy, toxicity and survival in localised oesophagogastric cancer: a pooled analysis of 3265 individual patient data from four large randomised trials (OE02, OE05, MAGIC and ST03). Eur J Cancer 137:45-56.

Aubrun F, Salvi N, Coriat P, and Riou B (2005) Sex- and age-related differences in morphine requirements for postoperative pain relief. Anesthesiology 103:156-160.

Audoly LP, Tilley SL, Goulet J, Key M, Nguyen M, Stock JL, McNeish JD, Koller BH, and Coffman TM (1999) Identification of specific EP receptors responsible for the hemodynamic effects of PGE2. Am J Physiol 277:H924-H930.

Averitt DL, Eidson LN, Doyle HH, and Murphy AZ (2019) Neuronal and glial factors contributing to sex differences in opioid modulation of pain. Neuropsychopharmacology 44:155-165.

Awidi A, Saleh A, Dweik M, Kailani B, Abu-Fara M, Nabulsi R, and Bener A (2011) Measurement of platelet reactivity of patients with cardiovascular disease on-treatment with acetyl salicylic acid: a prospective study. Heart Vessels 26:516-522.
Bai X, Zhang X, Li Y, Lu L, Li B, and He X (2015) Sex differences in peripheral muopioid receptor mediated analgesia in rat orofacial persistent pain model. PLoS One 10:e122924.

Baigent C, Blackwell L, Collins R, Emberson J, Godwin J, Peto R, Buring J, Hennekens C, Kearney P, Meade T, et al.; Antithrombotic Trialists' (ATT) Collaboration (2009) Aspirin in the primary and secondary prevention of vascular disease: collaborative meta-analysis of individual participant data from randomised trials. Lancet 373:1849-1860.

Baigent C, Blackwell L, Emberson J, Holland LE, Reith C, Bhala N, Peto R, Barnes EH, Keech A, Simes J, et al.; Cholesterol Treatment Trialists' (CTT) Collaboration (2010) Efficacy and safety of more intensive lowering of LDL cholesterol: a metaanalysis of data from 170,000 participants in 26 randomised trials. Lancet $\mathbf{3 7 6}$ 1670-1681.

Barrett AC, Smith ES, and Picker MJ (2002) Sex-related differences in mechanical nociception and antinociception produced by mu- and kappa-opioid receptor agonists in rats. Eur J Pharmacol 452:163-173.

Baumhäkel M, Müller U, and Böhm M (2009) Influence of gender of physicians and patients on guideline-recommended treatment of chronic heart failure in a crosssectional study. Eur J Heart Fail 11:299-303.

Bean-Mayberry B, Yano EM, Mor MK, Bayliss NK, Xu X, and Fine MJ (2009) Does sex influence immunization status for influenza and pneumonia in older veterans? $J$ Am Geriatr Soc 57:1427-1432.

Becker DM, Segal J, Vaidya D, Yanek LR, Herrera-Galeano JE, Bray PF, Moy TF, Becker LC, and Faraday N (2006) Sex differences in platelet reactivity and response to low-dose aspirin therapy. JAMA 295:1420-1427.

Bennett BM, Twiddy DA, Moffat JA, Armstrong PW, and Marks GS (1983) Sexrelated difference in the metabolism of isosorbide dinitrate following incubation in human blood. Biochem Pharmacol 32:3729-3734.

Berger JS, Roncaglioni MC, Avanzini F, Pangrazzi I, Tognoni G, and Brown DL (2006) Aspirin for the primary prevention of cardiovascular events in women and men: a sex-specific meta-analysis of randomized controlled trials. JAMA 295 : 306-313

Berkley KJ (1997) Sex differences in pain. Behav Brain Sci 20:371-380; discussion $435-513$

Bernal SA, Morgan MM, and Craft RM (2007) PAG mu opioid receptor activation underlies sex differences in morphine antinociception. Behav Brain Res 177: $126-133$.

Bernbom N, Nørrung B, Saadbye P, Mølbak L, Vogensen FK, and Licht TR (2006) Comparison of methods and animal models commonly used for investigation of fecal microbiota: effects of time, host and gender. J Microbiol Methods 66:87-95.

Bersoff-Matcha SJ, Chamberlain C, Cao C, Kortepeter C, and Chong WH (2019) Fournier Gangrene associated with sodium-glucose cotransporter-2 inhibitors: a review of spontaneous postmarketing cases. Ann Intern Med 170:764-769.

Berthold HK, Gouni-Berthold I, Bestehorn KP, Böhm M, and Krone W (2008) Physician gender is associated with the quality of type 2 diabetes care. $J$ Intern Med 264:340-350.

Bessesen DH and Van Gaal LF (2018) Progress and challenges in anti-obesity pharmacotherapy. Lancet Diabetes Endocrinol 6:237-248.

Bijur PE, Esses D, Birnbaum A, Chang AK, Schechter C, and Gallagher EJ (2008) Response to morphine in male and female patients: analgesia and adverse events. Clin J Pain 24:192-198.

Borenstein M, Hedges LV, Higgins JP, and Rothstein HR (2010) A basic introduction to fixed-effect and random-effects models for meta-analysis. Res Synth Methods 1 $97-111$.

Bots SH, Groepenhoff F, Eikendal ALM, Tannenbaum C, Rochon PA, Regitz-Zagrosek V, Miller VM, Day D, Asselbergs FW, and den Ruijter HM (2019) Adverse drug reactions to guideline-recommended heart failure drugs in women: a systematic review of the literature. JACC Heart Fail 7:258-266.

Boudreau D, Von Korff M, Rutter CM, Saunders K, Ray GT, Sullivan MD, Campbel CI, Merrill JO, Silverberg MJ, Banta-Green C, et al. (2009) Trends in long-term opioid therapy for chronic non-cancer pain. Pharmacoepidemiol Drug Saf 18: 1166-1175

Boyer JS, Morgan MM, and Craft RM (1998) Microinjection of morphine into the rostral ventromedial medulla produces greater antinociception in male compared to female rats. Brain Res $\mathbf{7 9 6}: 315-318$

Brahmer J, Reckamp KL, Baas P, Crinò L, Eberhardt WE, Poddubskaya E, Antonia S, Pluzanski A, Vokes EE, Holgado E, et al. (2015) Nivolumab versus docetaxel in advanced squamous-cell non-small-cell lung cancer. $N$ Engl J Med 373:123-135.

Brandão AP, de Oliveira TC, de Cunto Brandileone MC, Gonçalves JE, Yara TI, and Simonsen V (2004) Persistence of antibody response to pneumococcal capsular polysaccharides in vaccinated long term-care residents in Brazil. Vaccine $\mathbf{2 3}$ $762-768$

Bright AS, Herrera-Garcia G, Moscovitz JE, You D, Guo GL, and Aleksunes LM (2016) Regulation of drug disposition gene expression in pregnant mice with Car receptor activation. Nucl Receptor Res 3:101193.

Brink-Muinen Av, van Dulmen S, Messerli-Rohrbach V, and Bensing J (2002) Do gender-dyads have different communication patterns? A comparative study in Western-European general practices. Patient Educ Couns 48:253-264.

Brookoff D (2000a) Chronic pain: 1. A new disease? Hosp Pract (1995) 35:45-52, 59 Brookoff D (2000b) Chronic pain: 2. The case for opioids. Hosp Pract (1995) 35 : 69-72,75-76, 81-84.

Brunton LL (2018) Goodman and Gilman's: The Pharmacological Basis of Therapeutics, McGraw-Hill Education, New York.

Buchovecky CM, Turley SD, Brown HM, Kyle SM, McDonald JG, Liu B, Pieper AA, Huang W, Katz DM, Russell DW, et al. (2013) A suppressor screen in Mecp2 mutant mice implicates cholesterol metabolism in Rett syndrome. Nat Genet $\mathbf{4 5}$ 1013-1020.

Caku A, Pellerin D, Bouvier P, Riou E, and Corbin F (2014) Effect of lovastatin on behavior in children and adults with fragile X syndrome: an open-label study. $A m$ $J$ Med Genet A 164A:2834-2842. 
Campbell CI, Weisner C, Leresche L, Ray GT, Saunders K, Sullivan MD, BantaGreen CJ, Merrill JO, Silverberg MJ, Boudreau D, et al. (2010) Age and gender trends in long-term opioid analgesic use for noncancer pain. Am J Public Health 100:2541-2547.

Campesi I, Romani A, and Franconi F (2019) The sex-gender effects in the road to tailored botanicals. Nutrients 11:1637.

Canadian Cooperative Study Group (1978) A randomized trial of aspirin and sulfinpyrazone in threatened stroke. N Engl J Med 299:53-59.

Capodanno D and Angiolillo DJ (2010) Impact of race and gender on antithrombotic therapy. Thromb Haemost 104:471-484.

Caricilli AM, Penteado E, de Abreu LL, Quaresma PG, Santos AC, Guadagnini D, Razolli D, Mittestainer FC, Carvalheira JB, Velloso LA, et al. (2012) Topiramate treatment improves hypothalamic insulin and leptin signaling and action and reduces obesity in mice. Endocrinology 153:4401-4411.

Carmody RN and Turnbaugh PJ (2014) Host-microbial interactions in the metabolism of therapeutic and diet-derived xenobiotics. J Clin Invest 124:4173-4181.

Carrero JJ, Hecking M, Chesnaye NC, and Jager KJ (2018) Sex and gender disparities in the epidemiology and outcomes of chronic kidney disease. Nat Rev Nephrol 14:151-164.

Castro A, Pyke RM, Zhang X, Thompson WK, Day CP, Alexandrov LB, Zanetti M, and Carter H (2020) Strength of immune selection in tumors varies with sex and age. Nat Commun 11:4128.

Cataldi M, Muscogiuri G, Savastano S, Barrea L, Guida B, Taglialatela M, and Colao A (2019) Gender-related issues in the pharmacology of new anti-obesity drugs. Obes Rev 20:375-384.

Centers for Disease Control and Prevention (CDC) (2013) Vital signs: overdoses of prescription opioid pain relievers and other drugs among women--United States, 1999-2010. MMWR Morb Mortal Whly Rep 62:537-542

Cepeda MS and Carr DB (2003) Women experience more pain and require more morphine than men to achieve a similar degree of analgesia. Anesth Analg 97: 1464-1468.

Cepeda MS, Farrar JT, Baumgarten M, Boston R, Carr DB, and Strom BL (2003) Side effects of opioids during short-term administration: effect of age, gender, and race. Clin Pharmacol Ther 74:102-112.

Chakrabarti S, Liu NJ, and Gintzler AR (2010) Formation of mu-/kappa-opioid receptor heterodimer is sex-dependent and mediates female-specific opioid analgesia. Proc Natl Acad Sci USA 107:20115-20119.

Chambers C, Skowronski DM, Rose C, Serres G, Winter AL, Dickinson JA, Jassem A Gubbay JB, Fonseca K, Drews SJ, et al. (2018) Should sex Be considered an effect modifier in the evaluation of influenza vaccine effectiveness? Open Forum Infect Dis 5:ofy 211 .

Chauvel N, Le Vaillant M, and Pelletier-Fleury N (2013) Variation in HbA1c prescription for patients with diabetes in French general practice: an observational study prior to the implementation of a P4P programme. Eur J Public Health 23 61-66.

Chen CY, Chuang SY, Fang CC, Huang LC, Hsieh IC, Pan WH, Yeh HI, Wu CC, Yin WH, and Chen JW (2014) Gender disparities in optimal lipid control among patients with coronary artery disease. J Atheroscler Thromb $\mathbf{2 1}$ (Suppl 1):S20-S28

Chung L, Bey AL, Towers AJ, Cao X, Kim IH, and Jiang YH (2018) Lovastatin suppresses hyperexcitability and seizure in Angelman syndrome model. Neurobiol Dis 110:12-19.

CIBIS-II (1999) The Cardiac Insufficiency Bisoprolol Study II (CIBIS-II): a randomised trial. Lancet 353:9-13.

Ciccone GK and Holdcroft A (1999) Drugs and sex differences: a review of drugs relating to anaesthesia. $\mathrm{Br}$ J Anaesth 82:255-265.

Cicero TJ, Nock B, O'Connor L, and Meyer ER (2002) Role of steroids in sex differences in morphine-induced analgesia: activational and organizational effects. $J$ Pharmacol Exp Ther 300:695-701.

Clayton JA (2016) Studying both sexes: a guiding principle for biomedicine. FASEB J 30:519-524.

Clayton JA and Collins FS (2014) Policy: NIH to balance sex in cell and animal studies. Nature 509:282-283.

Cockshott WP, Thompson GT, Howlett LJ, and Seeley ET (1982) Intramuscular or intralipomatous injections? N Engl J Med 307:356-358.

Collins R, Reith C, Emberson J, Armitage J, Baigent C, Blackwell L, Blumenthal R, Danesh J, Smith GD, DeMets D, et al. (2016) Interpretation of the evidence for the efficacy and safety of statin therapy. Lancet 388:2532-2561.

Comer SD, Cooper ZD, Kowalczyk WJ, Sullivan MA, Evans SM, Bisaga AM, and Vosburg SK (2010) Evaluation of potential sex differences in the subjective and analgesic effects of morphine in normal, healthy volunteers. Psychopharmacology (Berl) 208:45-55.

Conforti F, Pala L, Bagnardi V, De Pas T, Martinetti M, Viale G, Gelber RD, and Goldhirsch A (2018) Cancer immunotherapy efficacy and patients' sex: a systematic review and meta-analysis. Lancet Oncol 19:737-746.

Conforti F, Pala L, Bagnardi V, Viale G, De Pas T, Pagan E, Pennacchioli E, Cocorocchio E, Ferrucci PF, De Marinis F, et al. (2019) Sex-based heterogeneity in response to lung cancer immunotherapy: a systematic review and meta-analysis. $J$ Natl Cancer Inst 111:772-781.

Cook IF, Barr I, Hartel G, Pond D, and Hampson AW (2006) Reactogenicity and immunogenicity of an inactivated influenza vaccine administered by intramuscular or subcutaneous injection in elderly adults. Vaccine 24:2395-2402.

Cooke CM and Davidge ST (2019) Advanced maternal age and the impact on maternal and offspring cardiovascular health. Am J Physiol Heart Circ Physiol 317: H387-H394.

Corbier P, Edwards DA, and Roffi J (1992) The neonatal testosterone surge: a comparative study. Arch Int Physiol Biochim Biophys 100:127-131.

Cornacchia E, Golbus J, Maybaum J, Strahler J, Hanash S, and Richardson B (1988) Hydralazine and procainamide inhibit T cell DNA methylation and induce autoreactivity. J Immunol 140:2197-2200.
Craft RM (2003) Sex differences in opioid analgesia: "from mouse to man". Clin $J$ Pain 19:175-186.

Craft RM, Mogil JS, and Aloisi AM (2004) Sex differences in pain and analgesia: the role of gonadal hormones. Eur J Pain 8:397-411.

Craft RM, Stratmann JA, Bartok RE, Walpole TI, and King SJ (1999) Sex differences in development of morphine tolerance and dependence in the rat. Psychopharmacology (Berl) 143:1-7.

Croley AN, Zwetsloot KA, Westerkamp LM, Ryan NA, Pendergast AM, Hickner RC, Pofahl WE, and Gavin TP (2005) Lower capillarization, VEGF protein, and VEGF mRNA response to acute exercise in the vastus lateralis muscle of aged vs. young women. J Appl Physiol (1985) 99:1872-1879.

Culver AL, Ockene IS, Balasubramanian R, Olendzki BC, Sepavich DM, WactawskiWende J, Manson JE, Qiao Y, Liu S, Merriam PA, et al. (2012) Statin use and risk of diabetes mellitus in postmenopausal women in the Women's Health Initiative. Arch Intern Med 172:144-152.

Curhan SG, Eavey R, Shargorodsky J, and Curhan GC (2010) Analgesic use and the risk of hearing loss in men. Am J Med 123:231-237.

Dadashzadeh S, Javadian B, and Sadeghian S (2006) The effect of gender on the pharmacokinetics of verapamil and norverapamil in human. Biopharm Drug Dispos 27:329-334.

Dahrouge S, Seale E, Hogg W, Russell G, Younger J, Muggah E, Ponka D, and Mercer $\mathrm{J}$ (2016) A comprehensive assessment of family physician gender and quality of care: a cross-sectional analysis in Ontario, Canada. Med Care 54:277-286

Danska JS (2014) Sex matters for mechanism. Sci Transl Med 6:258fs 40.

Dart AM, Du XJ, and Kingwell BA (2002) Gender, sex hormones and autonomic nervous control of the cardiovascular system. Cardiovasc Res 53:678-687.

David LA, Maurice CF, Carmody RN, Gootenberg DB, Button JE, Wolfe BE, Ling AV Devlin AS, Varma Y, Fischbach MA, et al. (2014) Diet rapidly and reproducibly alters the human gut microbiome. Nature 505:559-563.

Dayananda L, Belaval VV, Raina A, and Chandana R (2014) Intended intramuscular gluteal injections: are they truly intramuscular? J Postgrad Med 60:175-178.

Dhakal S and Klein SL (2019) Host factors impact vaccine efficacy: implications for seasonal and universal influenza vaccine programs. $J$ Virol 93: e00797-e00819.

Dhir A and Kulkarni SK (2008) Antidepressant-like effect of 17beta-estradiol: in volvement of dopaminergic, serotonergic, and (or) sigma-1 receptor systems. Can J Physiol Pharmacol 86:726-735.

Diabetes Prevention Program Research Group (2019) Long-term effects of metformin on diabetes prevention: identification of subgroups that benefited most in the diabetes prevention program and diabetes prevention program outcomes study. $D i$ abetes Care 42:601-608.

Diamanti-Kandarakis E, Katsikis I, Piperi C, Alexandraki K, and Panidis D (2007) Effect of long-term orlistat treatment on serum levels of advanced glycation endproducts in women with polycystic ovary syndrome. Clin Endocrinol (Oxf) 66: 103-109.

Digitalis Investigation Group (1997) The effect of digoxin on mortality and morbidity in patients with heart failure. $N$ Engl J Med 336:525-533.

Dominianni C, Sinha R, Goedert JJ, Pei Z, Yang L, Hayes RB, and Ahn J (2015) Sex, body mass index, and dietary fiber intake influence the human gut microbiome. PLoS One 10:e124599.

Dong M, Cioffi G, Wang J, Waite KA, Ostrom QT, Kruchko C, Lathia JD, Rubin JB Berens ME, Connor J, et al. (2020) Sex differences in cancer incidence and survival: a pan-cancer analysis. Cancer Epidemiol Biomarkers Prev 29:1389-1397.

Doyle HH, Eidson LN, Sinkiewicz DM, and Murphy AZ (2017) Sex differences in microglia activity within the periaqueductal gray of the rat: a potential mechanism driving the dimorphic effects of morphine. J Neurosci 37:3202-3214.

Doyle HH and Murphy AZ (2017) Sex differences in innate immunity and its impact on opioid pharmacology. J Neurosci Res 95:487-499.

Doyle HH and Murphy AZ (2018) Sex-dependent influences of morphine and its metabolites on pain sensitivity in the rat. Physiol Behav 187:32-41.

Duckles SP and Miller VM (2010) Hormonal modulation of endothelial NO production. Pflugers Arch 459:841-851.

Elander NO, Aughton K, Ghaneh P, Neoptolemos JP, Palmer DH, Cox TF, Campbell F, Costello E, Halloran CM, Mackey JR, et al.; European Study Group for Pancreatic Cancer (2018) Expression of dihydropyrimidine dehydrogenase (DPD) and hENT1 predicts survival in pancreatic cancer. $\mathrm{Br} J$ Cancer 118:947-954.

Elzahaf RA, Tashani OA, Unsworth BA, and Johnson MI (2012) The prevalence of chronic pain with an analysis of countries with a Human Development Index less than 0.9: a systematic review without meta-analysis. Curr Med Res Opin 28 1221-1229.

Endrich MM, Blank PR, and Szucs TD (2009) Influenza vaccination uptake and socioeconomic determinants in 11 European countries. Vaccine 27:4018-4024.

Engler RJ, Nelson MR, Klote MM, VanRaden MJ, Huang CY, Cox NJ, Klimov A Keitel WA, Nichol KL, Carr WW, et al.; Walter Reed Health Care System Influenza Vaccine Consortium (2008) Half- vs full-dose trivalent inactivated influenza vaccine (2004-2005): age, dose, and sex effects on immune responses. Arch Intern Med 168:2405-2414.

Ergul A, Shoemaker K, Puett D, and Tackett RL (1998) Gender differences in the expression of endothelin receptors in human saphenous veins in vitro. J Pharmaco Exp Ther 285:511-517.

Eugene AR (2016) Metoprolol dose equivalence in adult men and women based on gender differences: pharmacokinetic modeling and simulations. Med Sci (Basel) 4 18.

Fadini GP, Bonora BM, and Avogaro A (2017) SGLT2 inhibitors and diabetic ketoacidosis: data from the FDA Adverse Event Reporting System. Diabetologia 60:1385-1389.

Fadiran EO and Zhang L (2015) Effects of sex differences in the pharmacokinetics of drugs and their impact on the safety of medicines in women, in Medicines for Women (Harrison-Woolrych M ed) pp 41-68, ADIS, Geneva.

Feghali M, Venkataramanan R, and Caritis S (2015) Pharmacokinetics of drugs in pregnancy. Semin Perinatol 39:512-519. 
Ferris RL, Blumenschein G Jr, Fayette J, Guigay J, Colevas AD, Licitra L, Harrington K, Kasper S, Vokes EE, Even C, et al. (2016) Nivolumab for recurrent squamous-cell carcinoma of the head and neck. $N$ Engl J Med 375:1856-1867.

Fillingim RB, King CD, Ribeiro-Dasilva MC, Rahim-Williams B, and Riley JL 3rd (2009) Sex, gender, and pain: a review of recent clinical and experimental findings. $J$ Pain 10:447-485.

Fillingim RB, Ness TJ, Glover TL, Campbell CM, Hastie BA, Price DD, and Staud R (2005) Morphine responses and experimental pain: sex differences in side effects and cardiovascular responses but not analgesia. J Pain 6:116-124.

Fink AL, Engle K, Ursin RL, Tang WY, and Klein SL (2018) Biological sex affects vaccine efficacy and protection against influenza in mice. Proc Natl Acad Sci USA 115: $12477-12482$

Fink AL and Klein SL (2015) Sex and gender impact immune responses to vaccines among the elderly. Physiology (Bethesda) 30:408-416.

Fischer M, Baessler A, and Schunkert H (2002) Renin angiotensin system and gender differences in the cardiovascular system. Cardiovasc Res 53:672-677.

Flanagan KL, Fink AL, Plebanski M, and Klein SL (2017) Sex and gender differences in the outcomes of vaccination over the life course. Annu Rev Cell Dev Biol 33 $577-599$.

Flock GB, Cao X, Maziarz M, and Drucker DJ (2013) Activation of enteroendocrine membrane progesterone receptors promotes incretin secretion and improves glucose tolerance in mice. Diabetes 62:283-290.

Forest MG, De Peretti E, and Bertrand J (1976) Hypothalamic-pituitary-gonadal relationships in man from birth to puberty. Clin Endocrinol (Oxf) 5:551-569.

Forslund K, Hildebrand F, Nielsen T, Falony G, Le Chatelier E, Sunagawa S, Prifti E, Vieira-Silva S, Gudmundsdottir V, Pedersen HK, et al.; MetaHIT consortium (2015) Disentangling type 2 diabetes and metformin treatment signatures in the human gut microbiota. Nature 528:262-266.

France M, Skorich E, Kadrofske M, Swain GM, and Galligan JJ (2016) Sex-related differences in small intestinal transit and serotonin dynamics in high-fat-diet-induced obesity in mice. Exp Physiol 101:81-99.

Franconi F and Campesi I (2014a) Pharmacogenomics, pharmacokinetics and pharmacodynamics: interaction with biological differences between men and women. $\mathrm{Br}$ $J$ Pharmacol 171:580-594.

Franconi F and Campesi I (2014b) Sex and gender influences on pharmacological response: an overview. Expert Rev Clin Pharmacol 7:469-485.

Franconi F, Campesi I, Colombo D, and Antonini P (2019) Sex-gender variable: methodological recommendations for increasing scientific value of clinical studies. Cells 8:476.

Franconi F, Rosano G, Basili S, Montella A, and Campesi I (2017) Human cells involved in atherosclerosis have a sex. Int $J$ Cardiol 228:983-1001.

Franconi F, Rosano G, and Campesi I (2015) Need for gender-specific pre-analytical testing: the dark side of the moon in laboratory testing. Int J Cardiol 179:514-535.

Franzini L, Ardigò D, Cavalot F, Miccoli R, Rivellese AA, Trovati M, Zavaroni I, and Vaccaro O (2013) Women show worse control of type 2 diabetes and cardiovascular disease risk factors than men: results from the MIND. IT Study Group of the Italian Society of Diabetology. Nutr Metab Cardiovasc Dis 23: 235-241.

Frenk SM, Porter KS, and Paulozzi LJ (2015) Prescription opioid analgesic use among adults: United States, 1999-2012. NCHS Data Brief No 189, February 2015 $1-8$

Friede KA, Infeld MM, Tan RS, Knickerbocker HJ, Myers RA, Dubois LG, Thompson JW, Kaddurah-Daouk R, Ginsburg GS, Ortel TL, et al. (2020) Influence of sex on platelet reactivity in response to aspirin. J Am Heart Assoc 9:e014726.

Fu EL, Trevisan M, Clase CM, Evans M, Lindholm B, Rotmans JI, van Diepen M, Dekker FW, and Carrero JJ (2019) Association of acute increases in plasma creatinine after renin-angiotensin blockade with subsequent outcomes. Clin J Am Soc Nephrol 14:1336-1345.

Fulcher J, O'Connell R, Voysey M, Emberson J, Blackwell L, Mihaylova B, Simes J, Collins R, Kirby A, Colhoun H, et al ; Cholesterol Treatment Trialists' (CTT) Collaboration (2015) Efficacy and safety of LDL-lowering therapy among men and women: meta-analysis of individual data from 174,000 participants in 27 randomised trials. Lancet 385:1397-1405.

Furman D, Hejblum BP, Simon N, Jojic V, Dekker CL, Thiébaut R, Tibshirani RJ, and Davis MM (2014) Systems analysis of sex differences reveals an immunosuppressive role for testosterone in the response to influenza vaccination. Proc Nat Acad Sci USA 111:869-874.

Gabler NB, French B, Strom BL, Liu Z, Palevsky HI, Taichman DB, Kawut SM, and Halpern SD (2012) Race and sex differences in response to endothelin receptor antagonists for pulmonary arterial hypertension. Chest 141:20-26.

Garcia M, Mulvagh SL, Merz CN, Buring JE, and Manson JE (2016) Cardiovascular disease in women: clinical perspectives. Circ Res 118:1273-1293.

Geller SE, Koch AR, Roesch P, Filut A, Hallgren E, and Carnes M (2018) The more things change, the more they stay the same: a study to evaluate compliance with inclusion and assessment of women and minorities in randomized controlled trials. Acad Med 93:630-635.

Gerstein HC, Colhoun HM, Dagenais GR, Diaz R, Lakshmanan M, Pais P, Probstfield J, Riesmeyer JS, Riddle MC, Rydén L, et al; REWIND Investigators (2019) Dulaglutide and cardiovascular outcomes in type 2 diabetes (REWIND): a doubleblind, randomised placebo-controlled trial. Lancet 394:121-130.

Ghahramani NM, Ngun TC, Chen PY, Tian Y, Krishnan S, Muir S, Rubbi L, Arnold AP, de Vries GJ, Forger NG, et al. (2014) The effects of perinatal testosterone exposure on the DNA methylome of the mouse brain are late-emerging. Biol Sex Differ 5:8.

Ghali JK, Piña IL, Gottlieb SS, Deedwania PC, and Wikstrand JC; MERIT-HF Study Group (2002) Metoprolol CR/XL in female patients with heart failure: analysis of the experience in Metoprolol Extended-Release Randomized Intervention Trial in Heart Failure (MERIT-HF). Circulation 105:1585-1591.

Giacchetti S, Dugué PA, Innominato PF, Bjarnason GA, Focan C, Garufi C, Tumolo S, Coudert B, Iacobelli S, Smaaland R, et al.; ARTBC International Chronotherapy
Group (2012) Sex moderates circadian chemotherapy effects on survival of patients with metastatic colorectal cancer: a meta-analysis. Ann Oncol 23:3110-3116.

Gilbert MP, Marre M, Holst JJ, Garber A, Baeres FM, Thomsen H, and Pratley RE (2016) Comparison of the long-term effects of liraglutide and glimepiride monotherapy on bone mineral density in patients with type 2 diabetes. Endocr Pract 22: 406-411.

Glasson JC, Sawyer WT, Lindley CM, and Ginsberg B (2002) Patient-specific factors affecting patient-controlled analgesia dosing. J Pain Palliat Care Pharmacother 16:5-21.

Goldberg RB, Aroda VR, Bluemke DA, Barrett-Connor E, Budoff M, Crandall JP, Dabelea D, Horton ES, Mather KJ, Orchard TJ, et al; Diabetes Prevention Program Research Group (2017) Effect of long-term metformin and lifestyle in the diabetes prevention program and its outcome study on coronary artery calcium. Circulation 136:52-64.

Goldblatt D, Southern J, Andrews N, Ashton L, Burbidge P, Woodgate S, Pebody R, and Miller E (2009) The immunogenicity of 7-valent pneumococcal conjugate vaccine versus 23 -valent polysaccharide vaccine in adults aged 50-80 years. Clin Infect Dis 49:1318-1325.

Goodarzi MO, Li X, Krauss RM, Rotter JI, and Chen YD (2013) Relationship of sex to diabetes risk in statin trials. Diabetes Care 36:e100-e101.

Goodrich JA and Hottendorf GH (1995) Tobramycin gender-related nephrotoxicity in Fischer but not Sprague-Dawley rats. Toxicol Lett 75:127-131.

Gouni-Berthold I and Berthold HK (2011) Role of physician gender in the quality of care of cardiometabolic diseases. Curr Pharm Des 17:3690-3698.

Gouni-Berthold I and Berthold HK (2012) Role of physician gender in drug therapy. Handb Exp Pharmacol 214:183-208.

Gradman AH, Weir MR, Wright M, Bush CA, and Keefe DL (2010) Efficacy, safety and tolerability of aliskiren, a direct renin inhibitor, in women with hypertension: a pooled analysis of eight studies. J Hum Hypertens 24:721-729.

Greenwood BN, Carnahan S, and Huang L (2018) Patient-physician gender concordance and increased mortality among female heart attack patients. Proc Natl Acad Sci USA 115:8569-8574.

Gupta S, Artomov M, Goggins W, Daly M, and Tsao H (2015) Gender disparity and mutation burden in metastatic melanoma. J Natl Cancer Inst 107:djv221.

Habib ZA, Havstad SL, Wells K, Divine G, Pladevall M, and Williams LK (2010) Thiazolidinedione use and the longitudinal risk of fractures in patients with type 2 diabetes mellitus. J Clin Endocrinol Metab 95:592-600.

Haebisch EM (1995) Transdermal glyceryl trinitrate (nitroglycerin) in healthy persons: acute effects on skin temperature and hemodynamic orthostatic response. Sao Paulo Med J 113:973-982.

Haizlip KM, Harrison BC, and Leinwand LA (2015) Sex-based differences in skeletal muscle kinetics and fiber-type composition. Physiology (Bethesda) 30:30-39.

Harada N, Hanaoka R, Horiuchi H, Kitakaze T, Mitani T, Inui H, and Yamaji R (2016) Castration influences intestinal microflora and induces abdominal obesity in high-fat diet-fed mice. Sci Rep 6:23001.

Haro C, Rangel-Zúñiga OA, Alcalá-Díaz JF, Gómez-Delgado F, Pérez-Martínez P, Delgado-Lista J, Quintana-Navarro GM, Landa BB, Navas-Cortés JA, TenaSempere M, et al. (2016) Intestinal microbiota is influenced by gender and body mass index. PLoS One 11:e0154090.

Harreiter J and Kautzky-Willer A (2018) Sex and gender differences in prevention of type 2 diabetes. Front Endocrinol (Lausanne) 9:220.

Harris WH, Salzman EW, Athanasoulis CA, Waltman AC, and DeSanctis RW (1977) Aspirin prophylaxis of venous thromboembolism after total hip replacement. $N$ Engl J Med 297:1246-1249.

Hegazi I and Wilson I (2013) Maintaining empathy in medical school: it is possible. Med Teach 35:1002-1008.

Hemo B, Endevelt R, Porath A, Stampfer MJ, and Shai I (2011) Adherence to weight loss medications; post-marketing study from HMO pharmacy data of one million individuals. Diabetes Res Clin Pract 94:269-275.

Henricks LM, Lunenburg CATC, de Man FM, Meulendijks D, Frederix GWJ, Kienhuis E, Creemers GJ, Baars A, Dezentjé VO, Imholz ALT, et al (2018) DPYD genotype-guided dose individualisation of fluoropyrimidine therapy in patients with cancer: a prospective safety analysis. Lancet Oncol 19:1459-1467.

Hernandez AF, Green JB, Janmohamed S, D'Agostino RB Sr, Granger CB, Jones NP, Leiter LA, Rosenberg AE, Sigmon KN, Somerville MC, et al. Harmony Outcomes committees and investigators (2018) Albiglutide and cardiovascular outcomes in patients with type 2 diabetes and cardiovascular disease (Harmony Outcomes): a double-blind, randomised placebo-controlled trial. Lancet 392:1519-1529.

Hernandez JP, Mota LC, Huang W, Moore DD, and Baldwin WS (2009) Sexually dimorphic regulation and induction of $\mathrm{P} 450 \mathrm{~s}$ by the constitutive androstane receptor (CAR). Toxicology 256:53-64.

Hilliard LM, Sampson AK, Brown RD, and Denton KM (2013) The "his and hers" of the renin-angiotensin system. Curr Hypertens Rep 15:71-79.

Hirsch IB, Xu Y, Davis KL, and Calingaert B (2011) Patient factors associated with glucagonlike peptide 1 receptor agonist use with and without insulin. Endocr Pract 17:707-716.

Ho PC, Triggs EJ, Bourne DW, and Heazlewood VJ (1985) The effects of age and sex on the disposition of acetylsalicylic acid and its metabolites. $\mathrm{Br} \mathrm{J}$ Clin Pharmacol 19:675-684.

Hodi FS, O'Day SJ, McDermott DF, Weber RW, Sosman JA, Haanen JB, Gonzalez R Robert C, Schadendorf D, Hassel JC, et al. (2010) Improved survival with ipilimumab in patients with metastatic melanoma. $N$ Engl $J$ Med 363:711-723.

Hojat M, Louis DZ, Markham FW, Wender R, Rabinowitz C, and Gonnella JS (2011) Physicians' empathy and clinical outcomes for diabetic patients. Acad Med 86: 359-364

Hollister EB, Riehle K, Luna RA, Weidler EM, Rubio-Gonzales M, Mistretta TA Raza S, Doddapaneni HV, Metcalf GA, Muzny DM, et al. (2015) Structure and function of the healthy pre-adolescent pediatric gut microbiome. Microbiome 3:36. Holman RR, Bethel MA, Mentz RJ, Thompson VP, Lokhnygina Y, Buse JB, Chan JC, Choi J, Gustavson SM, Iqbal N, et al.; EXSCEL Study Group (2017) Effects of once- 
weekly exenatide on cardiovascular outcomes in type 2 diabetes. $N$ Engl J Med 377:1228-1239.

Holtman JR Jr, Jing X, and Wala EP (2003) Sex-related differences in the enhancement of morphine antinociception by NMDA receptor antagonists in rats. Pharmacol Biochem Behav 76:285-293.

Hoste EA, Bagshaw SM, Bellomo R, Cely CM, Colman R, Cruz DN, Edipidis K, Forni LG, Gomersall CD, Govil D, et al. (2015) Epidemiology of acute kidney injury in critically ill patients: the multinational AKI-EPI study. Intensive Care Med 41: $1411-1423$

Iizumi T, Taniguchi T, Yamazaki W, Vilmen G, Alekseyenko AV, Gao Z, Perez Perez GI, and Blaser MJ (2016) Effect of antibiotic pre-treatment and pathogen challenge on the intestinal microbiota in mice. Gut Pathog 8:60.

Inker LA, Levey AS, Tighiouart H, Shafi T, Eckfeldt JH, Johnson C, Okparavero A, Post WS, Coresh J, and Shlipak MG (2017) Performance of glomerular filtration rate estimating equations in a community-based sample of Blacks and Whites: the multiethnic study of atherosclerosis. Nephrol Dial Transplant 33 : $417-425$

International Diabetes Federation (2019) IDF Diabetes Atlas, International Diabetes Federation, Brussels, Belgium.

Jašarević E, Howard CD, Misic AM, Beiting DP, and Bale TL (2017) Stress during pregnancy alters temporal and spatial dynamics of the maternal and offspring microbiome in a sex-specific manner. Sci Rep 7:44182.

Ji Y, Murphy AZ, and Traub RJ (2006) Sex differences in morphine-induced analgesia of visceral pain are supraspinally and peripherally mediated. Am J Physiol Regul Integr Comp Physiol 291:R307-R314.

Ji Y, Murphy AZ, and Traub RJ (2007) Estrogen modulation of morphine analgesia of visceral pain in female rats is supraspinally and peripherally mediated. J Pain 8 494-502.

Ji Y, Tang B, and Traub RJ (2008) The visceromotor response to colorectal distention fluctuates with the estrous cycle in rats. Neuroscience 154:1562-1567.

Johnsson KM, Ptaszynska A, Schmitz B, Sugg J, Parikh SJ, and List JF (2013) Vulvovaginitis and balanitis in patients with diabetes treated with dapagliflozin. $J$ Diabetes Complications 27:479-484

Joseph S, Nicolson TJ, Hammons G, Word B, Green-Knox B, and Lyn-Cook B (2015) Expression of drug transporters in human kidney: impact of sex, age, and ethnicity. Biol Sex Differ 6:4

Journath G, Hellénius M-L, Manhem K, Kjellgren KI, and Nilsson PM; Hyper-Q Study Group, Sweden (2008) Association of physician's sex with risk factor control in treated hypertensive patients from Swedish primary healthcare. J Hypertens $\mathbf{2 6}$ $2050-2056$

Kapil V, Rathod KS, Khambata RS, Bahra M, Velmurugan S, Purba A, S Watson D, Barnes MR, Wade WG, and Ahluwalia A (2018) Sex differences in the nitratenitrite-NO pathway: role of oral nitrate-reducing bacteria. Free Radic Biol Med 126:113-121

Kautzky-Willer A and Harreiter J (2017) Sex and gender differences in therapy of type 2 diabetes. Diabetes Res Clin Pract 131:230-241.

Kautzky-Willer A and Harreiter J (2018) Needle beats pill in gestational diabetes mellitus. Nat Rev Endocrinol 14:448-449.

Kautzky-Willer A, Harreiter J, and Pacini G (2016) Sex and gender differences in risk, pathophysiology and complications of type 2 diabetes mellitus. Endocr Rev 37 $278-316$.

Kautzky-Willer A, Kosi L, Mihaljevic R, Lin J, and Wang E (2012) Glycemic control and hypoglycemia prevalence according to gender: an analysis of RCT data. $\mathrm{Di}$ abetes 61:A252.

Kautzky-Willer A and Lemmens-Gruber R (2012) Obesity and diabetes, in Sex and Gender Differences in Pharmacology (Regitz-Zagrosek V ed) pp 307-340, Springer, Berlin.

Kautzky-Willer A, Thurner S, and Klimek P (2017) Use of statins offsets insulinrelated cancer risk. J Intern Med 281:206-216.

Kendall MJ, Quarterman CP, Jack DB, and Beeley L (1982) Metoprolol pharmacokinetics and the oral contraceptive pill. Br J Clin Pharmacol 14:120-122.

Kennedy J, Roll JM, Schraudner T, Murphy S, and McPherson S (2014) Prevalence of persistent pain in the U.S. Adult population: new data from the 2010 national health interview survey. J Pain 15:979-984.

Kepler KL, Kest B, Kiefel JM, Cooper ML, and Bodnar RJ (1989) Roles of gender, gonadectomy and estrous phase in the analgesic effects of intracerebroventricular morphine in rats. Pharmacol Biochem Behav 34:119-127.

Kim C, McEwen LN, Gerzoff RB, Marrero DG, Mangione CM, Selby JV, and Herman WH (2005) Is physician gender associated with the quality of diabetes care? $D i$ abetes Care 28:1594-1598.

Kishino S, Nomura A, Itoh S, Nakagawa T, Takekuma Y, Sugawara M, Furukawa H, Todo S, and Miyazaki K (2002) Age- and gender-related differences in carbohydrate concentrations of alpha1-acid glycoprotein variants and the effects of glycoforms on their drug-binding capacities. Eur J Clin Pharmacol 58:621-628.

Klein SL, Jedlicka A, and Pekosz A (2010) The Xs and Y of immune responses to viral vaccines. Lancet Infect Dis 10:338-349.

Klein SL, Schiebinger L, Stefanick ML, Cahill L, Danska J, de Vries GJ, Kibbe MR, McCarthy MM, Mogil JS, Woodruff TK, et al. (2015) Opinion: sex inclusion in basic research drives discovery. Proc Natl Acad Sci USA 112:5257-5258.

Kloner RA, Sowers JR, DiBona GF, Gaffney M, and Wein M (1995) Effect of amlodipine on left ventricular mass in the Amlodipine Cardiovascular Community Trial. J Cardiovasc Pharmacol 26:471-476.

Kluger AY, Tecson KM, Lee AY, Lerma EV, Rangaswami J, Lepor NE, Cobble ME, and McCullough PA (2019) Class effects of SGLT2 inhibitors on cardiorenal outcomes. Cardiovasc Diabetol 18:99.

Kneale BJ, Chowienczyk PJ, Brett SE, Coltart DJ, and Ritter JM (2000) Gender differences in sensitivity to adrenergic agonists of forearm resistance vasculature. $J$ Am Coll Cardiol 36:1233-1238.

Kokras N, Sotiropoulos I, Besinis D, Tzouveka EL, Almeida OFX, Sousa N, and Dalla C (2019) Neuroplasticity-related correlates of environmental enrichment combined with physical activity differ between the sexes. Eur Neuropsychopharmacol 29: $1-15$.

Komukai K, Mochizuki S, and Yoshimura M (2010) Gender and the renin-angiotensin-aldosterone system. Fundam Clin Pharmacol 24:687-698.

Konigstein M, Rosso R, Topaz G, Postema PG, Friedensohn L, Heller K, Zeltser D, Belhassen B, Adler A, and Viskin S (2016) Drug-induced Brugada syndrome: clinical characteristics and risk factors. Heart Rhythm 13:1083-1087.

Koren O, Goodrich JK, Cullender TC, Spor A, Laitinen K, Bäckhed HK, Gonzalez A, Werner JJ, Angenent LT, Knight R, et al. (2012) Host remodeling of the gut microbiome and metabolic changes during pregnancy. Cell 150:470-480.

Kostis WJ, Cheng JQ, Dobrzynski JM, Cabrera J, and Kostis JB (2012) Meta-analysis of statin effects in women versus men. $J$ Am Coll Cardiol 59:572-582.

Krähenmann-Müller S, Virgini VS, Blum MR, da Costa BR, Collet TH, Martin Y, Cornuz J, Zimmerli L, Gaspoz JM, Bauer DC, et al. (2014) Patient and physician gender concordance in preventive care in university primary care settings. Prev Med 67:242-247.

Krämer HU, Raum E, Rüter G, Schöttker B, Rothenbacher D, Rosemann T, Szecsenyi $\mathrm{J}$, and Brenner $\mathrm{H}$ (2012) Gender disparities in diabetes and coronary heart disease medication among patients with type 2 diabetes: results from the DIANA study. Cardiovasc Diabetol 11:88.

Krzanowska EK and Bodnar RJ (1999) Morphine antinociception elicited from the ventrolateral periaqueductal gray is sensitive to sex and gonadectomy differences in rats. Brain Res 821:224-230.

Krzanowska EK, Ogawa S, Pfaff DW, and Bodnar RJ (2002) Reversal of sex differences in morphine analgesia elicited from the ventrolateral periaqueductal gray in rats by neonatal hormone manipulations. Brain Res 929:1-9.

Kurokawa J, Kodama M, Furukawa T, and Clancy CE (2012) Sex and gender aspects in antiarrhythmic therapy. Handb Exp Pharmacol 214:237-263.

Labbé L, Sirois C, Pilote S, Arseneault M, Robitaille NM, Turgeon J, and Hamelin BA (2000) Effect of gender, sex hormones, time variables and physiological urinary $\mathrm{pH}$ on apparent CYP2D6 activity as assessed by metabolic ratios of marker substrates. Pharmacogenetics 10:425-438.

Labib M (2003) acp Best Practice No 168. The investigation and management of obesity. J Clin Pathol 56:17-25.

Ladouceur R (2017) Fake medical news: is it better to be treated by a male physician or a female physician? Can Fam Physician 63:422.

Lai KP, Wong MH, and Wong CK (2004) Modulation of AhR-mediated CYP1A1 mRNA and EROD activities by 17beta-estradiol and dexamethasone in TCDDinduced H411E cells. Toxicol Sci 78:41-49.

Laib AK, Brünen S, Pfeifer P, Vincent P, and Hiemke C (2014) Serum concentrations of hydroxybupropion for dose optimization of depressed patients treated with bupropion. Ther Drug Monit 36:473-479.

Lampe JW, Fredstrom SB, Slavin JL, and Potter JD (1993) Sex differences in colonic function: a randomised trial. Gut 34:531-536.

Larauche M, Mulak A, Kim YS, Labus J, Million M, and Taché Y (2012) Visceral analgesia induced by acute and repeated water avoidance stress in rats: sex difference in opioid involvement. Neurogastroenterol Motil 24:1031-e547.

Last AR, Ference JD, and Menzel ER (2017) Hyperlipidemia: drugs for cardiovascular risk reduction in adults. Am Fam Physician 95:78-87.

Lee MS, Hsu CC, Wahlqvist ML, Tsai HN, Chang YH, and Huang YC (2011) Type 2 diabetes increases and metformin reduces total, colorectal, liver and pancreatic cancer incidences in Taiwanese: a representative population prospective cohort study of 800,000 individuals. BMC Cancer 11:20.

Leisegang MS, Bibli SI, Günther S, Pflüger-Müller B, Oo JA, Höper C, Seredinski S, Yekelchyk M, Schmitz-Rixen T, Schürmann C, et al. (2019) Pleiotropic effects of laminar flow and statins depend on the Krüppel-like factor-induced lncRNA MANTIS. Eur Heart J 40:2523-2533.

Leiter LA, Bain SC, Hramiak I, Jódar E, Madsbad S, Gondolf T, Hansen T, Holst I, and Lingvay I (2019) Cardiovascular risk reduction with once-weekly semaglutide in subjects with type 2 diabetes: a post hoc analysis of gender, age, and baseline CV risk profile in the SUSTAIN 6 trial. Cardiovasc Diabetol 18:73.

Lesogor A, Cohn JN, Latini R, Tognoni G, Krum H, Massie B, Zalewski A, Kandra A, Hua TA, and Gimpelewicz C (2013) Interaction between baseline and early worsening of renal function and efficacy of renin-angiotensin-aldosterone system blockade in patients with heart failure: insights from the Val-HeFT study. Eur $J$ Heart Fail 15:1236-1244.

Leung JW, Liu YL, Leung PS, Chan RC, Inciardi JF, and Cheng AF (2001) Expression of bacterial beta-glucuronidase in human bile: an in vitro study. Gastrointest Endosc 54:346-350.

Leutner M, Matzhold C, Bellach L, Deischinger C, Harreiter J, Thurner S, Klimek P, and Kautzky-Willer A (2019) Diagnosis of osteoporosis in statin-treated patients is dose-dependent. Ann Rheum Dis 78:1706-1711.

Li M, Wang B, Zhang M, Rantalainen M, Wang S, Zhou H, Zhang Y, Shen J, Pang X, Zhang M, et al. (2008) Symbiotic gut microbes modulate human metabolic phenotypes. Proc Natl Acad Sci USA 105:2117-2122.

Lim H, Kim SY, Lee E, Lee S, Oh S, Jung J, Kim KS, and Moon A (2019) Sexdependent adverse drug reactions to 5-fluorouracil in colorectal cancer. Biol Pharm Bull 42:594-600.

Link JC and Reue K (2017) Genetic basis for sex differences in obesity and lipid metabolism. Annu Rev Nutr 37:225-245.

Liu J, Ji H, Zheng W, Wu X, Zhu JJ, Arnold AP, and Sandberg K (2010) Sex differences in renal angiotensin converting enzyme 2 (ACE2) activity are 17 $\beta$-oestradiol-dependent and sex chromosome-independent. Biol Sex Differ 1:6.

LoGuidice A, Wallace BD, Bendel L, Redinbo MR, and Boelsterli UA (2012) Pharmacologic targeting of bacterial $\beta$-glucuronidase alleviates nonsteroidal antiinflammatory drug-induced enteropathy in mice. J Pharmacol Exp Ther 341: $447-454$.

LoMauro A and Aliverti A (2018) Sex differences in respiratory function. Breathe (Sheff) 14:131-140. 
Lorenzo ME, Hodgson A, Robinson DP, Kaplan JB, Pekosz A, and Klein SL (2011) Antibody responses and cross protection against lethal influenza A viruses differ between the sexes in C57BL/6 mice. Vaccine 29:9246-9255.

Loyd DR and Murphy AZ (2006) Sex differences in the anatomical and functional organization of the periaqueductal gray-rostral ventromedial medullary pathway in the rat: a potential circuit mediating the sexually dimorphic actions of morphine. $J$ Comp Neurol 496:723-738.

Loyd DR, Wang X, and Murphy AZ (2008) Sex differences in micro-opioid receptor expression in the rat midbrain periaqueductal gray are essential for eliciting sex differences in morphine analgesia. $J$ Neurosci 28:14007-14017.

Lu YF, Jin T, Xu Y, Zhang D, Wu Q, Zhang YK, and Liu J (2013) Sex differences in the circadian variation of cytochrome p450 genes and corresponding nuclear receptors in mouse liver. Chronobiol Int 30:1135-1143.

Lyon MJ, Steer LM, and Malmgren LT (2007) Stereological estimates indicate that aging does not alter the capillary length density in the human posterior cricoarytenoid muscle. J Appl Physiol (1985) 103:1815-1823.

Maas AH and Appelman YE (2010) Gender differences in coronary heart disease. Neth Heart J 18:598-602.

Mackay FJ, Pearce GL, and Mann RD (1999) Cough and angiotensin II receptor antagonists: cause or confounding? Br J Clin Pharmacol 47:111-114.

Mamza J, Mehta R, Donnelly R, and Idris I (2016) Important differences in the durability of glycaemic response among second-line treatment options when added to metformin in type 2 diabetes: a retrospective cohort study. Ann Med 48:224-234.

Mannucci E and Monami M (2017) Bone fractures with sodium-glucose co-transporter-2 inhibitors: how real is the risk? Drug Saf 40:115-119.

Mannucci E, Monami M, Dicembrini I, Piselli A, and Porta M (2014) Achieving $\mathrm{HbA} 1 \mathrm{c}$ targets in clinical trials and in the real world: a systematic review and meta-analysis. $J$ Endocrinol Invest 37:477-495.

Mansfield KE, Nitsch D, Smeeth L, Bhaskaran K, and Tomlinson LA (2016) Prescription of renin-angiotensin system blockers and risk of acute kidney injury: a population-based cohort study. BMJ Open 6:e012690.

Manteuffel M, Williams S, Chen W, Verbrugge RR, Pittman DG, and Steinkellner A (2014) Influence of patient sex and gender on medication use, adherence, and prescribing alignment with guidelines. $J$ Womens Health (Larchmt) 23:112-119.

Manubay J, Davidson J, Vosburg S, Jones J, Comer S, and Sullivan M (2015) Sex differences among opioid-abusing patients with chronic pain in a clinical trial. J Addict Med 9:46-52

Markle JG, Frank DN, Mortin-Toth S, Robertson CE, Feazel LM, Rolle-Kampczyk U, von Bergen M, McCoy KD, Macpherson AJ, and Danska JS (2013) Sex differences in the gut microbiome drive hormone-dependent regulation of autoimmunity. Science 339:1084-1088.

Marso SP, Bain SC, Consoli A, Eliaschewitz FG, Jódar E, Leiter LA, Lingvay I, Rosenstock J, Seufert J, Warren ML, et al.; SUSTAIN-6 Investigators (2016a) Semaglutide and cardiovascular outcomes in patients with type 2 diabetes. $N$ Engl $J$ Med 375:1834-1844.

Marso SP, Daniels GH, Brown-Frandsen K, Kristensen P, Mann JF, Nauck MA Nissen SE, Pocock S, Poulter NR, Ravn LS, et al.; LEADER Steering Committee; LEADER Trial Investigators (2016b) Liraglutide and cardiovascular outcomes in type 2 diabetes. $N$ Engl J Med 375:311-322.

Martin-Castillo B, Vazquez-Martin A, Oliveras-Ferraros C, and Menendez JA (2010) Metformin and cancer: doses, mechanisms and the dandelion and hormetic phenomena. Cell Cycle 9:1057-1064.

Mauvais-Jarvis F (2015) Sex differences in metabolic homeostasis, diabetes, and obesity. Biol Sex Differ 6:14.

Mauvais-Jarvis F, Arnold AP, and Reue K (2017) A guide for the design of pre-clinical studies on sex differences in metabolism. Cell Metab 25:1216-1230.

Mauvais-Jarvis F, Bairey Merz N, Barnes PJ, Brinton RD, Carrero JJ, DeMeo DL, De Vries GJ, Epperson CN, Govindan R, Klein SL, et al. (2020) Sex and gender: modifiers of health, disease, and medicine. Lancet 396:565-582.

Mauvais-Jarvis F, Clegg DJ, and Hevener AL (2013) The role of estrogens in control of energy balance and glucose homeostasis. Endocr Rev 34:309-338.

McCarthy MM, Auger AP, Bale TL, De Vries GJ, Dunn GA, Forger NG, Murray EK Nugent BM, Schwarz JM, and Wilson ME (2009) The epigenetics of sex differences in the brain. $J$ Neurosci $29: 12815-12823$.

McGill JB, Vlajnic A, Knutsen PG, Recklein C, Rimler M, and Fisher SJ (2013) Effect of gender on treatment outcomes in type 2 diabetes mellitus. Diabetes Res Clin Pract 102:167-174.

McMurray JJV, Jackson AM, Lam CSP, Redfield MM, Anand IS, Ge J, Lefkowitz MP, Maggioni AP, Martinez F, Packer M, et al. (2019a) Effects of sacubitril-valsartan versus valsartan in women compared with men with heart failure and preserved ejection fraction: insights from PARAGON-HF. Circulation 141:338-351.

McMurray JJV, Packer M, Desai AS, Gong J, Lefkowitz MP, Rizkala AR, Rouleau JL, Shi VC, Solomon SD, Swedberg K, et al.; PARADIGM-HF Investigators and Committees (2014a) Angiotensin-neprilysin inhibition versus enalapril in heart failure. N Engl J Med 371:993-1004.

McMurray JJV, Packer M, and Solomon SD (2014b) Neprilysin inhibition for heart failure. N Engl J Med 371:2336-2337.

McMurray JJV, Solomon SD, Inzucchi SE, Køber L, Kosiborod MN, Martinez FA, Ponikowski P, Sabatine MS, Anand IS, Bělohlávek J, et al.; DAPA-HF Trial Committees and Investigators (2019b) Dapagliflozin in patients with heart failure and reduced ejection fraction. N Engl J Med 381:1995-2008.

Mehta SS, Silver RJ, Aaronson A, Abrahamson M, and Goldfine AB (2006) Comparison of aspirin resistance in type 1 versus type 2 diabetes mellitus. Am $J$ Cardiol 97:567-570.

MERIT-HF (1999) Effect of metoprolol CR/XL in chronic heart failure: metoprolol CR/ $\mathrm{XL}$ randomised intervention trial in cCongestive heart failure (MERIT-HF). Lancet 353:2001-2007.

Merrill M, Sweitzer NK, Lindenfeld J, and Kao DP (2019) Sex differences in outcomes and responses to spironolactone in heart failure with preserved ejection fraction: a secondary analysis of TOPCAT trial. JACC Heart Fail 7:228-238.
Mikkola T, Turunen P, Avela K, Orpana A, Viinikka L, and Ylikorkala O (1995) 17 beta-estradiol stimulates prostacyclin, but not endothelin-1, production in human vascular endothelial cells. J Clin Endocrinol Metab 80:1832-1836.

Milano G, Etienne MC, Cassuto-Viguier E, Thyss A, Santini J, Frenay M, Renee N, Schneider M, and Demard F (1992) Influence of sex and age on fluorouracil clearance. J Clin Oncol 10:1171-1175.

Miletić D, Fuckar Z, Sustić A, Mozetic V, Stimac D, and Zauhar G (1998) Sonographic measurement of absolute and relative renal length in adults. J Clin Ultrasound 26: 185-189.

Miller PL and Ernst AA (2004) Sex differences in analgesia: a randomized trial of mu versus kappa opioid agonists. South Med J 97:35-41.

Mittelstrass K, Ried JS, Yu Z, Krumsiek J, Gieger C, Prehn C, Roemisch-Margl W, Polonikov A, Peters A, Theis FJ, et al. (2011) Discovery of sexual dimorphisms in metabolic and genetic biomarkers. PLoS Genet 7:e1002215.

Mogil JS (2012) Sex differences in pain and pain inhibition: multiple explanations of a controversial phenomenon. Nat Rev Neurosci 13:859-866.

Mogil JS and Bailey AL (2010) Sex and gender differences in pain and analgesia. Prog Brain Res 186:141-157.

Mohassel P and Mammen AL (2013) The spectrum of statin myopathy. Curr Opin Rheumatol 25:747-752.

Moore RD, Smith CR, Lipsky JJ, Mellits ED, and Lietman PS (1984) Risk factors for nephrotoxicity in patients treated with aminoglycosides. Ann Intern Med 100: 352-357.

Mora S, Glynn RJ, Hsia J, MacFadyen JG, Genest J, and Ridker PM (2010) Statins for the primary prevention of cardiovascular events in women with elevated highsensitivity C-reactive protein or dyslipidemia: results from the Justification for the Use of Statins in Prevention: an Intervention Trial Evaluating Rosuvastatin (JUPITER) and meta-analysis of women from primary prevention trials. Circulation 121:1069-1077.

Morris JA, Jordan CL, and Breedlove SM (2004) Sexual differentiation of the vertebrate nervous system. Nat Neurosci 7:1034-1039.

Motzer RJ, Escudier B, McDermott DF, George S, Hammers HJ, Srinivas S, Tykodi SS, Sosman JA, Procopio G, Plimack ER, et al.; CheckMate 025 Investigators (2015) Nivolumab versus everolimus in advanced renal-cell carcinoma. $N$ Engl J Med 373:1803-1813.

Mouat MA, Coleman JLJ, and Smith NJ (2018) GPCRs in context: sexual dimorphism in the cardiovascular system. Br J Pharmacol 175:4047-4059.

Moyer AM, Matey ET, and Miller VM (2019) Individualized medicine: sex, hormones, genetics, and adverse drug reactions. Pharmacol Res Perspect 7:e0541.

Müller F and Fromm MF (2011) Transporter-mediated drug-drug interactions. Pharmacogenomics 12:1017-1037.

Munger K and Baylis C (1988) Sex differences in renal hemodynamics in rats. Am J Physiol 254:F223-F231.

Murphy AZ, Suckow SK, Johns M, and Traub RJ (2009) Sex differences in the activation of the spinoparabrachial circuit by visceral pain. Physiol Behav 97:205-212. Myles PS, Hunt JO, and Moloney JT (1997) Postoperative 'minor' complications. Comparison between men and women. Anaesthesia 52:300-306.

Nahin RL (2015) Estimates of pain prevalence and severity in adults: United States, 2012. J Pain 16:769-780.

Napoli N, Chandran M, Pierroz DD, Abrahamsen B, Schwartz AV, and Ferrari SL IOF Bone and Diabetes Working Group (2017) Mechanisms of diabetes mellitusinduced bone fragility. Nat Rev Endocrinol 13:208-219.

Naqvi S, Godfrey AK, Hughes JF, Goodheart ML, Mitchell RN, and Page DC (2019) Conservation, acquisition, and functional impact of sex-biased gene expression in mammals. Science 365:eaaw7317.

Navarro G, Xu W, Jacobson DA, Wicksteed B, Allard C, Zhang G, De Gendt K, Kim $\mathrm{SH}, \mathrm{Wu} \mathrm{H}$, Zhang $\mathrm{H}$, et al. (2016) Extranuclear actions of the androgen receptor enhance glucose-stimulated insulin secretion in the male. Cell Metab 23:837-851.

Neal B, Perkovic V, Mahaffey KW, de Zeeuw D, Fulcher G, Erondu N, Shaw W, Law G, Desai M, and Matthews DR; CANVAS Program Collaborative Group (2017) Canagliflozin and cardiovascular and renal events in type 2 diabetes. $N$ Engl J Med 377:644-657.

Nematbakhsh M, Ebrahimian S, Tooyserkani M, Eshraghi-Jazi F, Talebi A, and Ashrafi F (2013) Gender difference in Cisplatin-induced nephrotoxicity in a rat model: greater intensity of damage in male than female. Nephrourol Mon 5: 818-821.

Neto OV, Raymundo S, Franzoi MA, do Carmo Artmann A, Tegner M, Müller VV, Hahn RZ, Alves GV, Schwartsmann G, Linden R, et al. (2018) DPD functional tests in plasma, fresh saliva and dried saliva samples as predictors of 5-fluorouracil exposure and occurrence of drug-related severe toxicity. Clin Biochem 56:18-25.

Neugarten J, Kasiske B, Silbiger SR, and Nyengaard JR (2002) Effects of sex on renal structure. Nephron 90:139-144.

Nguyen KA, Li L, Lu D, Yazdanparast A, Wang L, Kreutz RP, Whipple EC, and Schleyer TK (2018) A comprehensive review and meta-analysis of risk factors for statin-induced myopathy. Eur J Clin Pharmacol 74:1099-1109.

Nicholas JS and Barron DH (1932) The use of sodium amytal in production of anaesthesia in the rat. $J$ Pharmac Exp Ther 46:125-130.

Nilsson C, Niklasson M, Eriksson E, Björntorp P, and Holmäng A (1998) Imprinting of female offspring with testosterone results in insulin resistance and changes in body fat distribution at adult age in rats. J Clin Invest 101:74-78,

Nilsson E, De Deco P, Trevisan M, Bellocco R, Lindholm B, Lund LH, Coresh J, and Carrero JJ (2018) A real-world cohort study on the quality of potassium and creatinine monitoring during initiation of mineralocorticoid receptor antagonists in patients with heart failure. Eur Heart J Qual Care Clin Out comes 4:267-273.

Nohara K, Waraich RS, Liu S, Ferron M, Waget A, Meyers MS, Karsenty G, Burcelin R, and Mauvais-Jarvis F (2013) Developmental androgen excess programs sympathetic tone and adipose tissue dysfunction and predisposes to a cardiometabolic syndrome in female mice. Am J Physiol Endocrinol Metab 304:E1321-E1330 
Nohara K, Zhang Y, Waraich RS, Laque A, Tiano JP, Tong J, Münzberg H, and Mauvais-Jarvis F (2011) Early-life exposure to testosterone programs the hypothalamic melanocortin system. Endocrinology 152:1661-1669.

Org E, Mehrabian M, Parks BW, Shipkova P, Liu X, Drake TA, and Lusis AJ (2016) Sex differences and hormonal effects on gut microbiota composition in mice. Gut Microbes 7:313-322.

Ostan R, Monti D, Gueresi P, Bussolotto M, Franceschi C, and Baggio G (2016) Gender, aging and longevity in humans: an update of an intriguing/neglected scenario paving the way to a gender-specific medicine. Clin Sci (Lond) 130: $1711-1725$.

Ostlund H, Keller E, and Hurd YL (2003) Estrogen receptor gene expression in relation to neuropsychiatric disorders. Ann N Y Acad Sci 1007:54-63.

Overgaard RV, Petri KC, Jacobsen LV, and Jensen CB (2016) Liraglutide $3.0 \mathrm{mg}$ for weight management: a population pharmacokinetic analysis. Clin Pharmacokinet 55:1413-1422.

Pace S, Sautebin L, and Werz O (2017) Sex-biased eicosanoid biology: impact for sex differences in inflammation and consequences for pharmacotherapy. Biochem Pharmacol 145:1-11.

Packer M, Bristow MR, Cohn JN, Colucci WS, Fowler MB, Gilbert EM, and Shusterman NH; U.S. Carvedilol Heart Failure Study Group (1996) The effect of carvedilol on morbidity and mortality in patients with chronic heart failure. $N$ Engl J Med 334:1349-1355.

Paine MF, Ludington SS, Chen ML, Stewart PW, Huang SM, and Watkins PB (2005) Do men and women differ in proximal small intestinal CYP3A or P-glycoprotein expression? Drug Metab Dispos 33:426-433.

Papp R, Bett GCL, Lis A, Rasmusson RL, Baczkó I, Varró A, and Salama G (2017) Genomic upregulation of cardiac Cav1.2 $\alpha$ and NCX1 by estrogen in women. Biol Sex Differ 8:26.

Paseban M, Butler AE, and Sahebkar A (2019) Mechanisms of statin-induced newonset diabetes. J Cell Physiol 234:12551-12561.

Patti G, De Caterina R, Abbate R, Andreotti F, Biasucci LM, Calabrò P, Cioni G, Davì G, Di Sciascio G, Golia E, et al.; Working Group on Thrombosis of the Italian Society of Cardiology (2014) Platelet function and long-term antiplatelet therapy in women: is there a gender-specificity? A 'state-of-the-art' paper. Eur Heart J $\mathbf{3 5}$ 2213-2223b

Peckham EM and Traynor JR (2006) Comparison of the antinociceptive response to morphine and morphine-like compounds in male and female Sprague-Dawley rats. $J$ Pharmacol Exp Ther 316:1195-1201.

Pedersen O (2009) Intensified multifactorial treatment of patients with Type 2 diabetes: what can be achieved and does it pay off? J Diabetes 1:83-89.

Pencek R, Blickensderfer A, Li Y, Brunell SC, and Chen S (2012) Exenatide once weekly for the treatment of type 2 diabetes: effectiveness and tolerability in patient subpopulations. Int J Clin Pract 66:1021-1032.

Penno G, Solini A, Bonora E, Fondelli C, Orsi E, Zerbini G, Trevisan R, Vedovato M, Gruden G, Laviola L, et al.; Renal Insufficiency And Cardiovascular Events (RIACE) study, group (2013) Gender differences in cardiovascular disease risk factors, treatments and complications in patients with type 2 diabetes: the RIACE Italian multicentre study. J Intern Med 274:176-191.

Pfeffer MA, Claggett B, Diaz R, Dickstein K, Gerstein HC, Køber LV, Lawson FC, Ping L, Wei X, Lewis EF, et al.; ELIXA Investigators (2015) Lixisenatide in patients with type 2 diabetes and acute coronary syndrome. $N$ Engl J Med $\mathbf{3 7 3}$ 2247-2257.

Pham TV, Sosunov EA, Gainullin RZ, Danilo P Jr, and Rosen MR (2001) Impact of sex and gonadal steroids on prolongation of ventricular repolarization and arrhythmias induced by I(K)-blocking drugs. Circulation 103:2207-2212.

Phillips SP and Austin EB (2009) The feminization of medicine and population health. JAMA 301:863-864.

Pisanu C, Franconi F, Gessa GL, Mameli S, Pisanu GM, Campesi I, Leggio L, and Agabio R (2019) Sex differences in the response to opioids for pain relief a systematic review and meta-analysis. Pharmacol Res 148:104447.

Pitt B, Remme W, Zannad F, Neaton J, Martinez F, Roniker B, Bittman R, Hurley S, Kleiman J, and Gatlin M; Eplerenone Post-Acute Myocardial Infarction Heart Failure Efficacy and Survival Study Investigators (2003) Eplerenone, a selective aldosterone blocker, in patients with left ventricular dysfunction after myocardial infarction. N Engl J Med 348:1309-1321.

Pitt B, Zannad F, Remme WJ, Cody R, Castaigne A, Perez A, Palensky J, and Witte J; Randomized Aldactone Evaluation Study Investigators (1999) The effect of spironolactone on morbidity and mortality in patients with severe heart failure N Engl J Med 341:709-717.

Posillico CK, Terasaki LS, Bilbo SD, and Schwarz JM (2015) Examination of sex and minocycline treatment on acute morphine-induced analgesia and inflammatory gene expression along the pain pathway in Sprague-Dawley rats. Biol Sex Differ 6 33

Potluri T, Fink AL, Sylvia KE, Dhakal S, Vermillion MS, Vom Steeg L, Deshpande S, Narasimhan H, and Klein SL (2019) Age-associated changes in the impact of sex steroids on influenza vaccine responses in males and females. NPJ Vaccines 4:29.

Qayyum R, Becker DM, Yanek LR, Moy TF, Becker LC, Faraday N, and Vaidya D (2008) Platelet inhibition by aspirin 81 and $325 \mathrm{mg} /$ day in men versus women without clinically apparent cardiovascular disease. Am J Cardiol 101:1359-1363.

Quinn GP, Axelrod J, and Brodie BB (1958) Species, strain and sex differences in metabolism of hexobarbital, aminopyrine, antipyrine and aniline. Biochem Pharmacol 1:152-159.

Rahrovan S, Fanian F, Mehryan P, Humbert P, and Firooz A (2018) Male versus female skin: what dermatologists and cosmeticians should know. Int $J$ Womens Dermatol 4:122-130.

Rathore SS, Curtis JP, Wang Y, Bristow MR, and Krumholz HM (2003) Association of serum digoxin concentration and outcomes in patients with heart failure. JAMA 289:871-878

Rathore SS, Wang Y, and Krumholz HM (2002) Sex-based differences in the effect of digoxin for the treatment of heart failure. N Engl J Med 347:1403-1411.
Reck M, Rodríguez-Abreu D, Robinson AG, Hui R, Csőszi T, Fülöp A, Gottfried M, Peled N, Tafreshi A, Cuffe S, et al: KEYNOTE-024 Investigators (2016) Pembrolizumab versus chemotherapy for PD-L1-positive non-small-cell lung cancer $N$ Engl J Med 375:1823-1833.

Regitz-Zagrosek V (2006) Therapeutic implications of the gender-specific aspects of cardiovascular disease. Nat Rev Drug Discov 5:425-438.

Regitz-Zagrosek V and Kararigas G (2017) Mechanistic pathways of sex differences in cardiovascular disease. Physiol Rev 97:1-37.

Regitz-Zagrosek V, Oertelt-Prigione S, Prescott E, Franconi F, Gerdts E, ForystLudwig A, Maas AH, Kautzky-Willer A, Knappe-Wegner D, Kintscher U, et al.; EUGenMed Cardiovascular Clinical Study Group (2016) Gender in cardiovascular diseases: impact on clinical manifestations, management, and outcomes. Eur Heart $J$ 37:24-34

Regitz-Zagrosek V, Roos-Hesselink JW, Bauersachs J, Blomström-Lundqvist C, Cífková R, De Bonis M, Iung B, Johnson MR, Kintscher U, Kranke P, et al.; ESC Scientific Document Group (2018) 2018 ESC Guidelines for the management of cardiovascular diseases during pregnancy. Eur Heart $J$ 39:3165-3241.

Reid RO, Friedberg MW, Adams JL, McGlynn EA, and Mehrotra A (2010) Associations between physician characteristics and quality of care. Arch Intern Med 170: 1442-1449.

Ridker PM, Cook NR, Lee IM, Gordon D, Gaziano JM, Manson JE, Hennekens CH, and Buring JE (2005) A randomized trial of low-dose aspirin in the primary prevention of cardiovascular disease in women. N Engl J Med 352:1293-1304.

Riedel K, Deussen AJ, Tolkmitt J, Weber S, Schlinkert P, Zatschler B, Friebel C, Müller B, El-Armouche A, Morawietz H, et al (2019) Estrogen determines sex differences in adrenergic vessel tone by regulation of endothelial $\beta$-adrenoceptor expression. Am J Physiol Heart Circ Physiol 317:H243-H254.

Robert C, Schachter J, Long GV, Arance A, Grob JJ, Mortier L, Daud A, Carlino MS, McNeil C, Lotem M, et al.; KEYNOTE-006 investigators (2015) Pembrolizumab versus ipilimumab in advanced melanoma. $N$ Engl J Med 372:2521-2532.

Robertson C, Avenell A, Boachie C, Stewart F, Archibald D, Douglas F, Hoddinott P, van Teijlingen E, and Boyers D (2016) Should weight loss and maintenance programmes be designed differently for men? A systematic review of long-term randomised controlled trials presenting data for men and women: the ROMEO project. Obes Res Clin Pract 10:70-84.

Roche DJ, Childs E, Epstein AM, and King AC (2010) Acute HPA axis response to naltrexone differs in female vs. male smokers. Psychoneuroendocrinology 35: 596-606.

Roche DJ and King AC (2015) Sex differences in acute hormonal and subjective response to naltrexone: the impact of menstrual cycle phase. Psychoneuroendocrinology 52:59-71.

Rochon PA, Gruneir A, Bell CM, Savage R, Gill SS, Wu W, Giannakeas V, Stall NM, Seitz DP, Normand SL, et al. (2018) Comparison of prescribing practices for older adults treated by female versus male physicians: a retrospective cohort study. PLoS One 13:e0205524.

Rosenson RS, Baker S, Banach M, Borow KM, Braun LT, Bruckert E, Brunham LR, Catapano AL, Elam MB, Mancini GBJ, et al. (2017) Optimizing cholesterol treatment in patients with muscle complaints. J Am Coll Cardiol 70:1290-1301.

Rossi MC, Cristofaro MR, Gentile S, Lucisano G, Manicardi V, Mulas MF, Napoli A Nicolucci A, Pellegrini F, Suraci C, et al.; AMD Annals Study Group (2013) Sex disparities in the quality of diabetes care: biological and cultural factors may play a different role for different outcomes: a cross-sectional observational study from the AMD Annals initiative. Diabetes Care 36:3162-3168.

Roter DL, Hall JA, and Aoki Y (2002) Physician gender effects in medical communication: a meta-analytic review. JAMA 288:756-764.

Routledge PA, Stargel WW, Kitchell BB, Barchowsky A, and Shand DG (1981) Sexrelated differences in the plasma protein binding of lignocaine and diazepam. $\mathrm{Br}$ $J$ Clin Pharmacol 11:245-250.

Rubin R (2018) Addressing barriers to inclusion of pregnant women in clinical trials. JAMA 320:742-744.

Ruggenenti P, Bettinaglio P, Pinares F, and Remuzzi G (2008) Angiotensin converting enzyme insertion/deletion polymorphism and renoprotection in diabetic and nondiabetic nephropathies. Clin J Am Soc Nephrol 3:1511-1525.

Rydberg DM, Holm L, Mejyr S, Loikas D, Schenck-Gustafsson K, von Euler M, Wettermark B, and Malmström RE (2014) Sex differences in spontaneous reports on adverse bleeding events of antithrombotic treatment. Eur J Clin Pharmacol $\mathbf{7 0}$ $117-126$

Sandberg K and Ji H (2003) Sex and the renin-angiotensin system: implications for gender differences in the progression of kidney disease. Adv Ren Replace Ther 10: $15-23$.

Santema BT, Ouwerkerk W, Tromp J, Sama IE, Ravera A, Regitz-Zagrosek V, Hillege H, Samani NJ, Zannad F, Dickstein K, et al.; ASIAN-HF investigators (2019) Identifying optimal doses of heart failure medications in men compared with women: a prospective, observational, cohort study. Lancet 394:1254-1263.

Sarton E, Olofsen E, Romberg R, den Hartigh J, Kest B, Nieuwenhuijs D, Burm A Teppema L, and Dahan A (2000) Sex differences in morphine analgesia: an experimental study in healthy volunteers. Anesthesiology 93:1245-1254, discussion

Sattar N, Preiss D, Murray HM, Welsh P, Buckley BM, de Craen AJ, Seshasai SR, McMurray JJ, Freeman DJ, Jukema JW, et al. (2010) Statins and risk of incident diabetes: a collaborative meta-analysis of randomised statin trials. Lancet $\mathbf{3 7 5}$ : $735-742$.

Schachter M (2005) Chemical, pharmacokinetic and pharmacodynamic properties of statins: an update. Fundam Clin Pharmacol 19:117-125.

Schiebinger L, Leopold SS, and Miller VM (2016) Editorial policies for sex and gender analysis. Lancet 388:2841-2842.

Schmidt M, Mansfield KE, Bhaskaran K, Nitsch D, Sørensen HT, Smeeth L, and Tomlinson LA (2017a) Adherence to guidelines for creatinine and potassium monitoring and discontinuation following renin-angiotensin system blockade: a UK general practice-based cohort study. BMJ Open 7:e012818. 
Schmidt M, Mansfield KE, Bhaskaran K, Nitsch D, Sørensen HT, Smeeth L, and Tomlinson LA (2017b) Serum creatinine elevation after renin-angiotensin system blockade and long term cardiorenal risks: cohort study. BMJ 356:j791.

Schmittdiel JA, Traylor A, Uratsu CS, Mangione CM, Ferrara A, and Subramanian U (2009) The association of patient-physician gender concordance with cardiovascular disease risk factor control and treatment in diabetes. $J$ Womens Health (Larchmt) 18:2065-2070.

Schunkert H, Danser AH, Hense HW, Derkx FH, Kürzinger S, and Riegger GA (1997) Effects of estrogen replacement therapy on the renin-angiotensin system in postmenopausal women. Circulation 95:39-45.

Schütt M, Zimmermann A, Hood R, Hummel M, Seufert J, Siegel E, Tytko A, and Holl RW; DPV initiative; German BMBF Competence Network Diabetes Mellitus (2015) Gender-specific effects of treatment with lifestyle, metformin or sulfonylurea on glycemic control and body weight: a German multicenter analysis on 9108 patients. Exp Clin Endocrinol Diabetes 123:622-626.

Schwartz GL, Turner ST, Chapman AB, and Boerwinkle E (2002) Interacting effects of gender and genotype on blood pressure response to hydrochlorothiazide. Kidney Int 62:1718-1723.

Schwartz JB (2003) The influence of sex on pharmacokinetics. Clin Pharmacokinet 42:107-121.

Schwartz JB (2007) The current state of knowledge on age, sex, and their interactions on clinical pharmacology. Clin Pharmacol Ther 82:87-96.

Secher A, Jelsing J, Baquero AF, Hecksher-Sørensen J, Cowley MA, Dalbøge LS, Hansen G, Grove KL, Pyke C, Raun K, et al. (2014) The arcuate nucleus mediates GLP-1 receptor agonist liraglutide-dependent weight loss. J Clin Invest 124: $4473-4488$.

Seeland U and Regitz-Zagrosek V (2012) Sex and gender differences in cardiovascular drug therapy. Handb Exp Pharmacol 214:211-236.

Shen EY, Ahern TH, Cheung I, Straubhaar J, Dincer A, Houston I, de Vries GJ, Akbarian S, and Forger NG (2015) Epigenetics and sex differences in the brain: a genome-wide comparison of histone-3 lysine-4 trimethylation (H3K4me3) in male and female mice. Exp Neurol 268:21-29.

Shi JG, Zhang Y, and Yeleswaram S (2011) The relevance of assessment of intestinal P-gp inhibition using digoxin as an in vivo probe substrate. Nat Rev Drug Discov 10:75.

Simon T, Mary-Krause M, Funck-Brentano C, and Jaillon P (2001) Sex differences in the prognosis of congestive heart failure: results from the Cardiac Insufficiency Bisoprolol Study (CIBIS II). Circulation 103:375-380.

Singh I and Morris AP (2011) Performance of transdermal therapeutic systems: effects of biological factors. Int J Pharm Investig 1:4-9.

Sinha N, Roy S, Huang B, Wang J, Padmanabhan V, and Sen A (2020) Developmental programming: prenatal testosterone-induced epigenetic modulation and its effect on gene expression in sheep ovary. Biol Reprod 102:1045-1054.

Sinnott SJ, Mansfield KE, Schmidt M, Bhaskaran K, Smeeth L, Nitsch D, and Tomlinson LA (2017) Biochemical monitoring after initiation of aldosterone antagonist therapy in users of renin-angiotensin system blockers: a UK primary care cohort study. BMJ Open 7:e018153.

Sirtori CR (2014) The pharmacology of statins. Pharmacol Res 88:3-11.

Smieszek A, Tomaszewski KA, Kornicka K, and Marycz K (2018) Metformin promotes osteogenic differentiation of adipose-derived stromal cells and exerts proosteogenic effect stimulating bone regeneration. J Clin Med 7:482.

Smirnova OV (2012) Gender-related differences in drug effects: the role of multidrug resistance proteins. Hum Physiol 38:331-341.

Soldin OP, Chung SH, and Mattison DR (2011) Sex differences in drug disposition. $J$ Biomed Biotechnol 2011:187103.

Soldin OP and Mattison DR (2009) Sex differences in pharmacokinetics and pharmacodynamics. Clin Pharmacokinet 48:143-157.

Soliman E, Ranjan S, Xu T, Gee C, Harker A, Barrera A, and Geddes J (2018) A narrative review of the success of intramuscular gluteal injections and its impact in psychiatry. Biodes Manuf 1:161-170.

Solomon SD, McMurray JJV, Anand IS, Ge J, Lam CSP, Maggioni AP, Martinez F, Packer M, Pfeffer MA, Pieske B, et al.; PARAGON-HF Investigators and Committees (2019) Angiotensin-Neprilysin inhibition in heart failure with preserved ejection fraction. N Engl J Med 381:1609-1620.

Sorge RE, LaCroix-Fralish ML, Tuttle AH, Sotocinal SG, Austin JS, Ritchie J, Chanda ML, Graham AC, Topham L, Begos S, et al. (2011) Spinal cord Toll-like receptor 4 mediates inflammatory and neuropathic hypersensitivity in male but not female mice. $J$ Neurosci 31:15450-15454

Spranger M, Aspey BS, and Harrison MJ (1989) Sex difference in antithrombotic effect of aspirin. Stroke 20:34-37.

Stein EA and Raal F (2014) Reduction of low-density lipoprotein cholesterol by monoclonal antibody inhibition of PCSK9. Annu Rev Med 65:417-431.

Stoffel EC, Ulibarri CM, and Craft RM (2003) Gonadal steroid hormone modulation of nociception, morphine antinociception and reproductive indices in male and female rats Pain 103.285-302.

Stoffel EC, Ulibarri CM, Folk JE, Rice KC, and Craft RM (2005) Gonadal hormone modulation of mu, kappa, and delta opioid antinociception in male and female rats. $J$ Pain 6:261-274.

Stolarz AJ and Rusch NJ (2015) Gender differences in cardiovascular drugs. Cardiovasc Drugs Ther 29:403-410.

Stone NJ and Grundy SM (2019) The 2018 AHA/ACC/Multi-Society Cholesterol guidelines: looking at past, present and future. Prog Cardiovasc Dis 62:375-383.

Stone NJ, Robinson JG, Lichtenstein AH, Bairey Merz CN, Blum CB, Eckel RH, Goldberg AC, Gordon D, Levy D, Lloyd-Jones DM, et al; American College of Cardiology/American Heart Association Task Force on Practice Guidelines (2014) 2013 ACC/AHA guideline on the treatment of blood cholesterol to reduce atherosclerotic cardiovascular risk in adults: a report of the American College of Cardiology/American Heart Association Task Force on Practice Guidelines [published correction appears in $J$ Am Coll Cardiol (2014) 63:3024-3025; (2015) 66:2812] J Am Coll Cardiol 63:2889-2934.
Stroes ES, Thompson PD, Corsini A, Vladutiu GD, Raal FJ, Ray KK, Roden M, Stein E, Tokgözoğlu L, Nordestgaard BG, et al.; European Atherosclerosis Society Consensus Panel (2015) Statin-associated muscle symptoms: impact on statin therapy-European atherosclerosis society consensus panel statement on assessment, aetiology and management. Eur Heart J 36:1012-1022.

Sun GE, Wells BJ, Yip K, Zimmerman R, Raghavan D, Kattan MW, and Kashyap SR (2014) Gender-specific effects of oral hypoglycaemic agents on cancer risk in type 2 diabetes mellitus. Diabetes Obes Metab 16:276-283.

Talaat KR, Greenberg ME, Lai MH, Hartel GF, Wichems CH, Rockman S, Jeanfreau RJ, Ghosh MR, Kabongo ML, Gittleson C, et al. (2010) A single dose of unadjuvanted novel $2009 \mathrm{H} 1 \mathrm{~N} 1$ vaccine is immunogenic and well tolerated in young and elderly adults. J Infect Dis 202:1327-1337.

Talesnik D (2018) Wenger puts women at heart of research. NIH Record Volume LXX, No 14, July 13, 2018.

Tanaka E and Hisawa S (1999) Clinically significant pharmacokinetic drug interactions with psychoactive drugs: antidepressants and antipsychotics and the cytochrome P450 system. J Clin Pharm Ther 24:7-16.

Tardif JC, Kouz S, Waters DD, Bertrand OF, Diaz R, Maggioni AP, Pinto FJ, Ibrahim R, Gamra H, Kiwan GS, et al. (2019) Efficacy and safety of low-dose colchicine after myocardial infarction. $N$ Engl J Med 381:2497-2505.

Taubel J, Prasad K, Rosano G, Ferber G, Wibberley H, Cole ST, Van Langenhoven L, Fernandes S, Djumanov D, and Sugiyama A (2019) Effects of the fluoroquinolones Moxifloxacin and Levofloxacin on the QT subintervals: sex differences in ventricular repolarization. J Clin Pharmacol 60:400-408.

Tchoukhine E, Takala P, Hakko H, Raidma M, Putkonen H, Räsänen P, Terevnikov V, Stenberg JH, Eronen M, and Joffe G (2011) Orlistat in clozapine- or olanzapine-treated patients with overweight or obesity: a 16-week open-label extension phase and both phases of a randomized controlled trial. J Clin Psychiatry 72:326-330.

Terner JM, Lomas LM, Smith ES, Barrett AC, and Picker MJ (2003) Pharmacogenetic analysis of sex differences in opioid antinociception in rats. Pain 106: 381-391.

Thomas DD, Waring ME, Ameli O, Reisman JI, and Vimalananda VG (2019) Patient characteristics associated with receipt of prescription weight-management medications among veterans participating in MOVE!. Obesity (Silver Spring) 27: $1168-1176$

Thompson PD, Clarkson P, and Karas RH (2003) Statin-associated myopathy. JAMA 289:1681-1690.

Thompson PD, Panza G, Zaleski A, and Taylor B (2016) Statin-associated side effects. J Am Coll Cardiol 67:2395-2410.

Tracy TS, Chaudhry AS, Prasad B, Thummel KE, Schuetz EG, Zhong XB, Tien YC, Jeong H, Pan X, Shireman LM, et al. (2016) Interindividual variability in Cytochrome P450-mediated drug metabolism. Drug Metab Dispos 44:343-351.

Trento M, Charrier L, Salassa M, Merlo S, Passera P, Cavallo F, and Porta M (2015) Depression, anxiety and cognitive function in patients with type 2 diabetes: an 8 year prospective observational study. Acta Diabetol 52:1157-1166.

Tsugawa Y, Jena AB, Figueroa JF, Orav EJ, Blumenthal DM, and Jha AK (2017) Comparison of hospital mortality and readmission rates for medicare patients treated by male vs female physicians. JAMA Intern Med 177:206-213.

Uchino S, Kellum JA, Bellomo R, Doig GS, Morimatsu H, Morgera S, Schetz M, Tan I, Bouman C, Macedo E, et al.; Beginning and Ending Supportive Therapy for the Kidney (BEST Kidney) Investigators (2005) Acute renal failure in critically ill patients: a multinational, multicenter study. JAMA 294:813-818.

US Food and Drug Administration; Center for Drug Evaluation and Research (2012a) Application number: 22580Orig1s000. Approval Letter.

US Food and Drug Administration; Center for Drug Evaluation and Research (2012b) Application number: 22580Orig1s000. Pharmacol Rev.

US Food and Drug Administration; Center for Drug Evaluation and Research (2014) Application number: 200063Orig1s000. Med Rev.

Vallianou NG, Stratigou T, and Tsagarakis S (2019) Metformin and gut microbiota: their interactions and their impact on diabetes. Hormones (Athens) 18 141-144.

Vashitz G, Meyer J, Parmet Y, Henkin Y, Peleg R, and Gilutz H (2011) Physician adherence to the dyslipidemia guidelines is as challenging an issue as patient adherence. Fam Pract 28:524-531.

Ventura-Clapier R, Dworatzek E, Seeland U, Kararigas G, Arnal JF, Brunelleschi S, Carpenter TC, Erdmann J, Franconi F, Giannetta E, et al. (2017) Sex in basic research: concepts in the cardiovascular field. Cardiovasc Res 113: $711-724$

Victor BM, Teal V, Ahedor L, and Karalis DG (2014) Gender differences in achieving optimal lipid goals in patients with coronary artery disease. Am $J$ Cardiol 113 $1611-1615$

Vukovich RA, Brannick LJ, Sugerman AA, and Neiss ES (1975) Sex differences in the intramuscular absorption and bioavailability of cephradine. Clin Pharmacol Ther 18:215-220.

Wagner AD, Grothey A, Andre T, Dixon JG, Wolmark N, Haller DG, Allegra CJ, de Gramont A, VanCutsem E, Alberts SR, et al. (2020) Sex and adverse events of adjuvant chemotherapy in colon cancer: an analysis of 34,640 patients in the ACCENT database. J Natl Cancer Inst DOI: 10.1093/jnci/djaa124 [published ahead of print].

Walle T, Walle K, Mathur RS, Palesch YY, and Conradi EC (1994) Propranolol metabolism in normal subjects: association with sex steroid hormones. Clin Phar macol Ther 56:127-132.

Wang CB, Shahjehan F, Merchea A, Li Z, Bekaii-Saab TS, Grothey A, Colibaseanu DT, and Kasi PM (2019) Impact of tumor location and variables associated with overall survival in patients with colorectal cancer: a Mayo clinic colon and rectal cancer registry study. Front Oncol 9:76.

Wang X, Traub RJ, and Murphy AZ (2006) Persistent pain model reveals sex difference in morphine potency. Am J Physiol Regul Integr Comp Physiol 291 R300-R306.

Ward NC, Watts GF, and Eckel RH (2019) Statin toxicity. Circ Res 124:328-350. 
Watanabe A, Yang CC, and Cheung WY (2018) Association of baseline patient characteristics with adjuvant chemotherapy toxicities in stage III colorectal cancer patients. Med Oncol 35:125.

Waxman DJ and Holloway MG (2009) Sex differences in the expression of hepatic drug-metabolizing enzymes. Mol Pharmacol 76:215-228.

Welle S, Tawil R, and Thornton CA (2008) Sex-related differences in gene expression in human skeletal muscle. PLoS One 3:e1385.

Wheeler S, Moore K, Forsberg CW, Riley K, Floyd JS, Smith NL, and Boyko EJ (2013) Mortality among veterans with type 2 diabetes initiating metformin, sulfonylurea or rosiglitazone monotherapy. Diabetologia 56:1934-1943.

Whitley H and Lindsey W (2009) Sex-based differences in drug activity. Am Fam Physician 80:1254-1258.

Wilding JP, Overgaard RV, Jacobsen LV, Jensen CB, and le Roux CW (2016) Exposure-response analyses of liraglutide $3.0 \mathrm{mg}$ for weight management. Diabetes Obes Metab 18:491-499.

Wing LM, Reid CM, Ryan P, Beilin LJ, Brown MA, Jennings GL, Johnston CI, McNeil JJ, Macdonald GJ, Marley JE, et al.; Second Australian National Blood Pressure Study Group (2003) A comparison of outcomes with angiotensin-converting--enzyme inhibitors and diuretics for hypertension in the elderly. $N$ Engl $J$ Med 348:583-592.

Wiviott SD, Raz I, Bonaca MP, Mosenzon O, Kato ET, Cahn A, Silverman MG, Zelniker TA, Kuder JF, Murphy SA, et al.; DECLARE-TIMI 58 Investigators (2019) Dapagliflozin and cardiovascular outcomes in type 2 diabetes. N Engl J Med 380:347-357.

Wu H, Esteve E, Tremaroli V, Khan MT, Caesar R, Mannerås-Holm L, Ståhlman M, Olsson LM, Serino M, Planas-Fèlix M, et al. (2017) Metformin alters the gut microbiome of individuals with treatment-naive type 2 diabetes, contributing to the therapeutic effects of the drug. Nat Med 23:850-858.

Xiao D, Pan H, Li F, Wu K, Zhang X, and He J (2016) Analysis of ultra-deep targeted sequencing reveals mutation burden is associated with gender and clinical outcome in lung adenocarcinoma. Oncotarget 7:22857-22864.

Yamada Y, Koizumi W, Nishikawa K, Gotoh M, Fuse N, Sugimoto N, Nishina T, Amagai K, Chin K, Niwa Y, et al. (2019) Sex differences in the safety of S-1 plus oxaliplatin and S-1 plus cisplatin for patients with metastatic gastric cancer. Cancer Sci 110:2875-2883.

Yamashita K, Mikami Y, Ikeda M, Yamamura M, Kubozoe T, Urakami A, Yoshida K, Kimoto M, and Tsunoda T (2002) Gender differences in the dihydropyrimidine dehydrogenase expression of colorectal cancers. Cancer Lett 188:231-236.

Yang L, Li Y, Hong H, Chang CW, Guo LW, Lyn-Cook B, Shi L, and Ning B (2012) Sex differences in the expression of drug-metabolizing and transporter genes in human liver. J Drug Metab Toxicol 3:1000119.
Yatsunenko T, Rey FE, Manary MJ, Trehan I, Dominguez-Bello MG, Contreras M, Magris M, Hidalgo G, Baldassano RN, Anokhin AP, et al. (2012) Human gut microbiome viewed across age and geography. Nature 486:222-227.

Yuan M, Tian C, Li X, Yang X, Wang X, Yang Y, Liu N, Kusano KF, Barajas-Martinez $\mathrm{H}, \mathrm{Hu} \mathrm{D}$, et al. (2018) Gender differences in prognosis and risk stratification of Brugada Syndrome: a pooled analysis of 4,140 patients from 24 clinical trials. Front Physiol 9:1127.

Yukawa E, Honda T, Ohdo S, Higuchi S, and Aoyama T (1997) Population-based investigation of relative clearance of digoxin in Japanese patients by multiple trough screen analysis: an update. J Clin Pharmacol 37:92-100.

Zhang H, Plutzky J, Shubina M, and Turchin A (2016) Drivers of the sex disparity in statin therapy in patients with coronary artery disease: a cohort study. PLoS One 11:e0155228.

Zhang M, Robitaille M, Showalter AD, Huang X, Liu Y, Bhattacharjee A, Willard FS, Han J, Froese S, Wei L, et al. (2014) Progesterone receptor membrane component 1 is a functional part of the glucagon-like peptide-1 (GLP-1) receptor complex in pancreatic $\beta$ cells. Mol Cell Proteomics 13:3049-3062.

Zhang Q, Rajagopalan S, Mavros P, Engel SS, Davies MJ, Yin D, and Radican L (2010) Differences in baseline characteristics between patients prescribed sitagliptin versus exenatide based on a US electronic medical record database. Adv Ther 27:223-232.

Zhou Y, Leri F, Low MJ, and Kreek MJ (2019) Sex differences in the effect of bupropion and naltrexone combination on alcohol drinking in mice. Pharmacol Biochem Behav 181:28-36.

Zhu FC, Guan XH, Li YH, Huang JY, Jiang T, Hou LH, Li JX, Yang BF, Wang L, Wang WJ, et al. (2020) Immunogenicity and safety of a recombinant adenovirus type-5-vectored COVID-19 vaccine in healthy adults aged 18 years or older: a randomised, double-blind, placebo-controlled, phase 2 trial. Lancet 396:479-488.

Zinman B, Lachin JM, and Inzucchi SE (2016) Empagliflozin, cardiovascular outcomes, and mortality in type 2 diabetes. $N$ Engl $J$ Med 374:1094.

Zinman B, Wanner C, Lachin JM, Fitchett D, Bluhmki E, Hantel S, Mattheus M, Devins T, Johansen OE, Woerle HJ, et al.; EMPA-REG OUTCOME Investigators (2015) Empagliflozin, cardiovascular outcomes, and mortality in type 2 diabetes. N Engl J Med 373:2117-2128.

Živković I, Bufan B, Petrušić V, Minić R, Arsenović-Ranin N, Petrović R, and Leposavić G (2015) Sexual diergism in antibody response to whole virus trivalent inactivated influenza vaccine in outbred mice. Vaccine 33:5546-5552.

Zivković I, Petrović R, Arsenović-Ranin N, Petrušić V, Minić R, Bufan B, Popović O, and Leposavić G (2018) Sex bias in mouse humoral immune response to influenza vaccine depends on the vaccine type. Biologicals 52:18-24. 


\section{Correction to "Sex- and Gender-Based Pharmacological Response to Drugs"}

In the above article [Mauvais-Jarvis F, Berthold HK, Campesi I, Carrero J-J, Dakal S, Franconi F, Gouni-Berthold I, Heiman ML, Kautzky-Willer A, Klein SL, Murphy A, Regitz-Zagrosek V, Reue K, and Rubin JB (2021) Pharmacol Rev, 73: 730-762; DOI: https://doi.org/10.1124/pharmrev.120.000206 ], the last name of the fifth author was misspelled. The correct spelling of the name is Santosh Dhakal. The PDF and HTML versions of the article and the table of contents have been corrected.

The authors apologize for any inconvenience caused by this error. 